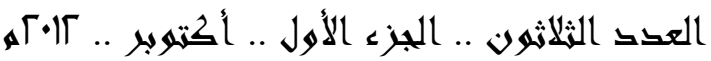

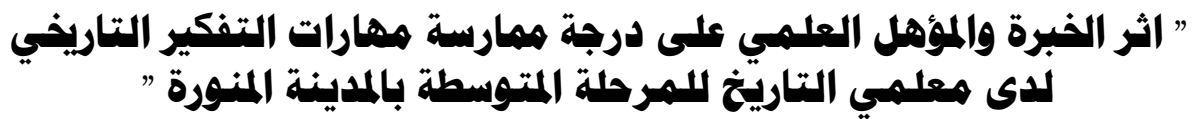

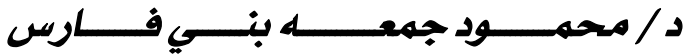

كليت التربيتش جامعت طيبت بالملدينت المنورة

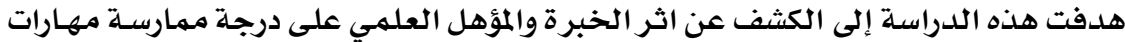

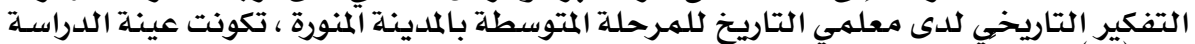

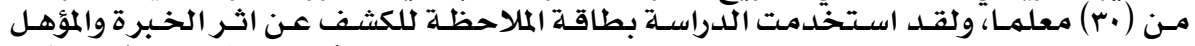

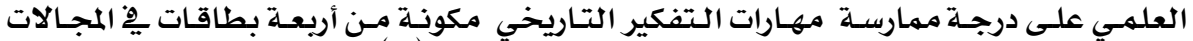

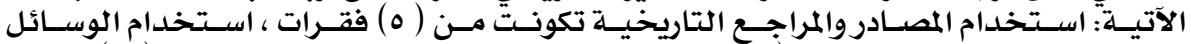

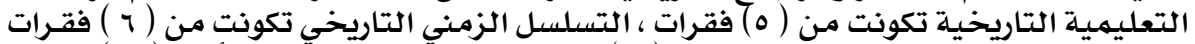

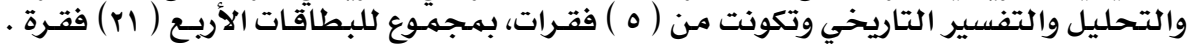

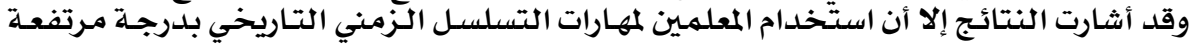

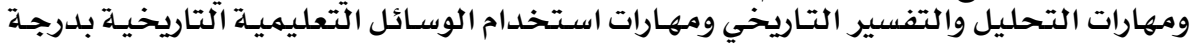

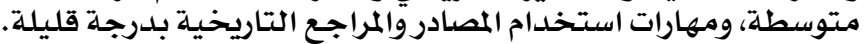

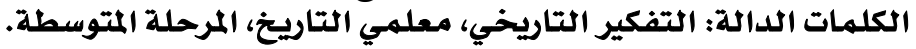

Impact of Teaching Experience and Qualification on Intermediate School History Teachers' Use of Historical Thinking Skills in Al-

Mahmoud Jum'ah Bani Faris

\title{
Madianh Al-Munawarah
}

\section{$\underline{\text { ABSTRACT }}$}

This study aimed to ascertain the impact of teaching experience and qualification on history teachers' degree of using of historical thinking skills at the intermediate schools in Al-Madinah Al-Munawarah. The sample of the study consisted of 30 history teachers. The study made use of an observation form which addressed four domains: using historical resources and references (5 items); using historical teaching aids (5 items); time hierarchy (6 items); and historical analysis and interpretation.Results indicated that the degree to which teachers of history use time hierarchy skills is quite high and their use of historical teaching aids is average, whereas their use of historical resources and references is quite low.

Keywords: historical thinking skills and history teachers

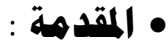

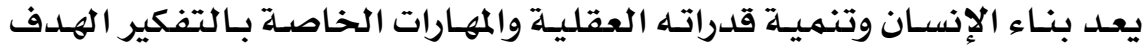

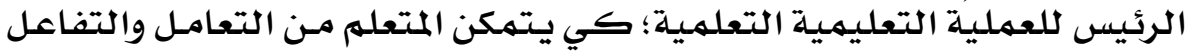

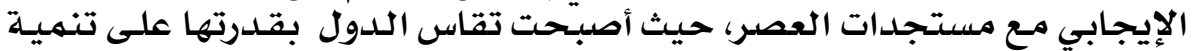

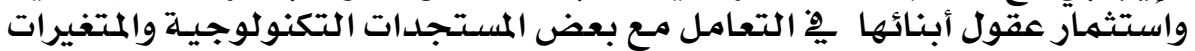
المتلاحقة.

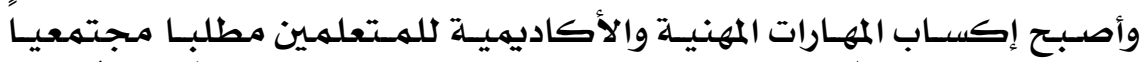

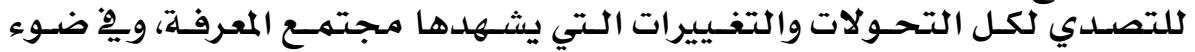

\section{Y}




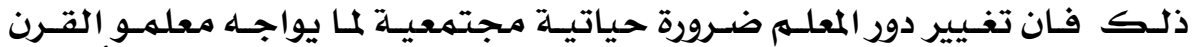

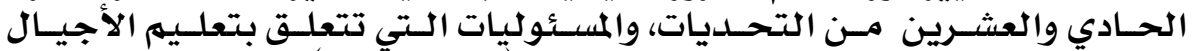

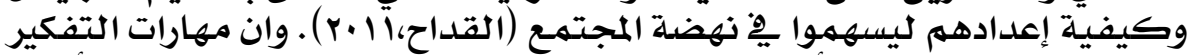

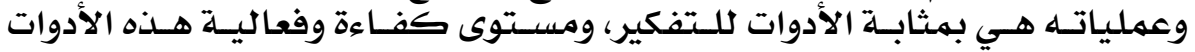

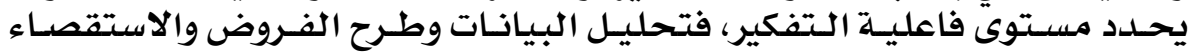

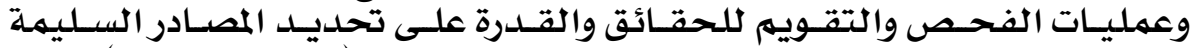

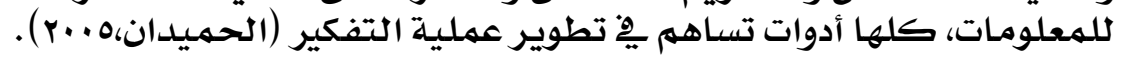

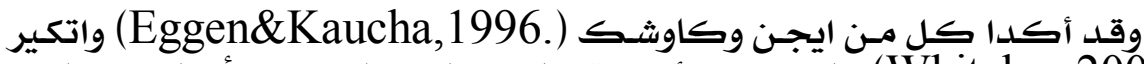

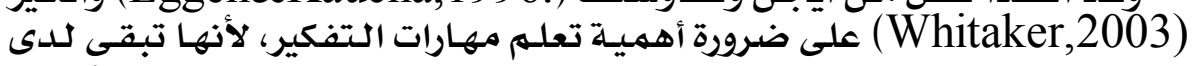

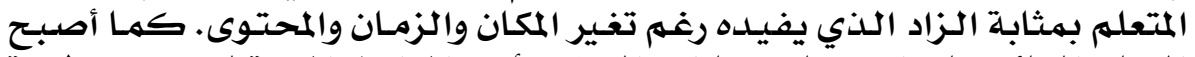

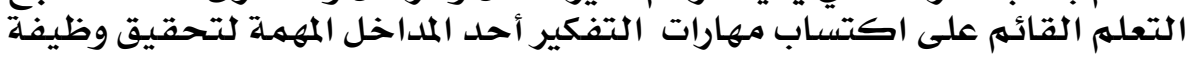

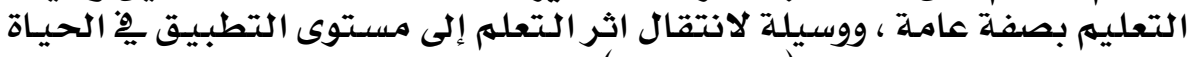

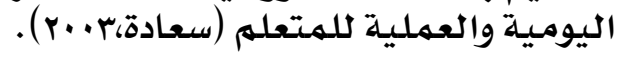

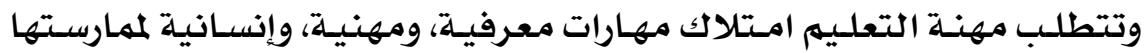

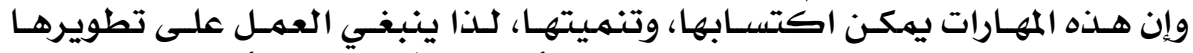

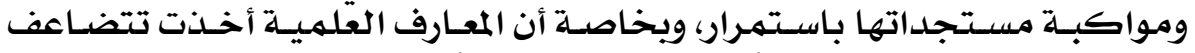

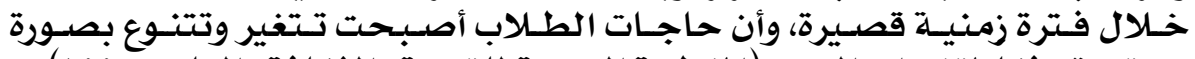

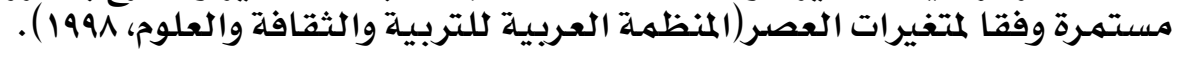

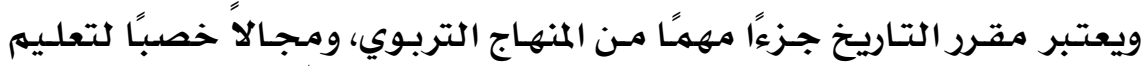

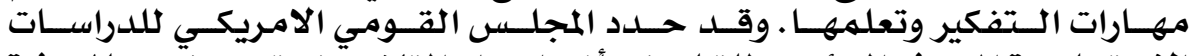

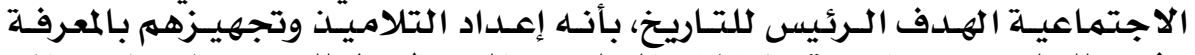

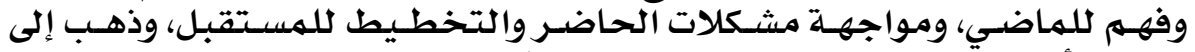

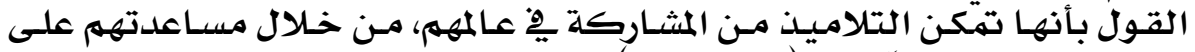

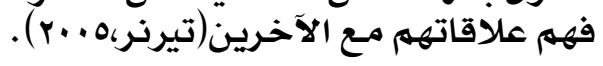

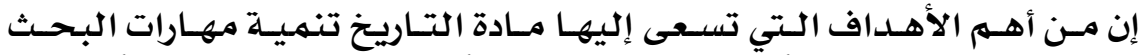

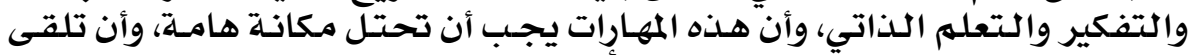

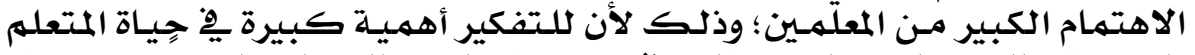

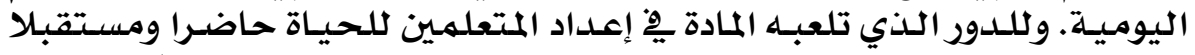

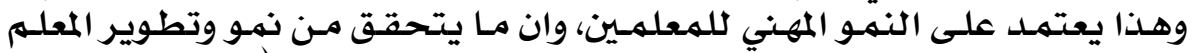

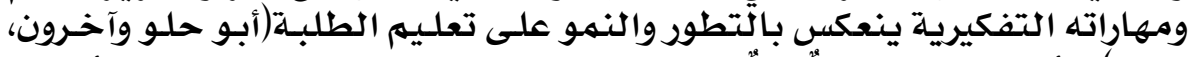

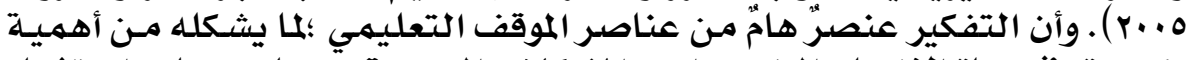

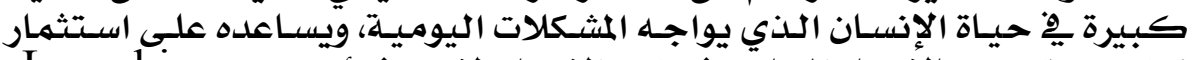

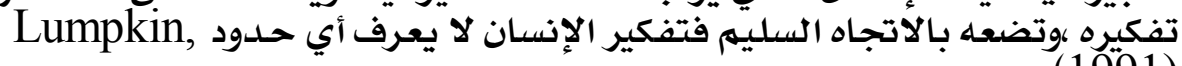

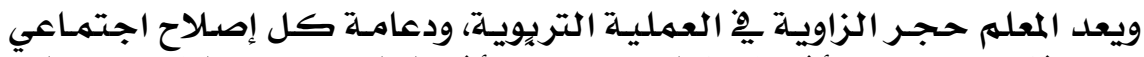

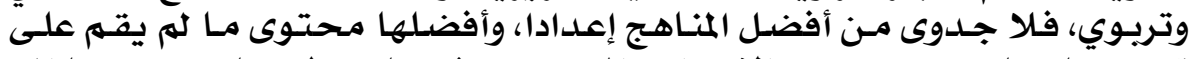

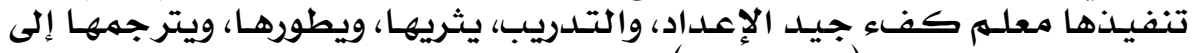

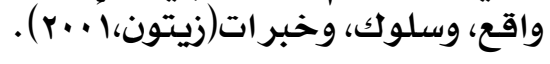


العقد الثلاثهون .. الجزء الأول .. أحتهبر .. آمه

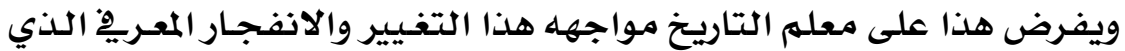

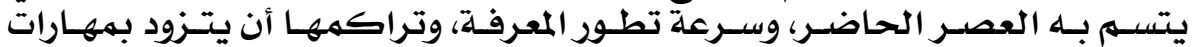

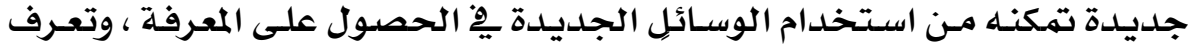

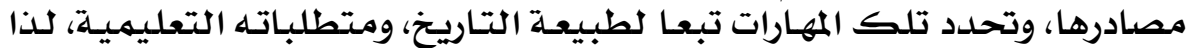

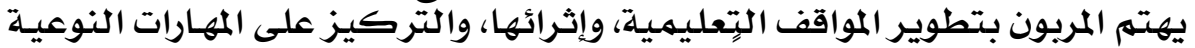

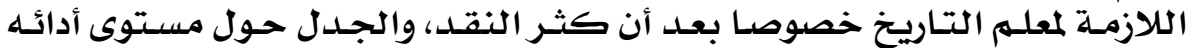

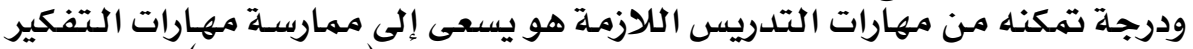

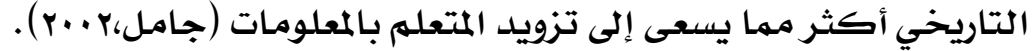

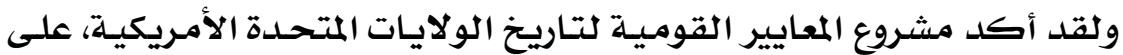

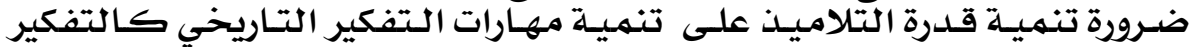

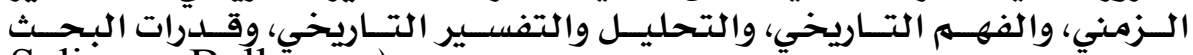

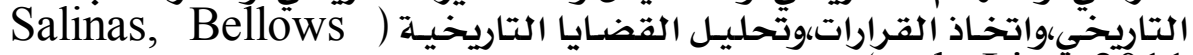

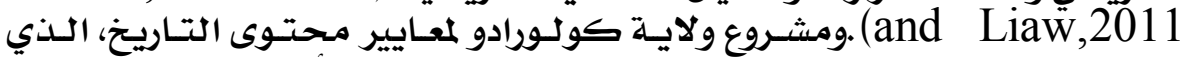

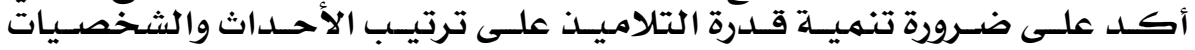

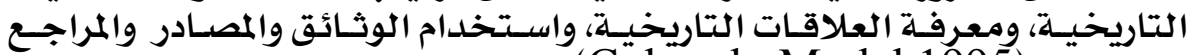
التتاريخية (Cölorado Model,1995).

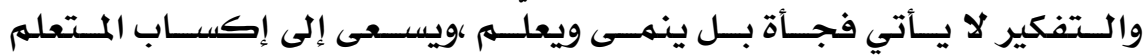

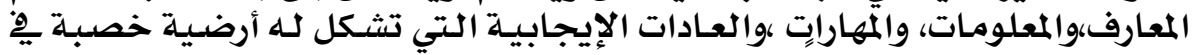

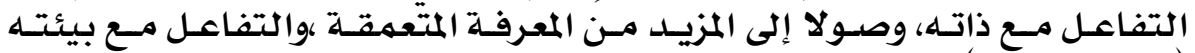

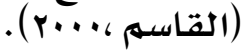

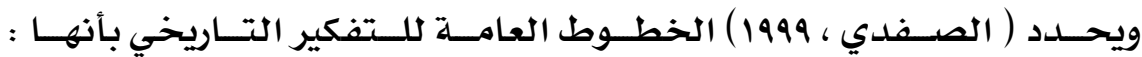

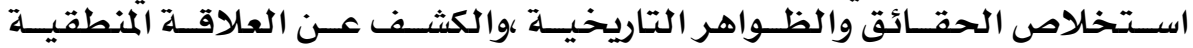

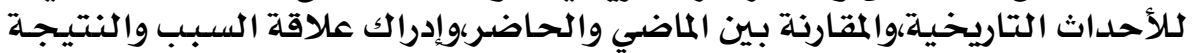
وتقويه الظاهرة التاريخية.

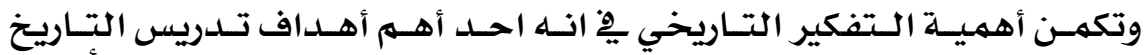

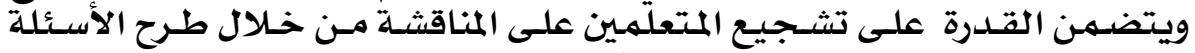

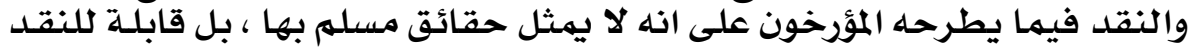

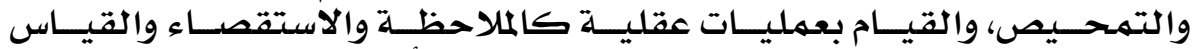

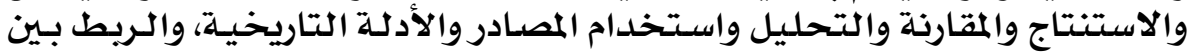

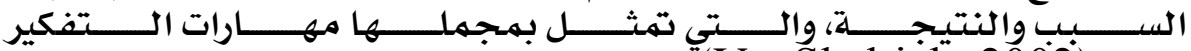

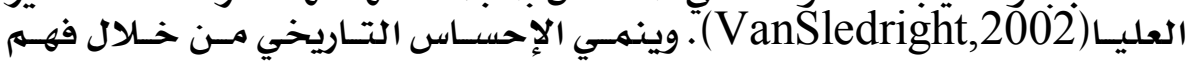

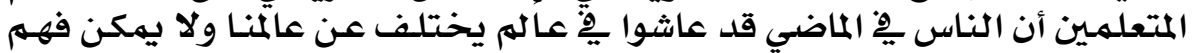

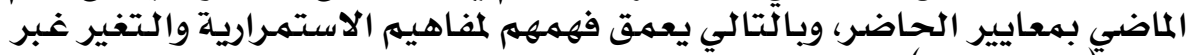

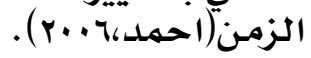

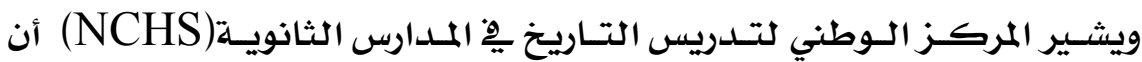

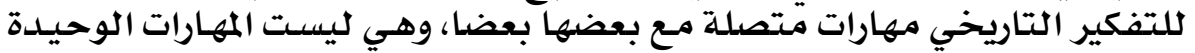

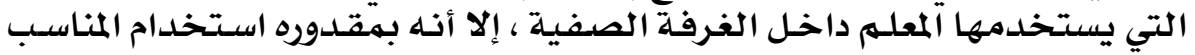

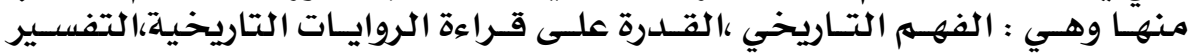




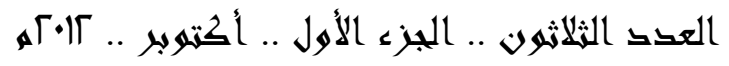

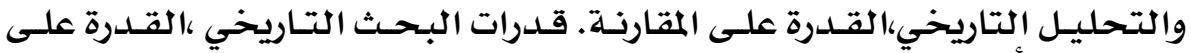

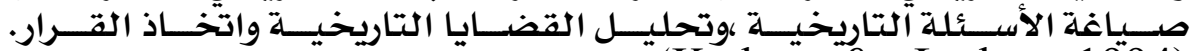

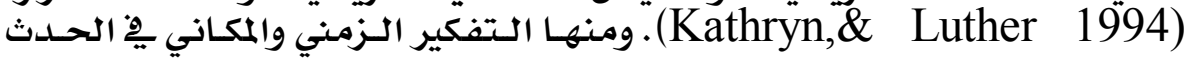

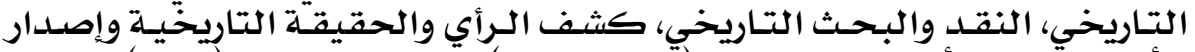

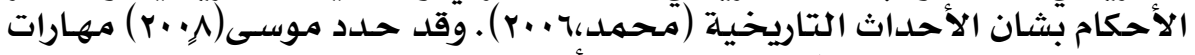

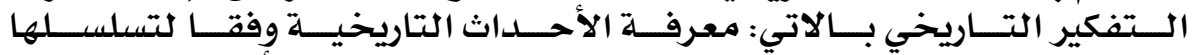

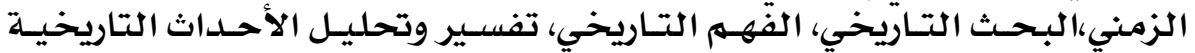

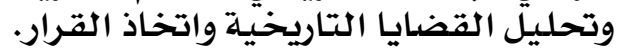

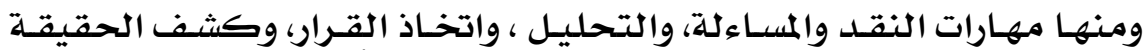

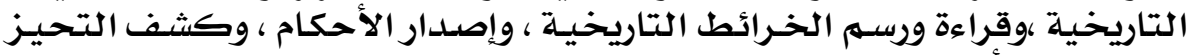

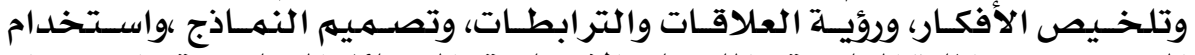

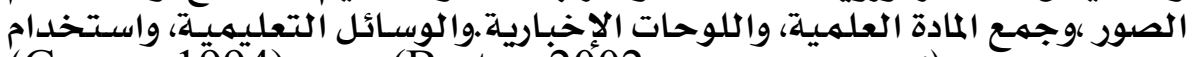

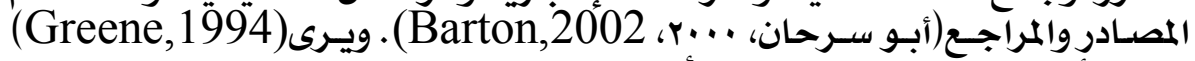

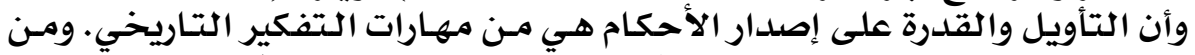

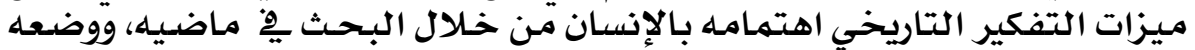

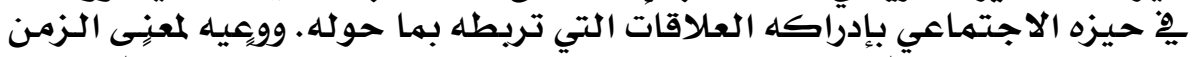

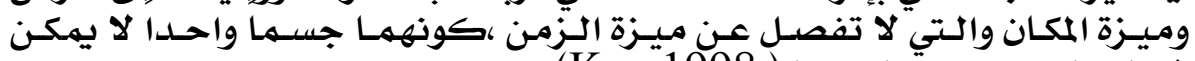

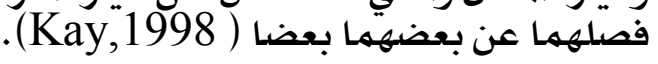

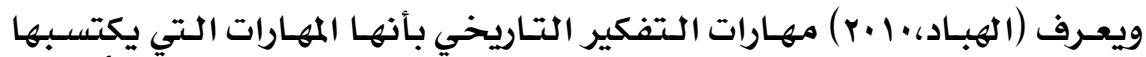

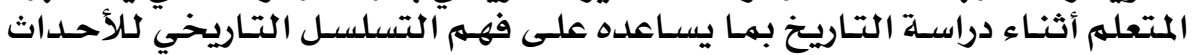

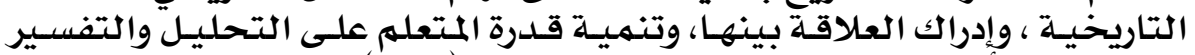

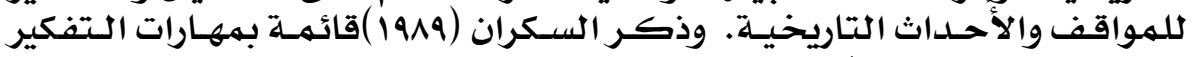

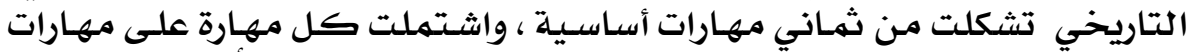

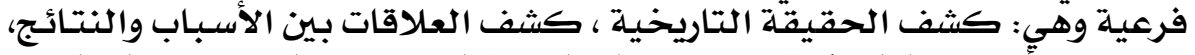

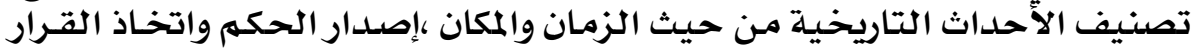

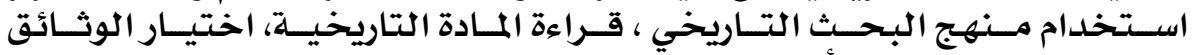
التاريخية، البحث عن البحن الأدلة التتاريخيّية.

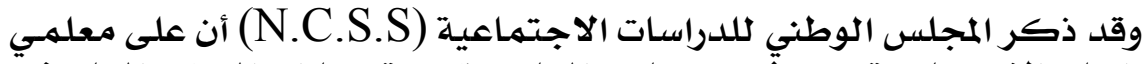

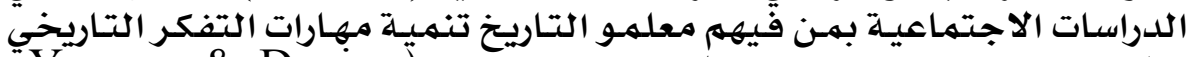

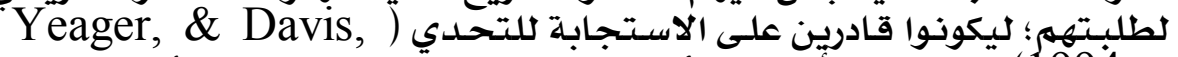

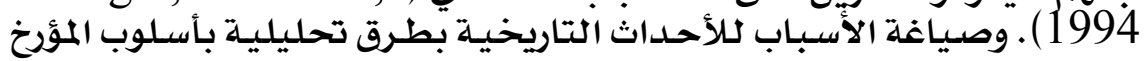

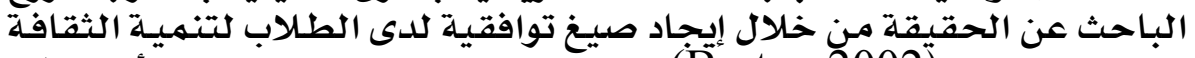

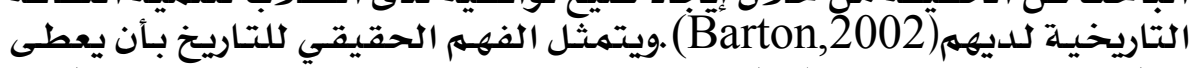

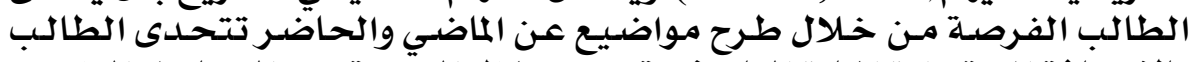

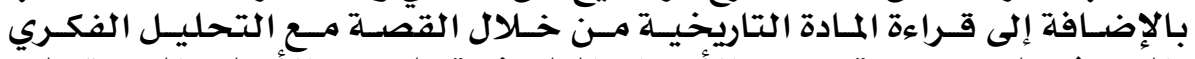

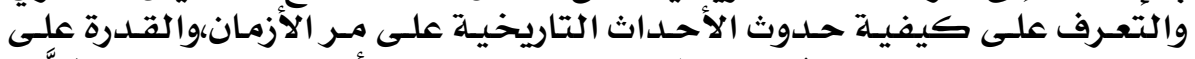

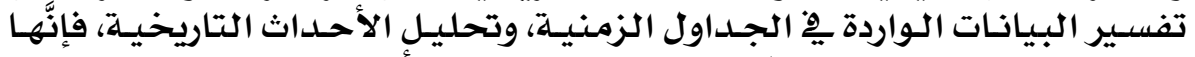

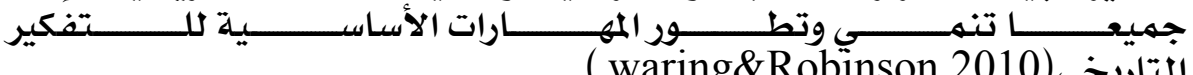
انتاريخي( waring\&Robinson,2010). 
العقد الثلاثيون .. الجزء الأول .. أحتهبر .. Гا. مه

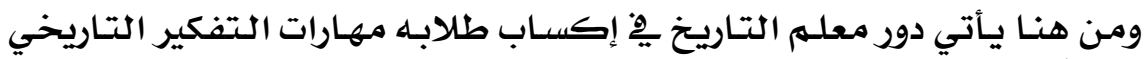

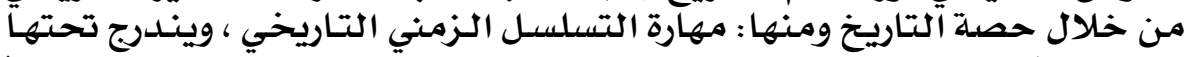

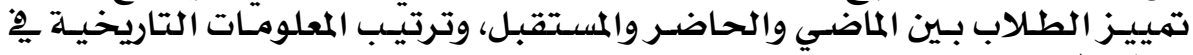

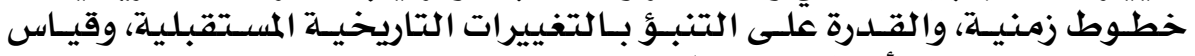

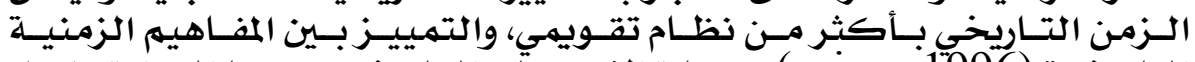

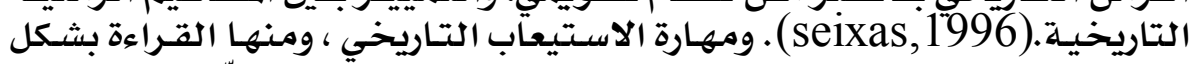

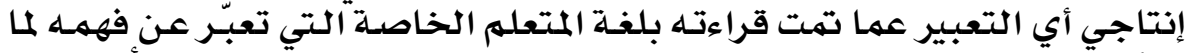

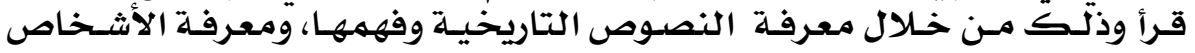

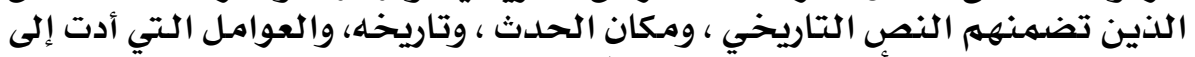

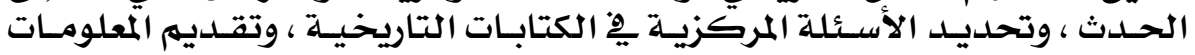

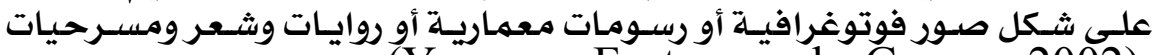

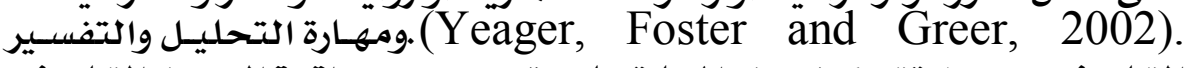

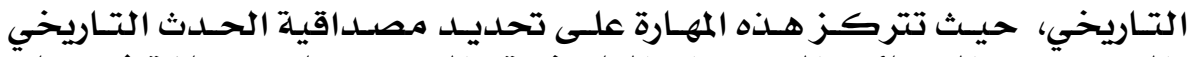

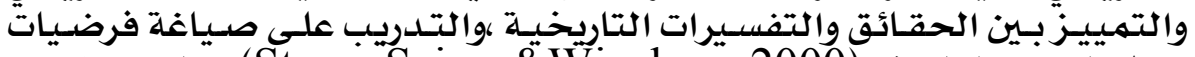

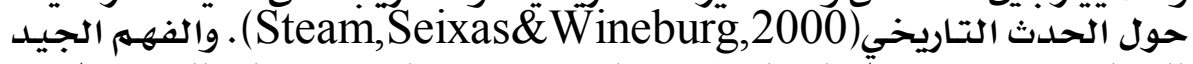

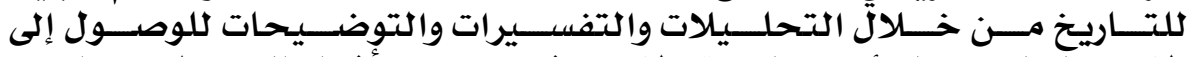

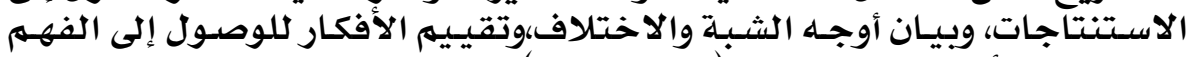

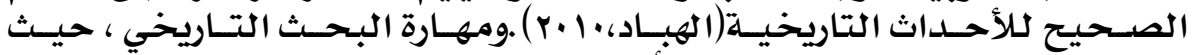

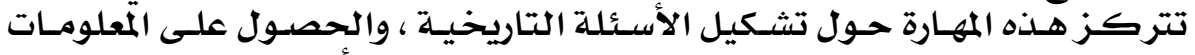

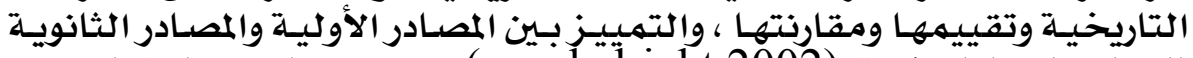

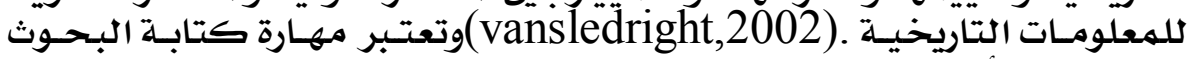

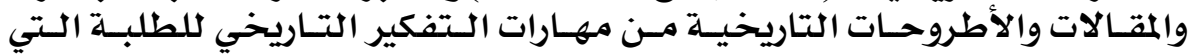

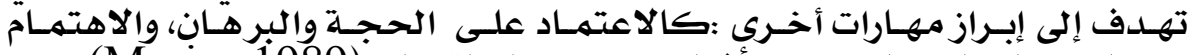

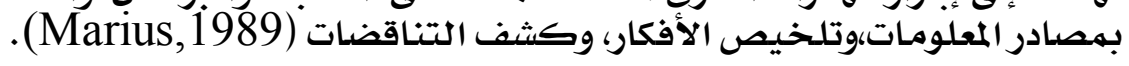

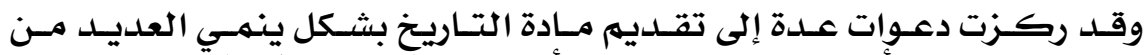

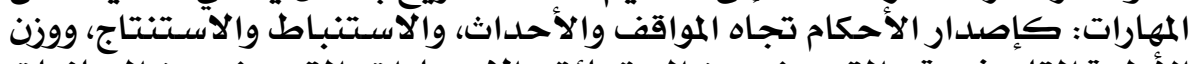

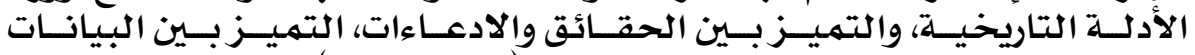

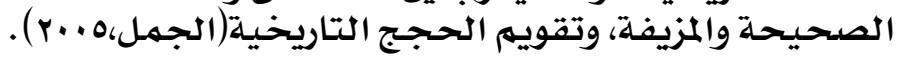

وقد أولت وزارة التربيـة والتعليهم هٍِ المملكة العربيـة السعودية اهتمـامـا كبيرا

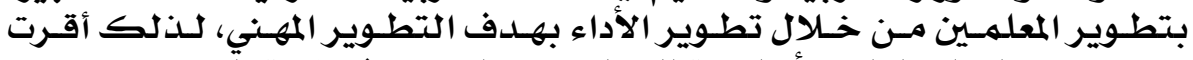

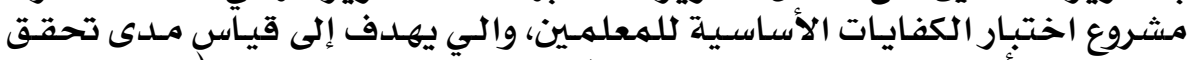

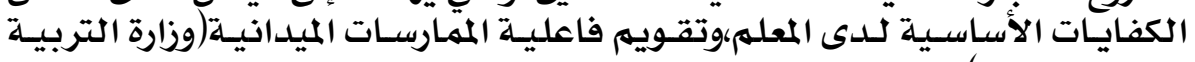

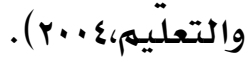

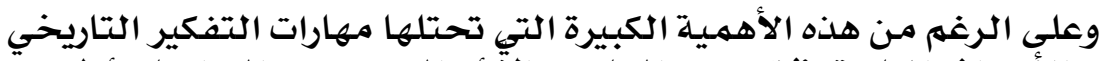

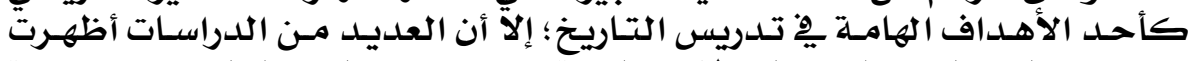

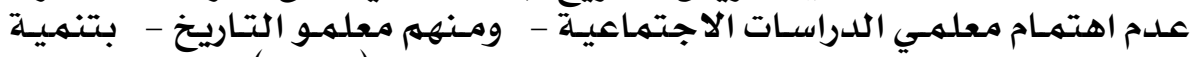

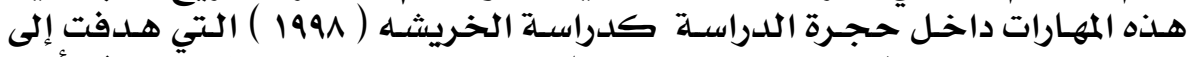

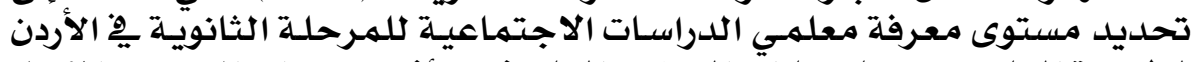

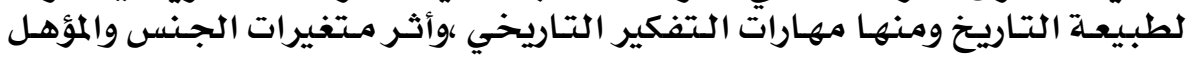

\section{$r r$}




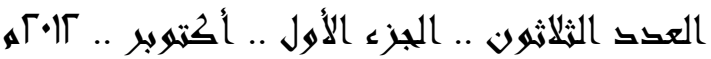

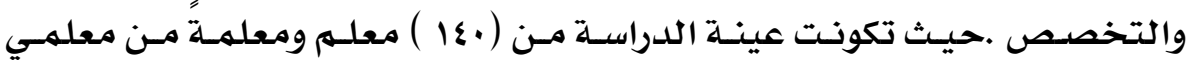

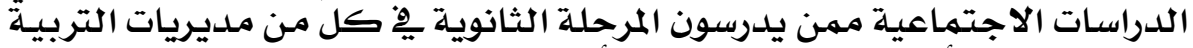

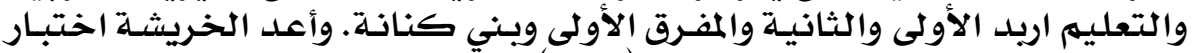

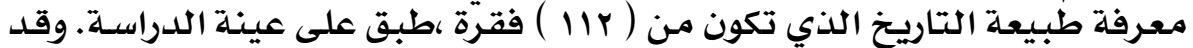

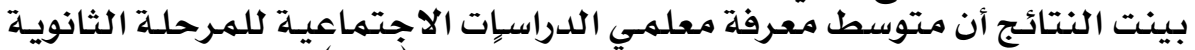

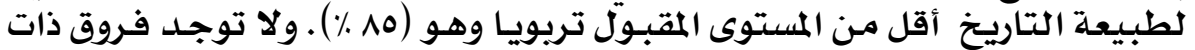

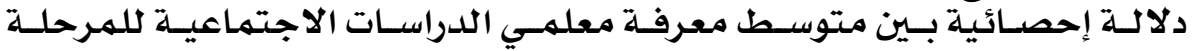

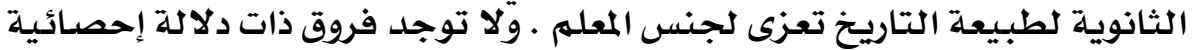

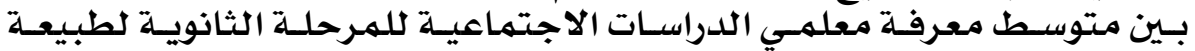

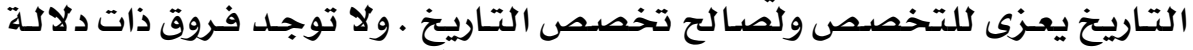

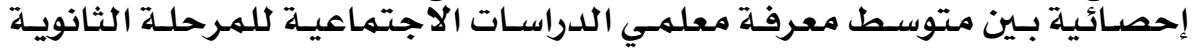

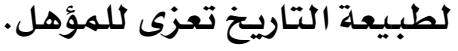

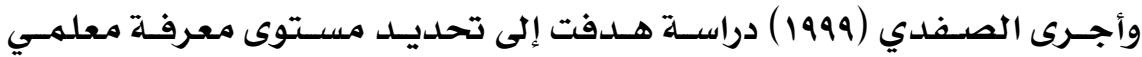

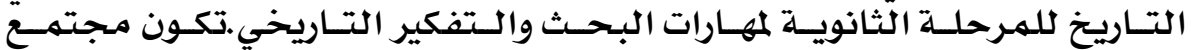

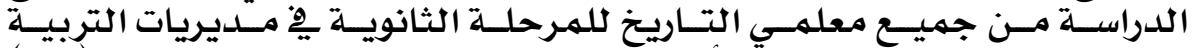

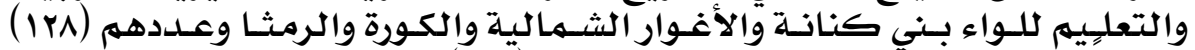

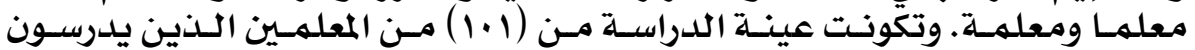

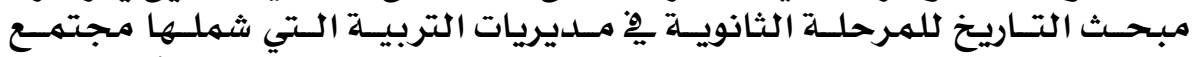

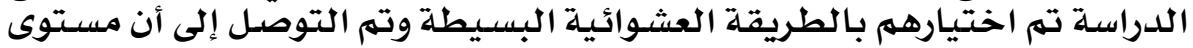

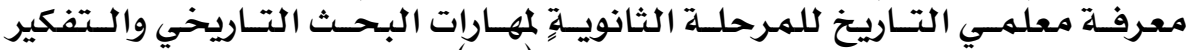

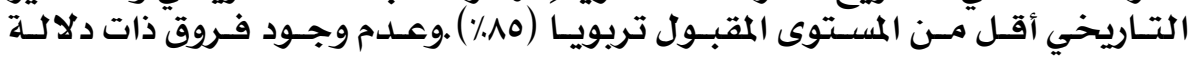

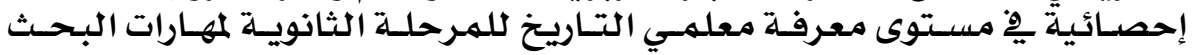

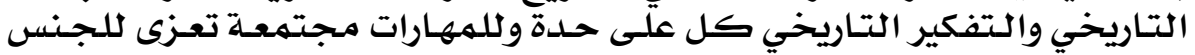
والمؤهل وألخبرة.

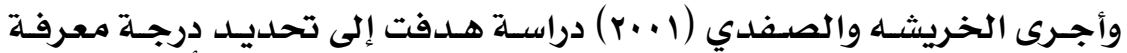

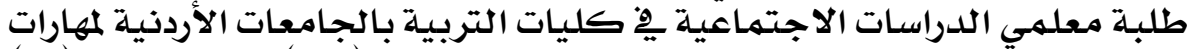

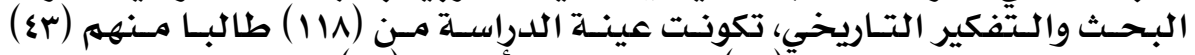

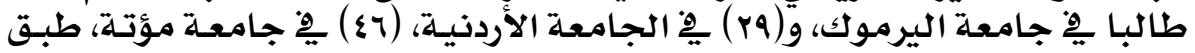

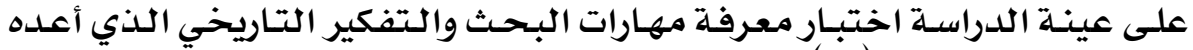

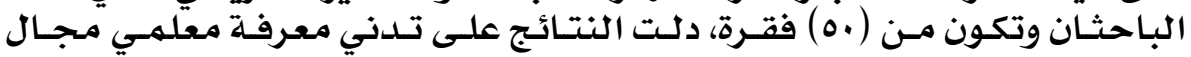

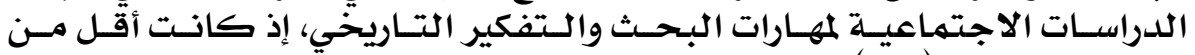

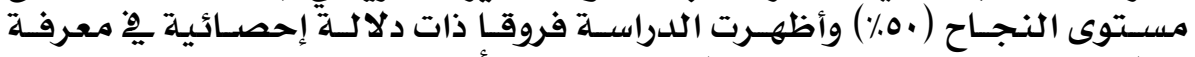

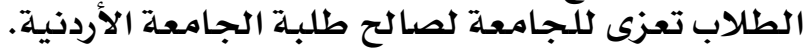

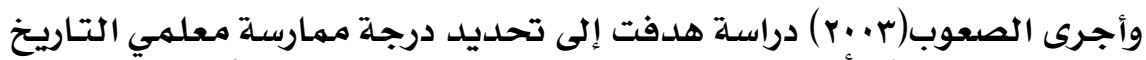

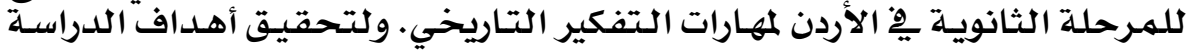

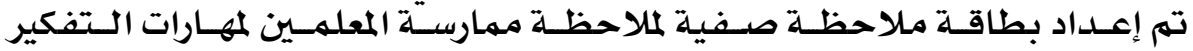

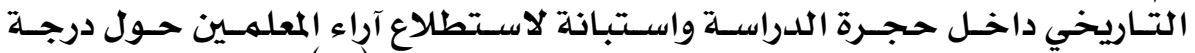

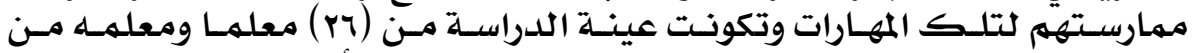

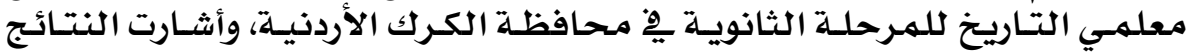

\section{$r \varepsilon$}


العقد الثلاثهون .. الجزء الأول .. أكتهبر .. آآمه

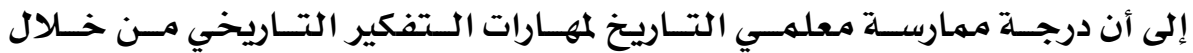

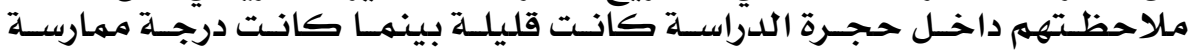
المعلمين لهذه المهارات من وجهة نظرة نظرهم كبيرة

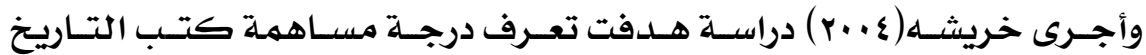

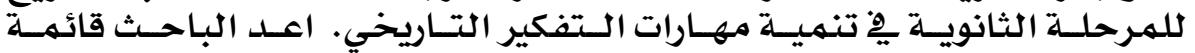

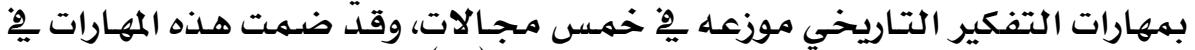

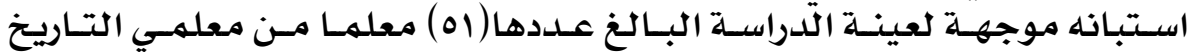

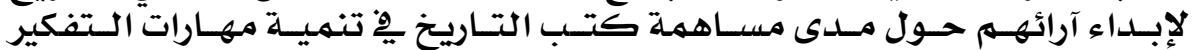

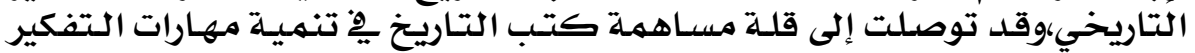

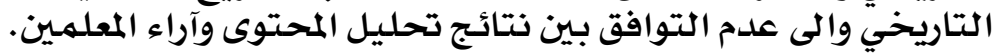

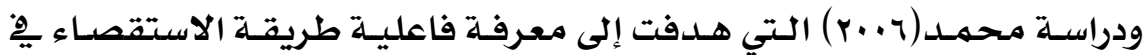

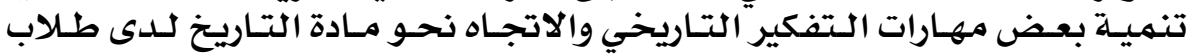

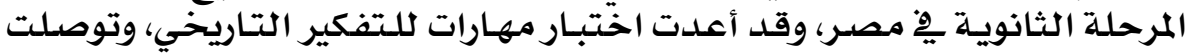
إلى فاعلية الطريقة فِّف تنمية مهارات التفكير التاريخي.

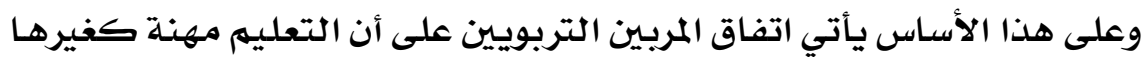

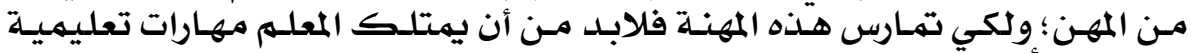

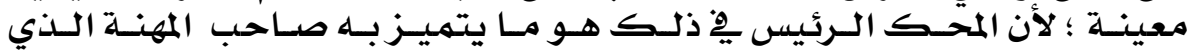

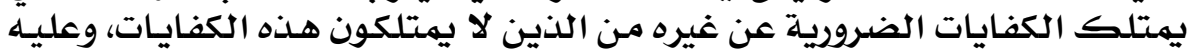

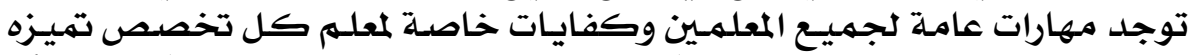

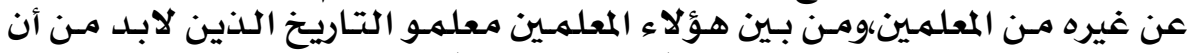

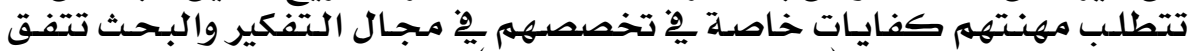

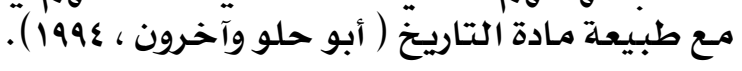

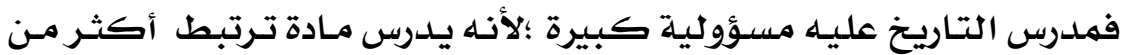

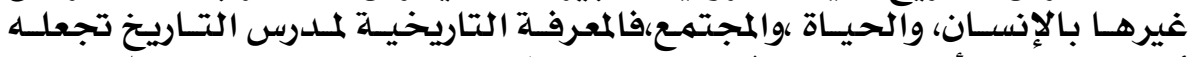

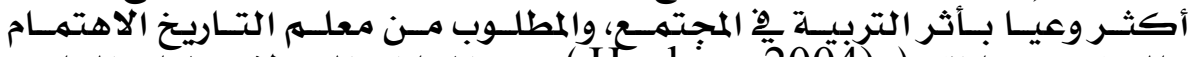

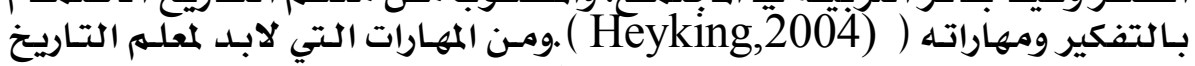

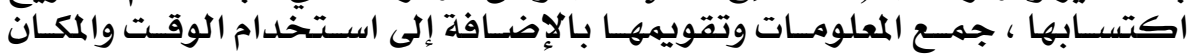

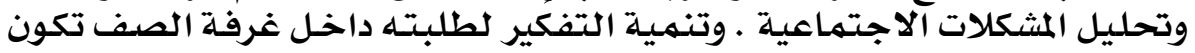

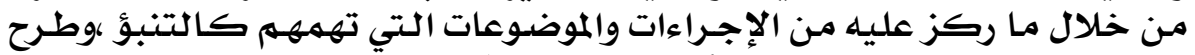

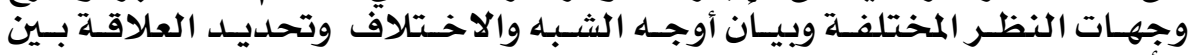

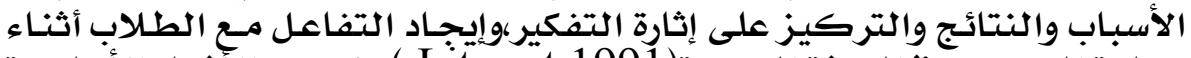

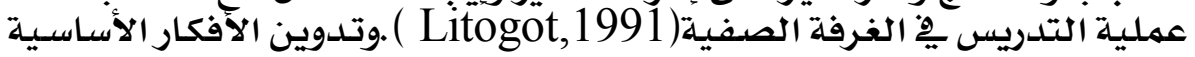

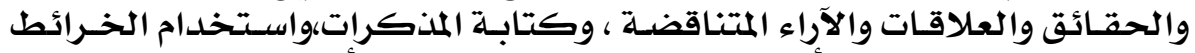

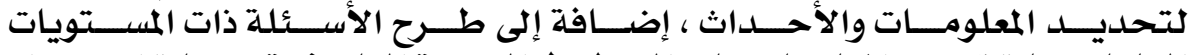

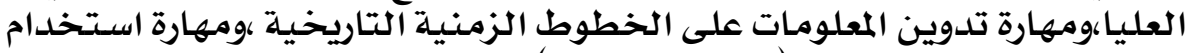

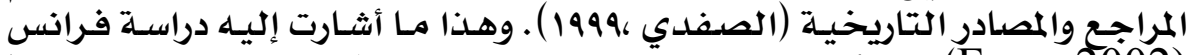

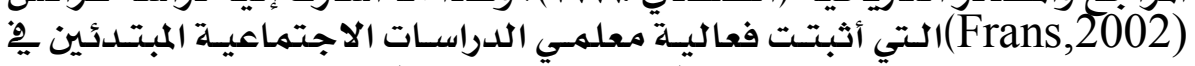

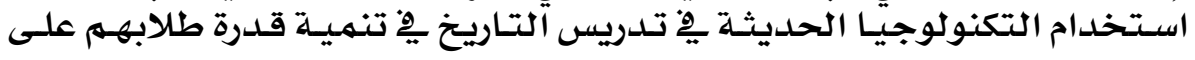

\section{ro}


العقد الثلاثهون .. الجزء الأول .. أحتهبر .. آمه

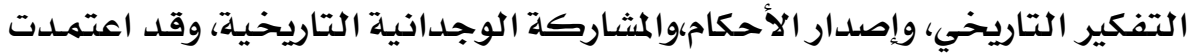

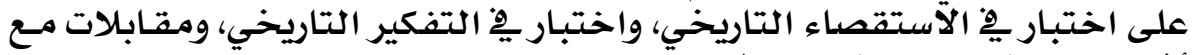

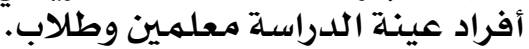

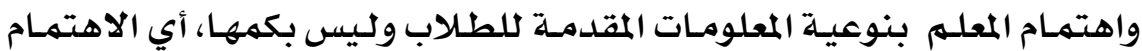

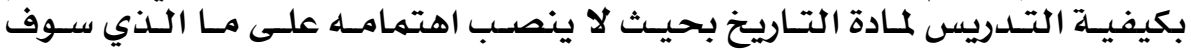

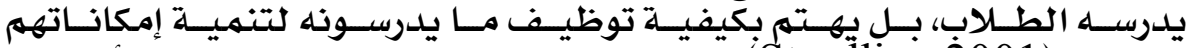

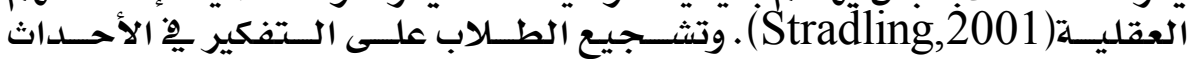

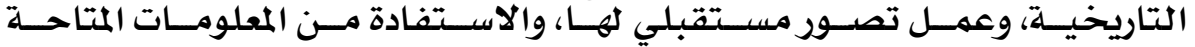

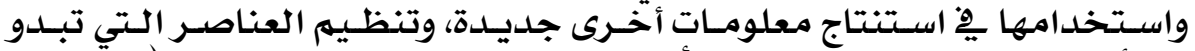

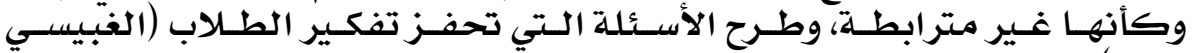
. ( r...)

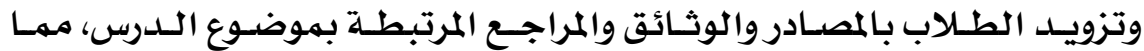

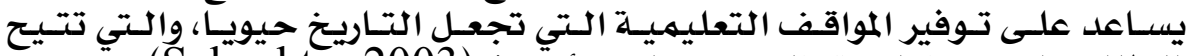

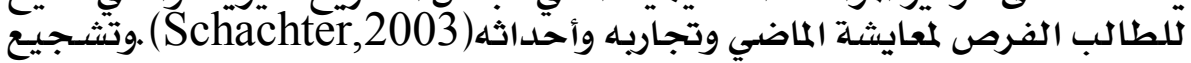

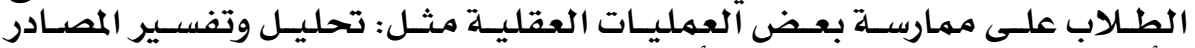

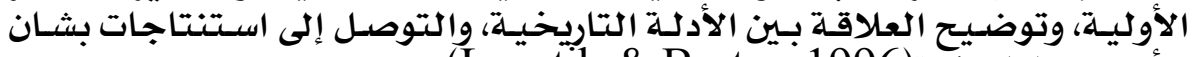

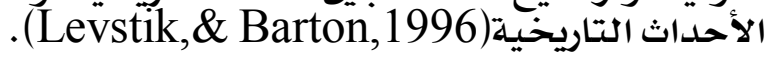

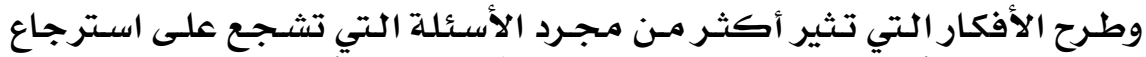

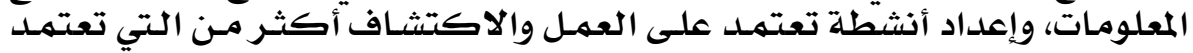

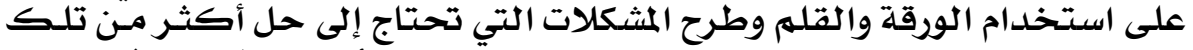

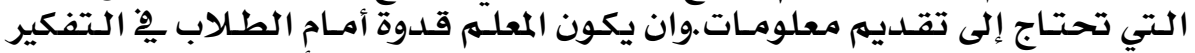

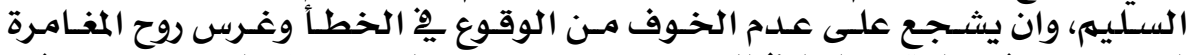

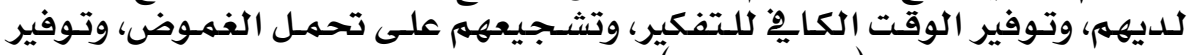

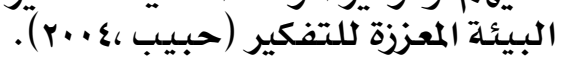

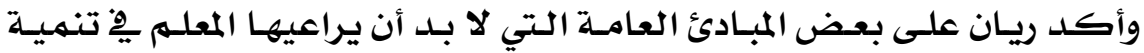

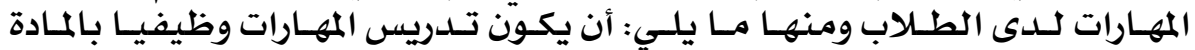

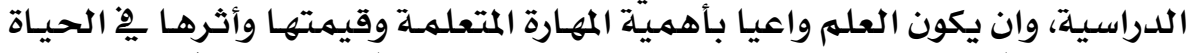

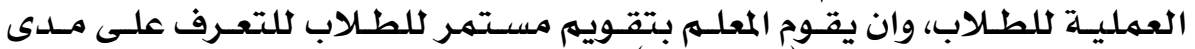

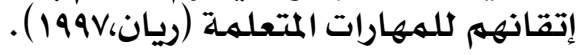

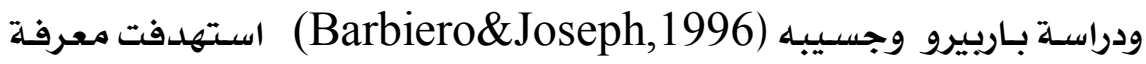

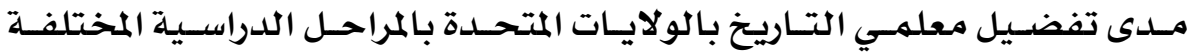

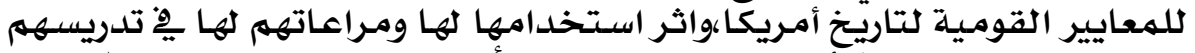

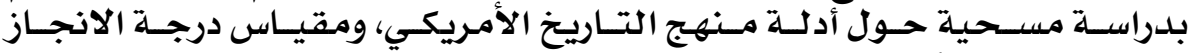

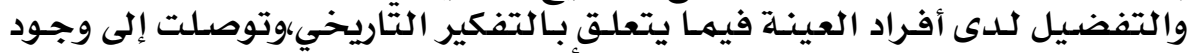

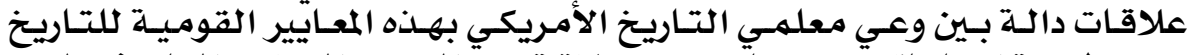

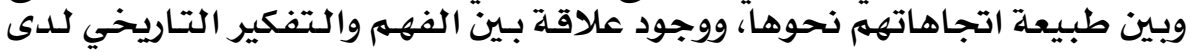

طلابهم.

\section{ry}




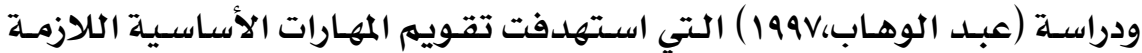

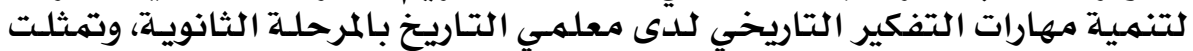

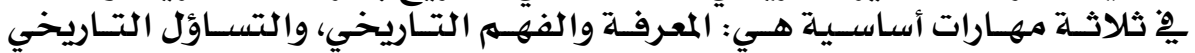

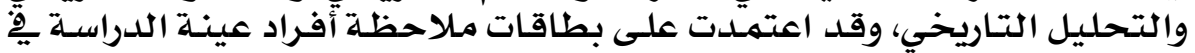

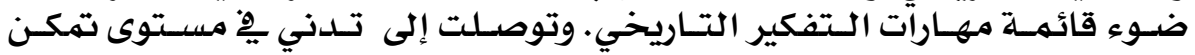

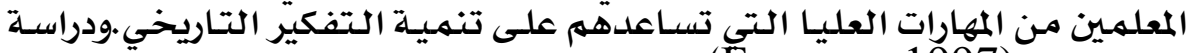

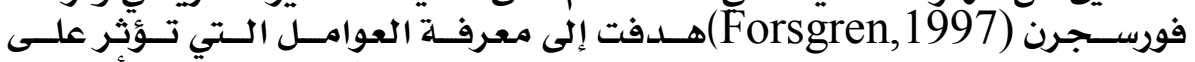

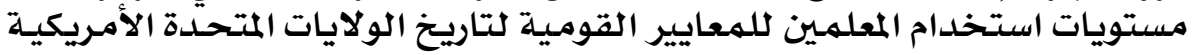

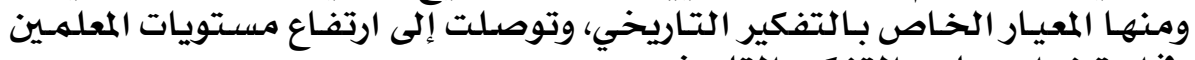

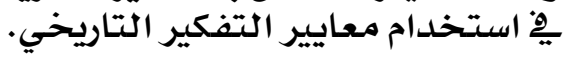

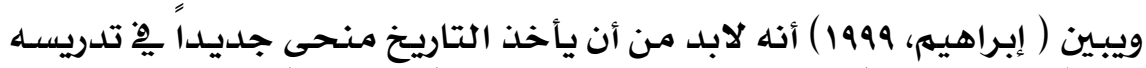

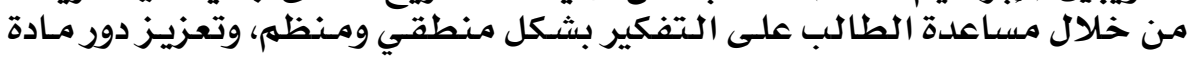

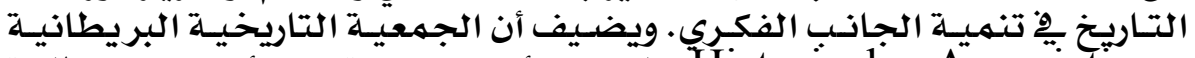
Historical Association

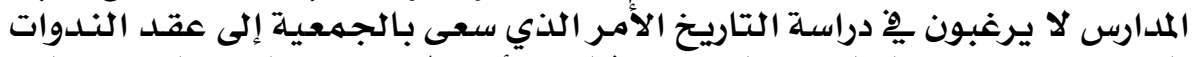

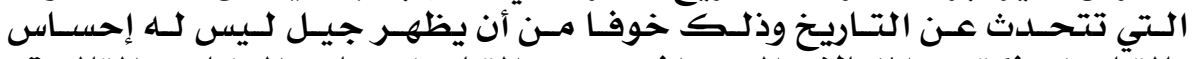

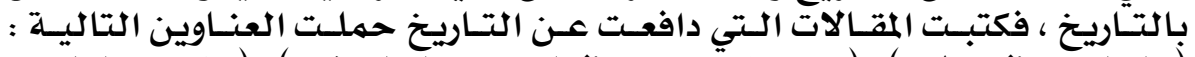

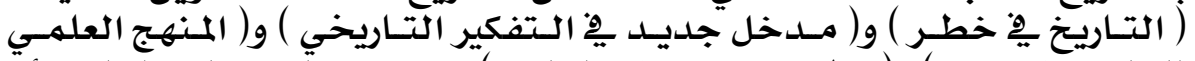

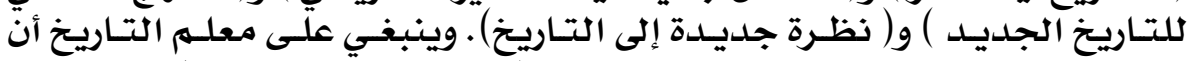

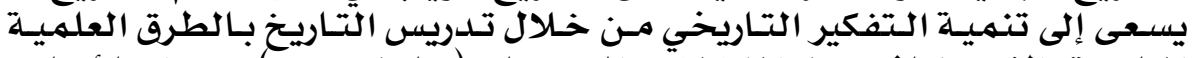

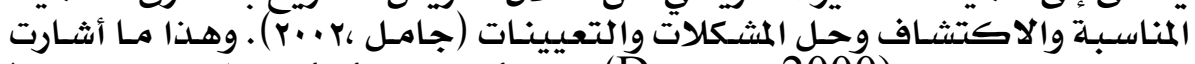

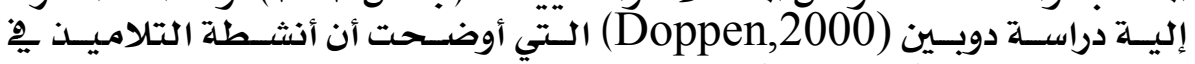

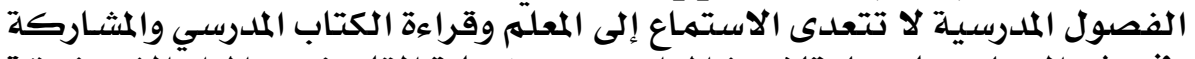

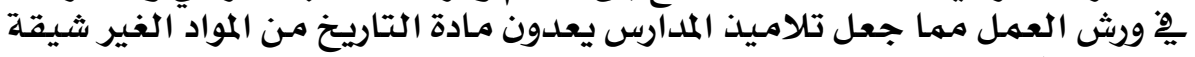

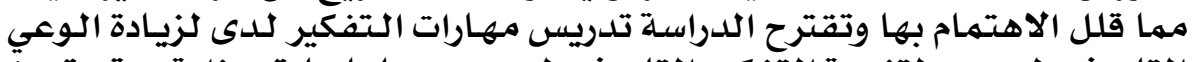

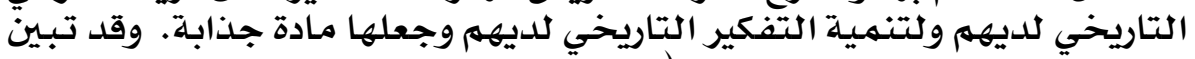

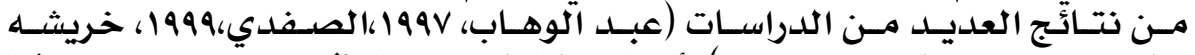

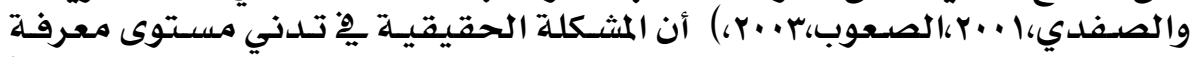

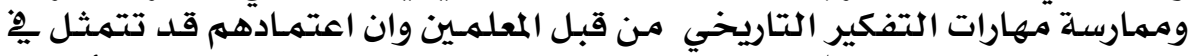

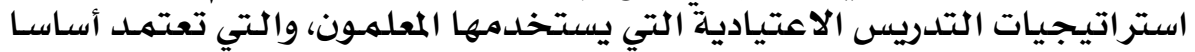

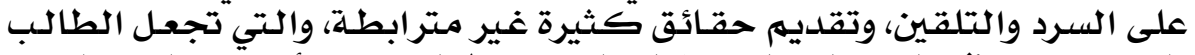

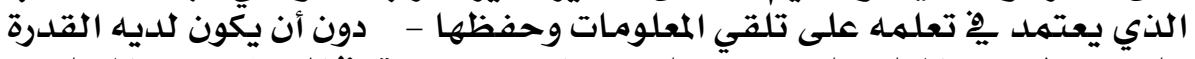

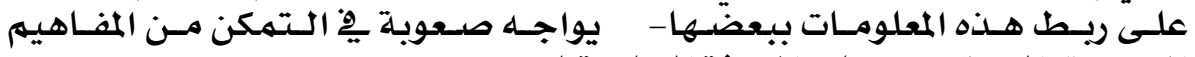

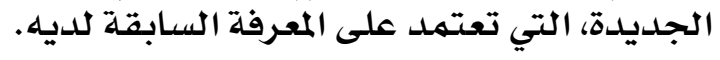

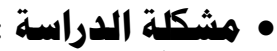

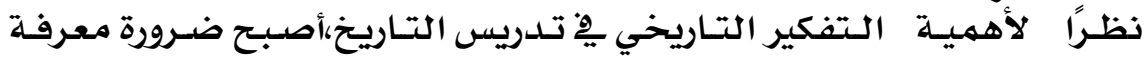

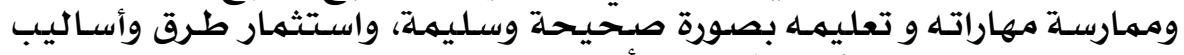

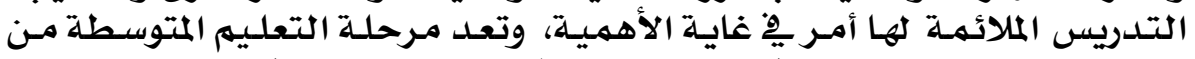

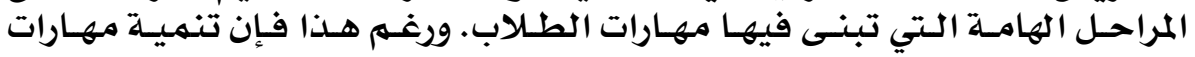




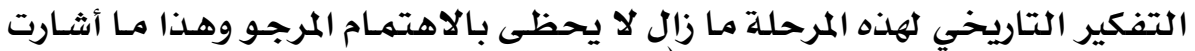

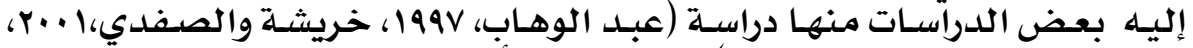

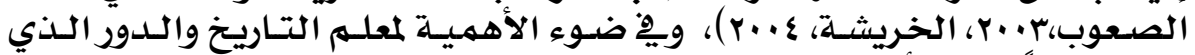

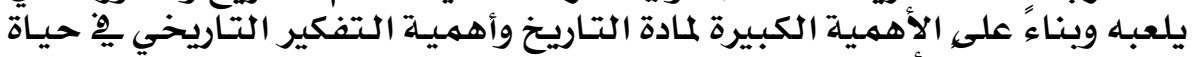

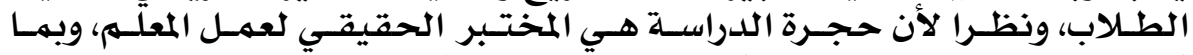

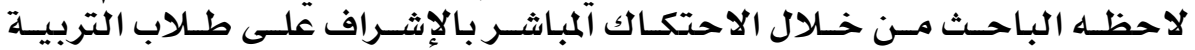

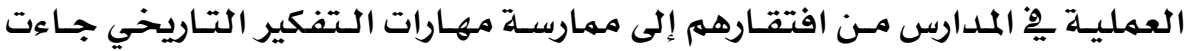

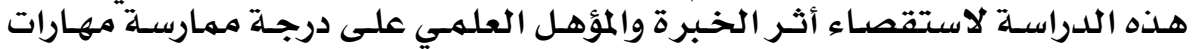

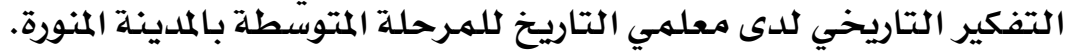

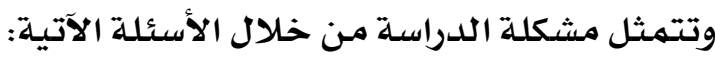

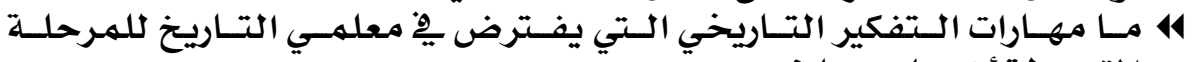

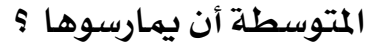

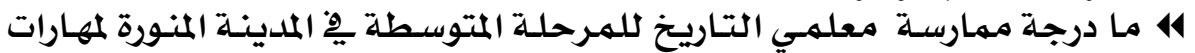

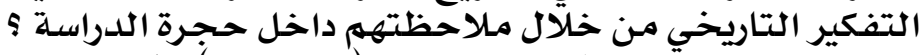

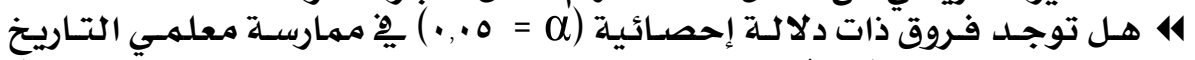

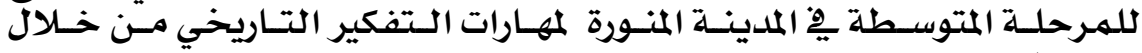

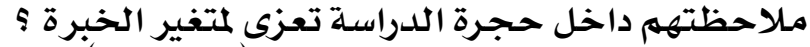

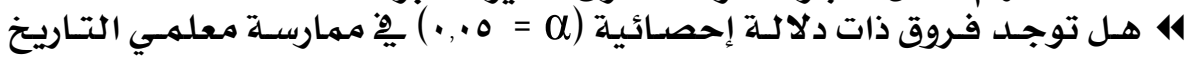

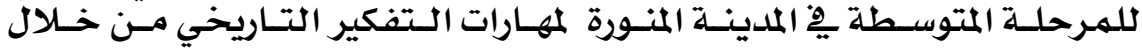

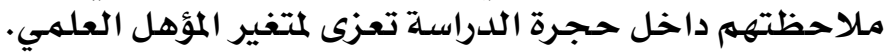
• أهداف الدراسة:

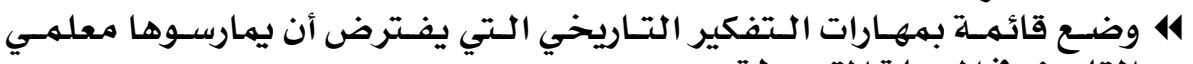

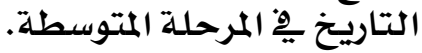

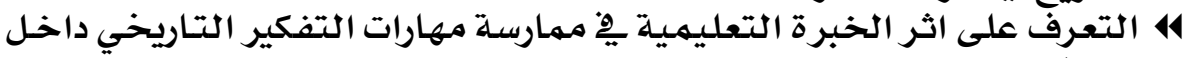

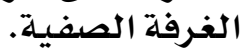
4 التعرف على أثر المؤهل التعليهـي يّْة ممارسـة مهارات التفكير التـاريخي داخل الغرفة الصفية.

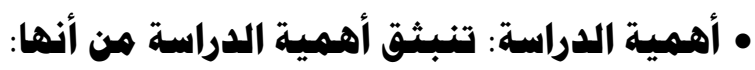

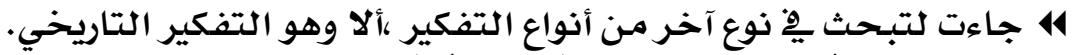

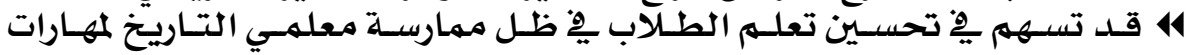
التفكير التاريخي.

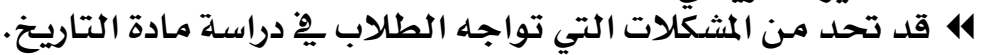

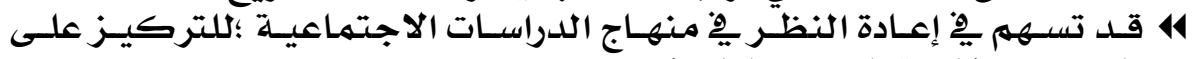
التفكير وبخاصة إعادة التفكير التتاريخي.

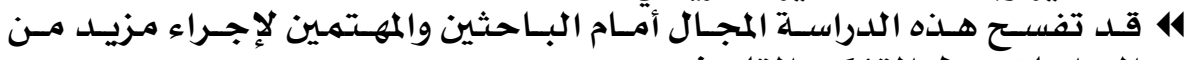

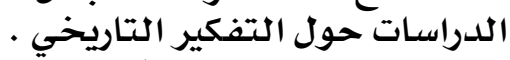

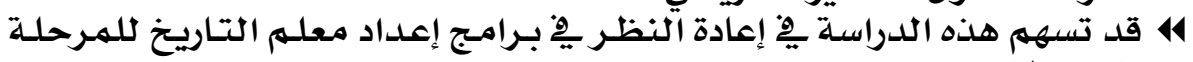
المتوسطة.

\section{ri}


العقد الثلاثهن .. الجزء الأول .. أكتهوبر .. Гامهم

• حدود الدراسة وهددداتها:

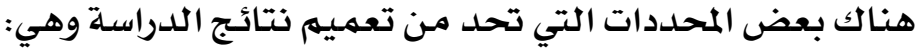

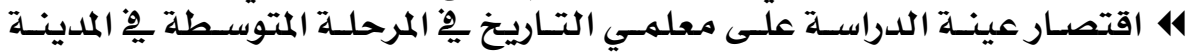

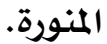
414 أداة الدراسة: (بطاقة الملاحظة ) من إعداد الباحث.

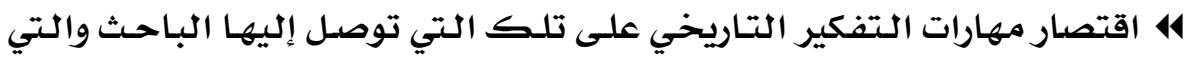

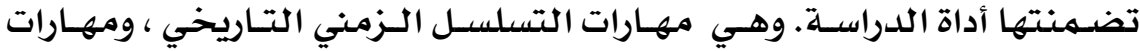

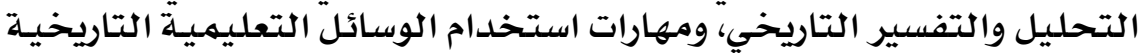
ومهارات استخدام المصادروألمراجع التاريخية. • مصطاتحات الدراسة وتعريفاتها الإجرائية:

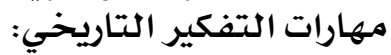

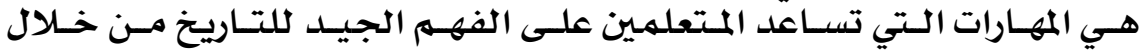

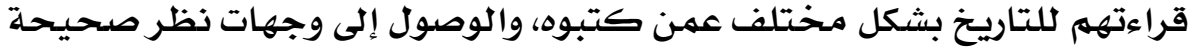

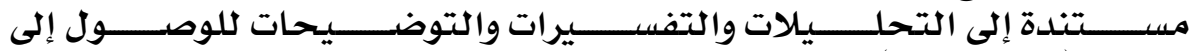

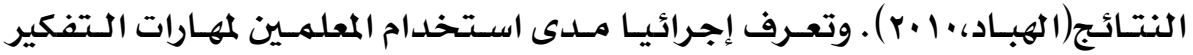

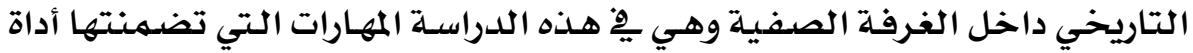

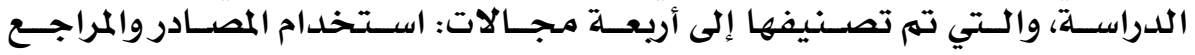

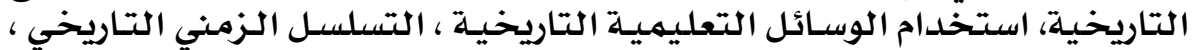

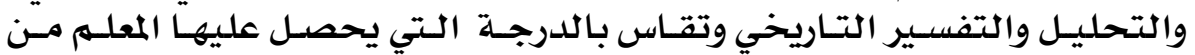
خلال بطاقة الملاحظة.

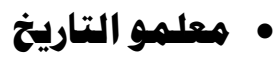

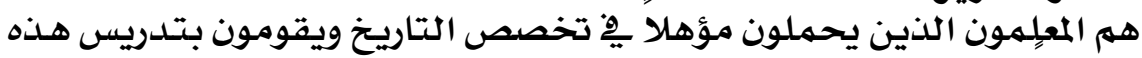

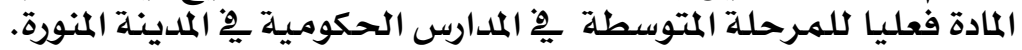

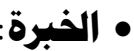
هي الخبرة التعليمية التي اكتسبها المعلهم مـن خـلال التدريس التي تراوحت

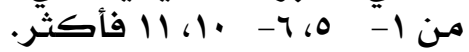

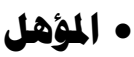

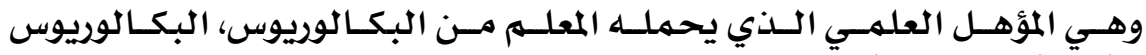
والدبلوم التربوي، والماجستير.

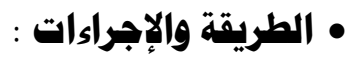

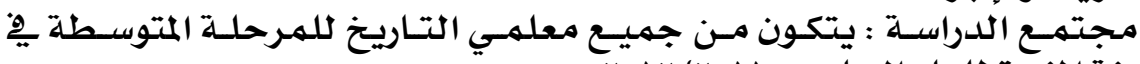

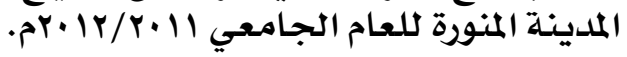

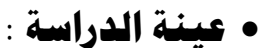

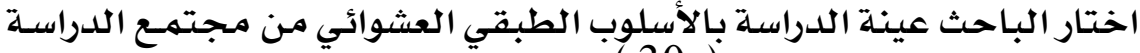

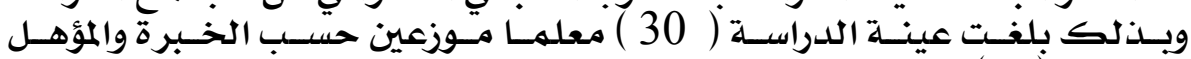
والجدول ( 1 ) يوضح ذلك توزينهمه.

\section{rq}


العقد الثلاثهون .. الجزء الأول .. أحتهوبر .. آمهم

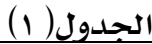

\begin{tabular}{|c|c|c|c|c|}
\hline آلمجموع & ماجستيّل فاعلى & بكائوريوسي +دبلوم 10 & بكالوريوس & الثن فؤهل \\
\hline 9 & 2 & 3 & 4 & $5-1$ \\
\hline$\frac{12}{9}$ & 3 & 3 & 6 & $10-6$ \\
\hline 30 & 8 & $\frac{4}{10}$ & 12 & المجموع \\
\hline
\end{tabular}

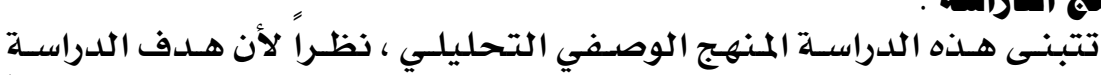

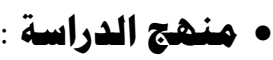

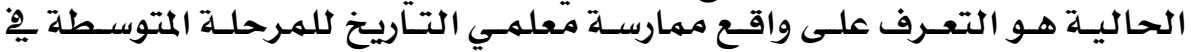
السعودية لمهارات التفكير التاريخي.

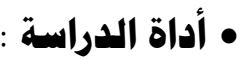

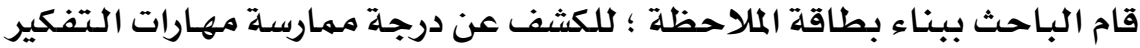

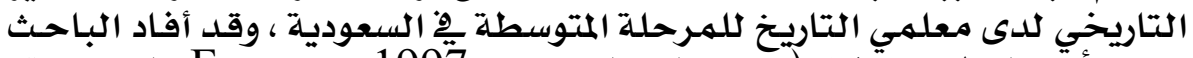

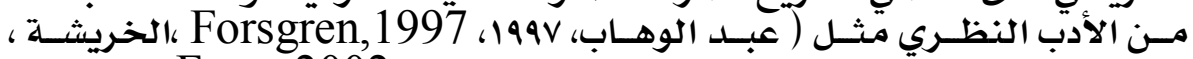

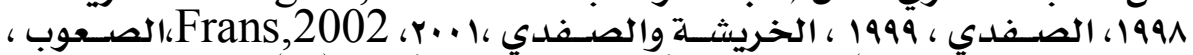

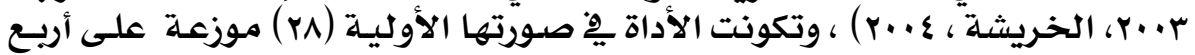

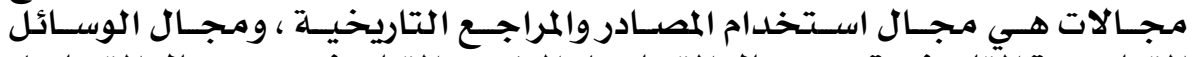

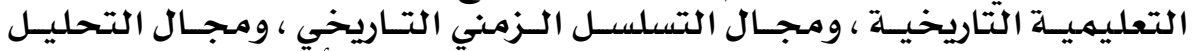

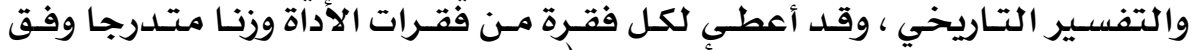

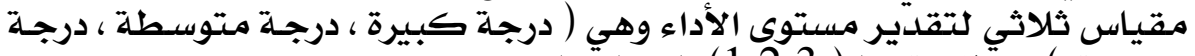
ضعيفة ) وتمثثل رقميا ( 1.2.3)على التوالي.

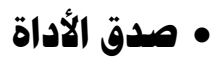

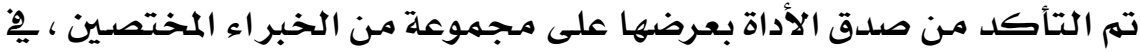

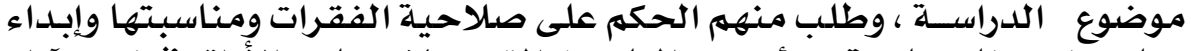

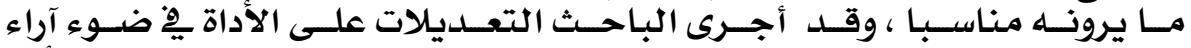

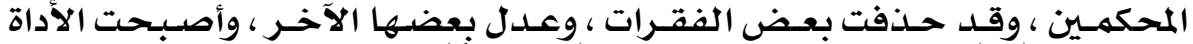

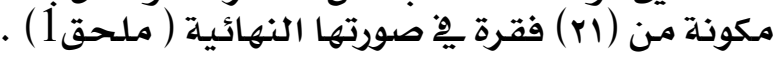

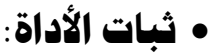

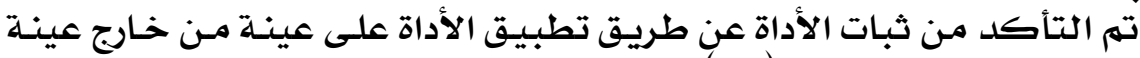

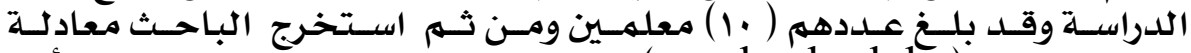

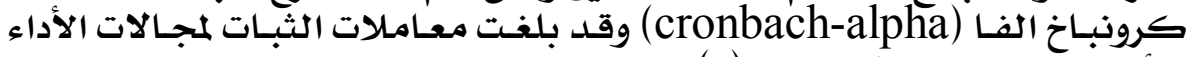

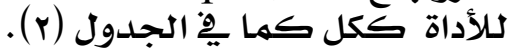
الجدول (r) : معاملات الثبات للمجالات الأربعة ِِِّ الدراسـة باستخدام معادلة كرونباخ

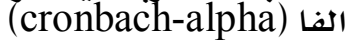

\begin{tabular}{|c|c|c|}
\hline معامل الثبات & وصف المجال & رقم المجال \\
\hline 0.88 & استخدامالمصادر والمراجع التاريخية . & 1 \\
\hline 0.86 & استخدام الوسائل التعليمية التاريخية . & 2 \\
\hline 0.92 & التسلسل الزمن التّاريخح & 3 \\
\hline $\mathbf{0 . 8 3}$ & التحليل والتسبر التاريخخ & 4 \\
\hline 0.93 & \multicolumn{2}{|c|}{ الآداة ككل هـ } \\
\hline
\end{tabular}

\section{$\varepsilon$.}


العقد الثلاثهون .. الجزء الأول .. أحتهوبر .. آمهم

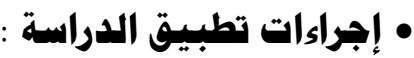

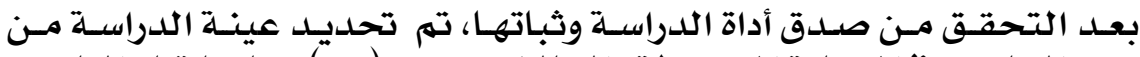

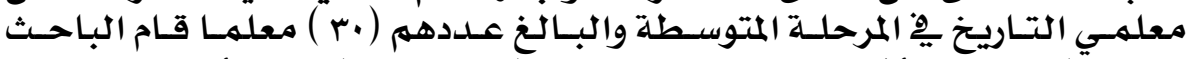

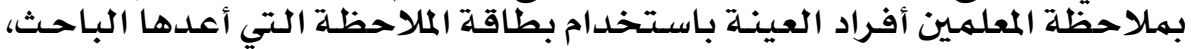

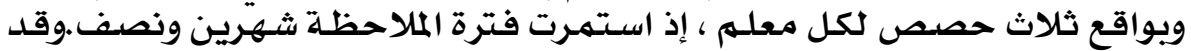

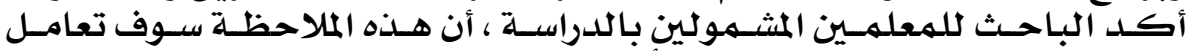

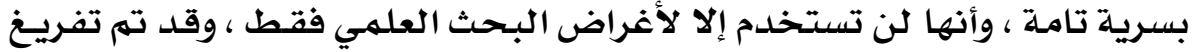

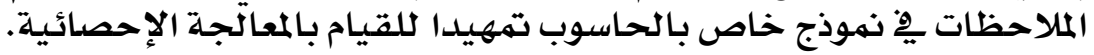

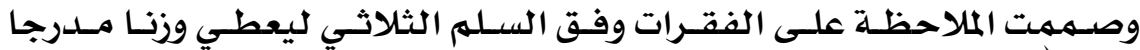

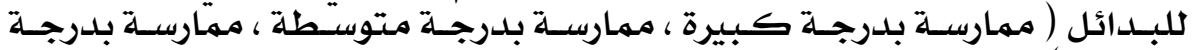

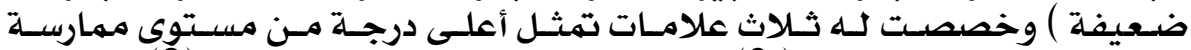

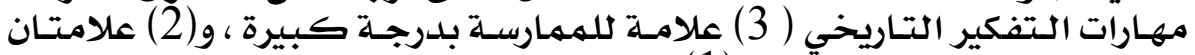

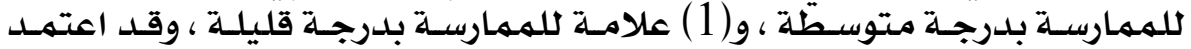

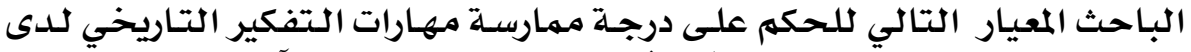
معلمي التاريخ للمرحلة المتوسطة فِّ السعودية على النحو الآتي:

\begin{tabular}{|c|c|}
\hline بلرجة كبيرة & $3-2.33$ \\
\hline بلرجةٌ متؤوسطة & $2.32-1.67$ \\
\hline بدرجة ضعيفة & $1.66-$ \\
\hline
\end{tabular}

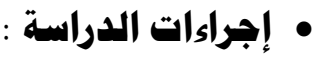

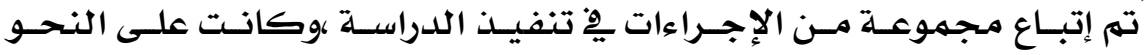

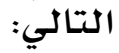

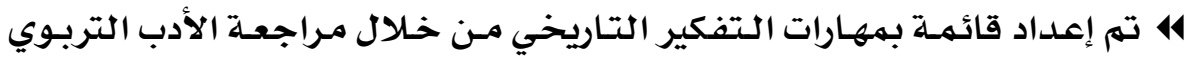

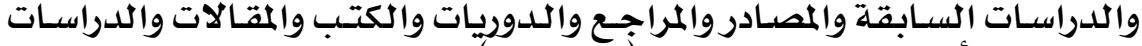

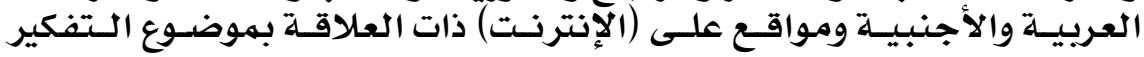

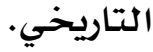

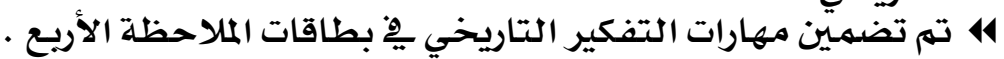

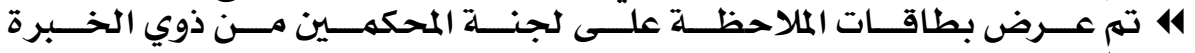

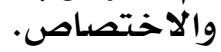
4 وبـذلك تم التأكلد مـن صـدق بطاقـات الملاحظة بحسـاب نسبة الاتفـاق بـين المجكمين.

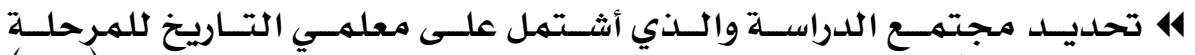

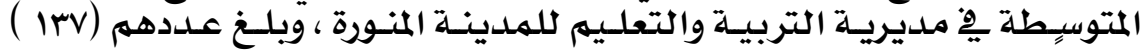

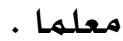

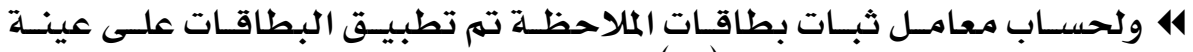
استطلاعية بلغ عدد أفرادها (. (1) معلمين.

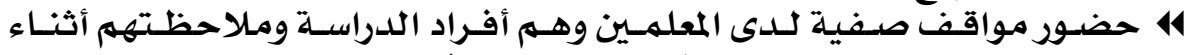
الموقف الصفي حيث تم ملاحظة كل معلهم يو ثلاثة مواقف صفية مـن قبل

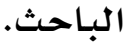

\section{$\varepsilon 1$}


العكق الثلاثهون .. الجزء الأول .. أكتهبر .. זا•مه

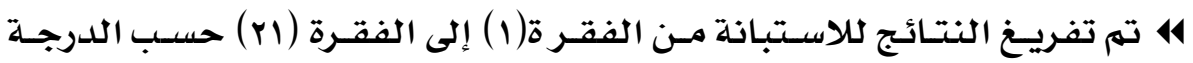

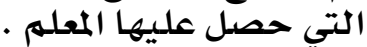

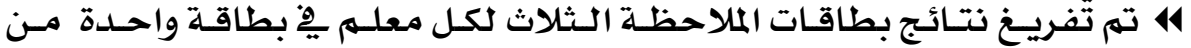

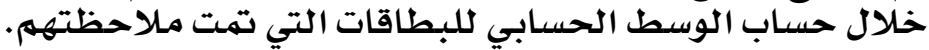

\section{• نتائج الدراسة وهناقشتهاب الوسطا :}

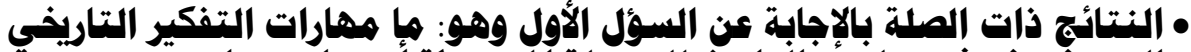

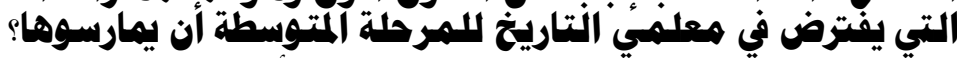

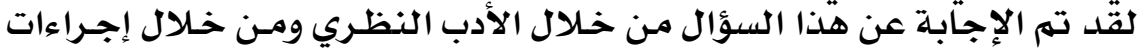
الدراسة . تمبل

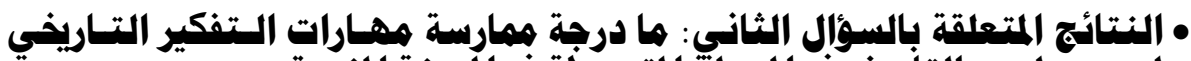

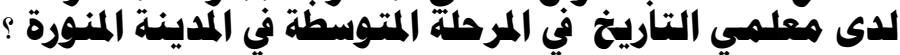

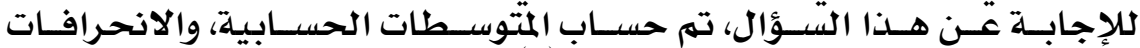

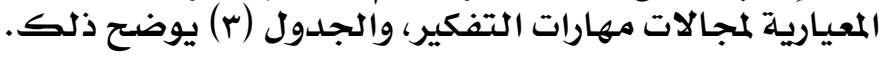

الجدول (r ) : المتوسطات الحسابية والانحرافات المعيارية لمجالات مهارات التفكير مرتبة تنازليا

\begin{tabular}{|c|c|c|c|c|c|}
\hline الاتحراف المعياري & المتوسط الحسابي & عدد الفقرات & المجال & الرقم - الرق & الرتبة \\
\hline 0.71 & 2.35 مرتفعة & 6 & التسلسل الزمن ـ التاريخح & 3 & 1 \\
\hline 0.76 & 1.8 متوسطة & 5 & التحليل,والقسبر التاريخخ . & 4 & 2 \\
\hline 0.81 & 1.7 متوسطة & 5 & استخدام الوسائل التعليمية التاريخنة . & 2 & 3 \\
\hline 0.74 & 1.5 & 5 & استخدام المصادروالمراجع التاريخية & 1 & 4 \\
\hline 0.78 & 1.86 & 21 & اةكلك:متوسطة & & \\
\hline
\end{tabular}

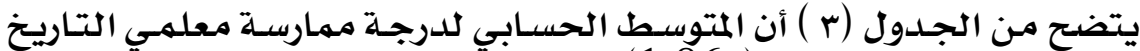

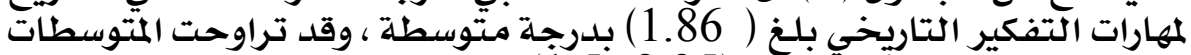

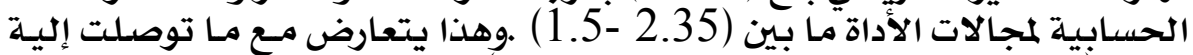

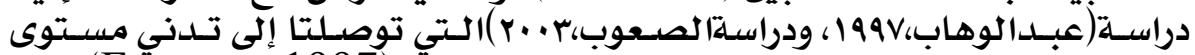

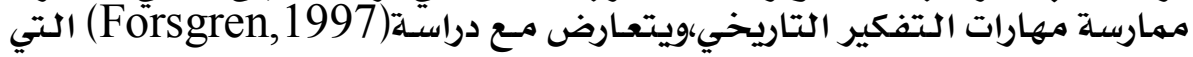

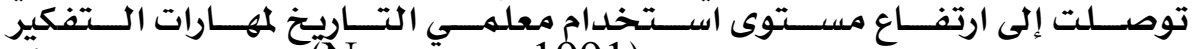

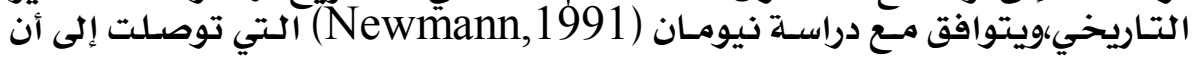

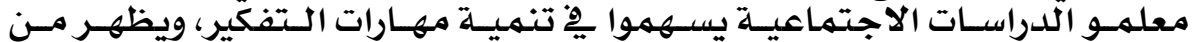

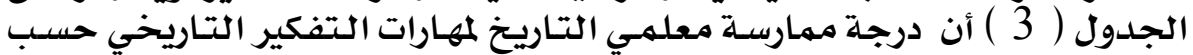

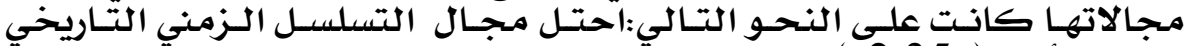

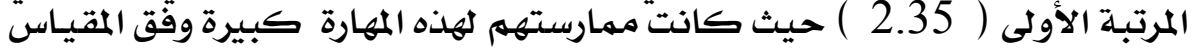

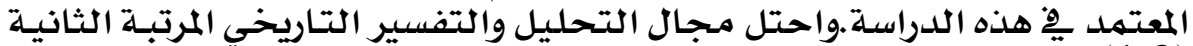

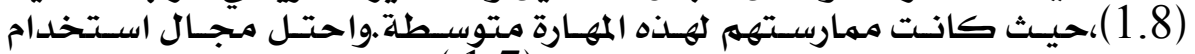

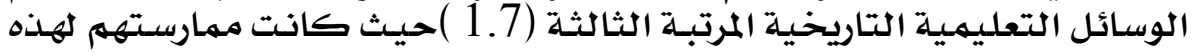

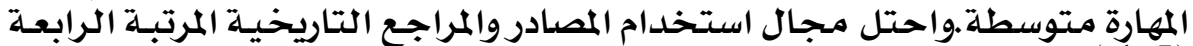

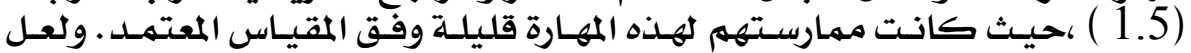

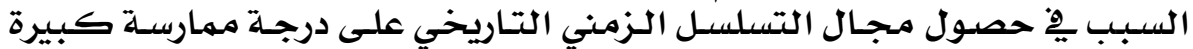

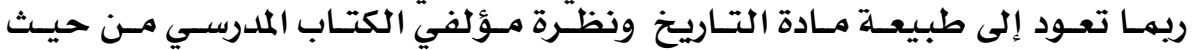

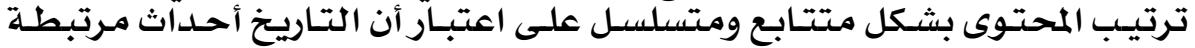

\section{$\varepsilon Y$}




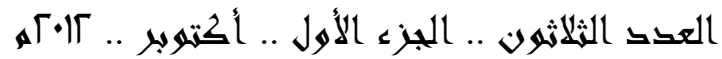

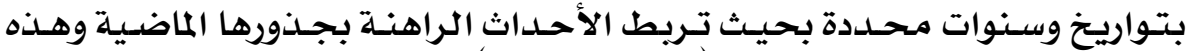

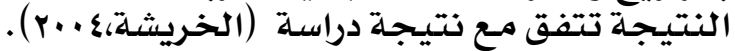

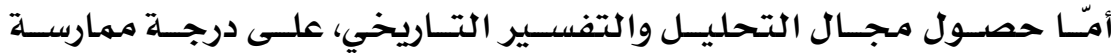

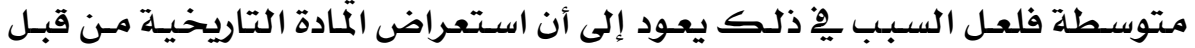

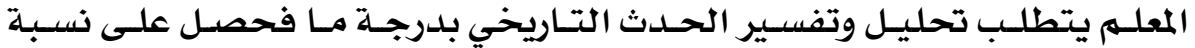

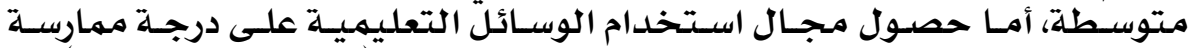

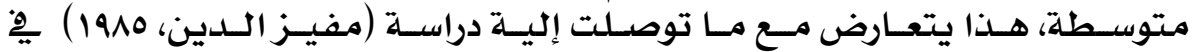

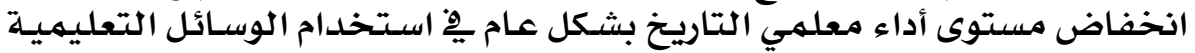

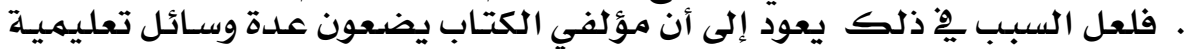

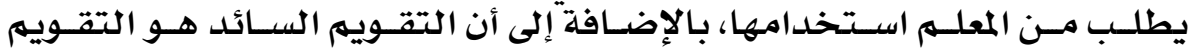

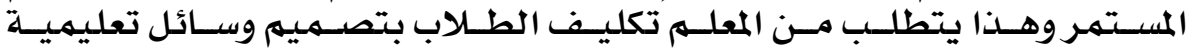

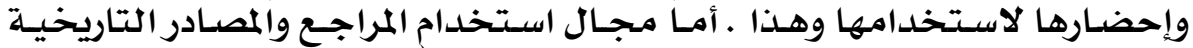

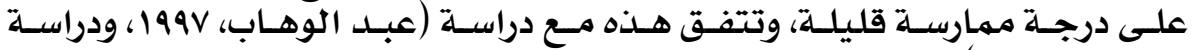

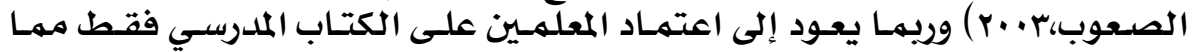

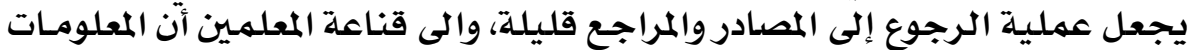

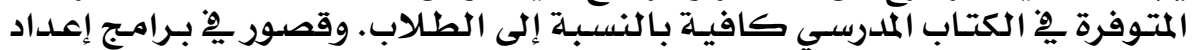

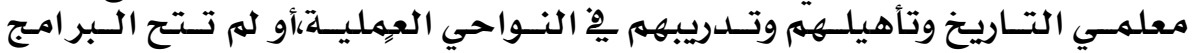

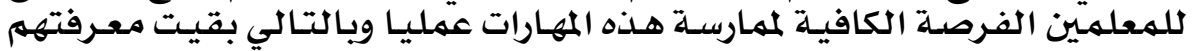

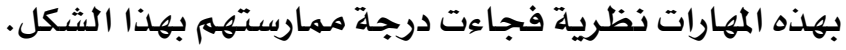

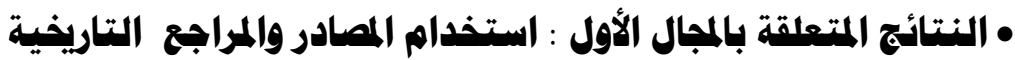

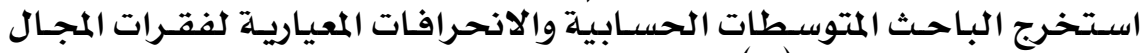

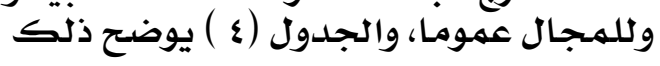

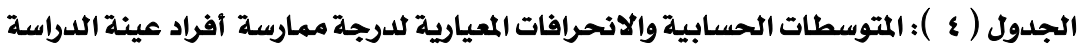

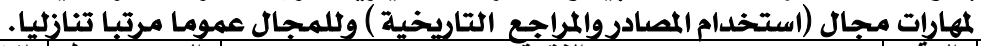

\begin{tabular}{|c|c|c|c|c|}
\hline المعياري اف المئ & 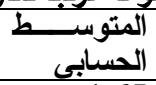 & 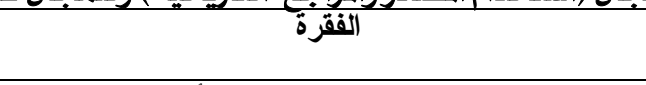 & الرقق & الرتبة \\
\hline 0.77 & 1.65 & 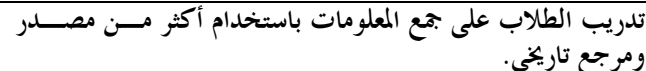 & 2 & 1 \\
\hline 0.75 & 1.60 & إلتاريخية. الطلاب إلى كيفية الحصول على المعرفة من المصادر والمراجع & 3 & 2 \\
\hline 0.74 & 1.50 & تلدريب الطلاب على تقييم الأدلة التاريخية. & 5 & 3 \\
\hline 0.74 & 1.40 & تدريب الطلاب على التمييز بين المصادر والمراجع التاريخية . & 1 & 4 \\
\hline 0.74 & 1.30 & 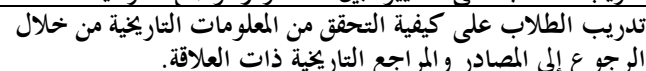 & 4 & 5 \\
\hline$. \vee V \leqslant$ & 1.50 & 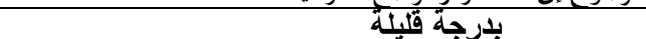 & & \\
\hline
\end{tabular}

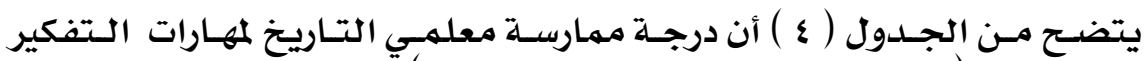

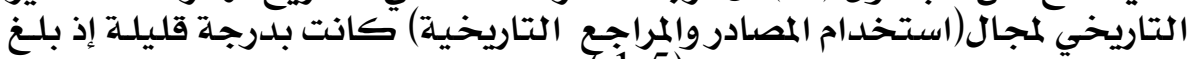

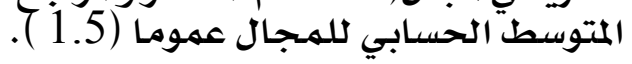

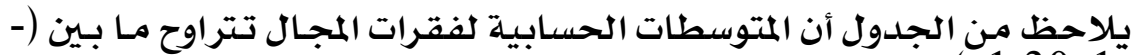

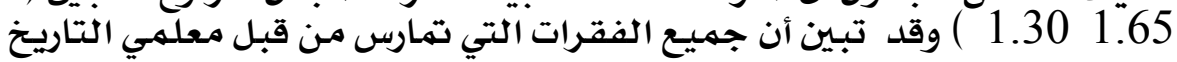

\section{$\varepsilon \mu$}




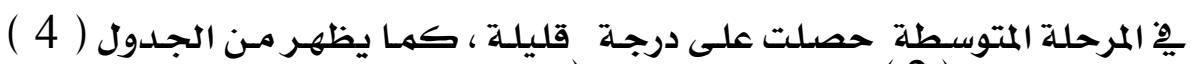

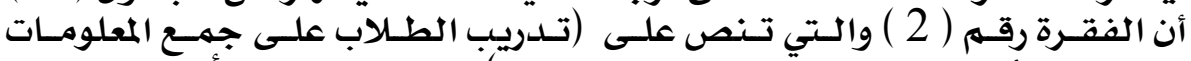

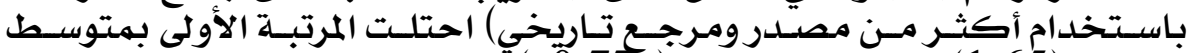

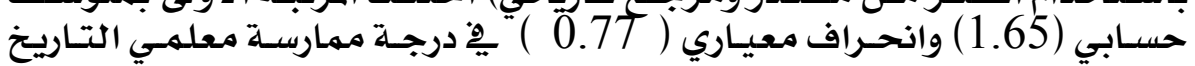

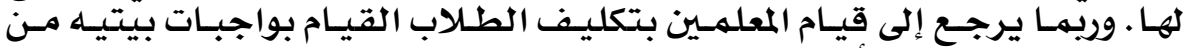

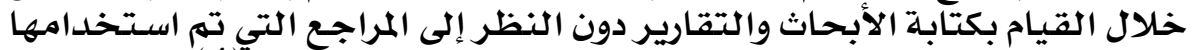

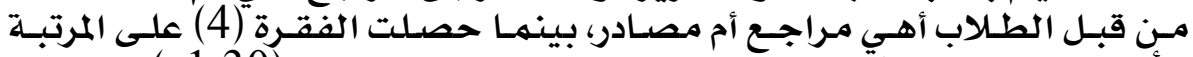

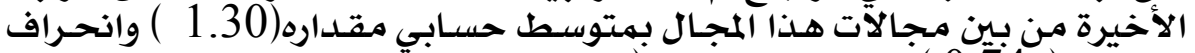

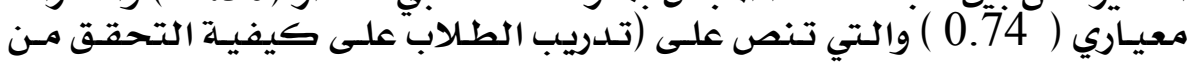

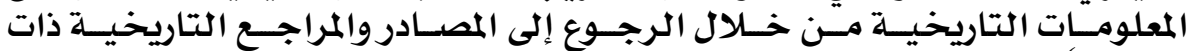

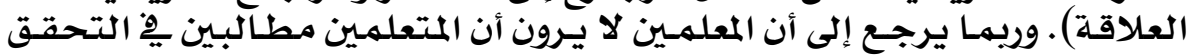

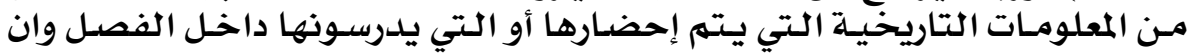

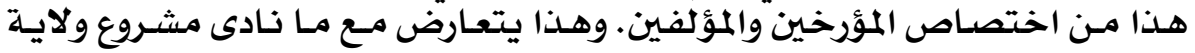

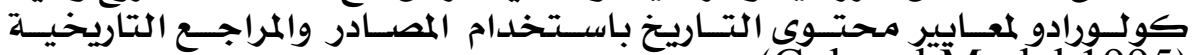
.(Colorad Model,1995)

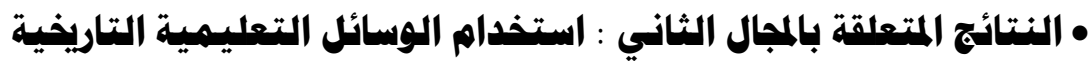

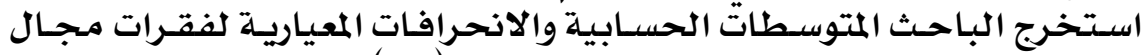

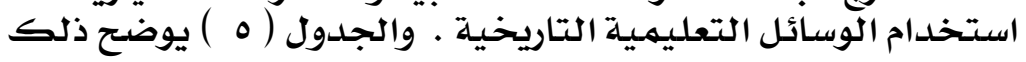

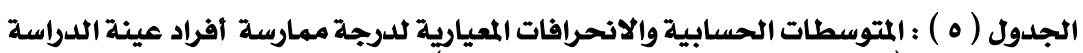

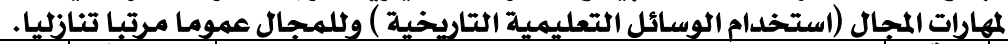

\begin{tabular}{|c|c|c|c|c|}
\hline المعياري & الحستوسي & الفقرة & آلزرقم & الرتبة \\
\hline..$\wedge \Gamma$ & $1 . \wedge$ & تثنيع الطلاب على عمل ملف للإحاث التاريخية . & r & 1 \\
\hline$\therefore \vee 9$ & $1 . \Lambda$. & تدريب الطلاب على قر اءة الخر ائط ألتاريخية وتتفتير ها & $\varepsilon$ & r \\
\hline$. \wedge \leqslant$ & 1.vo & 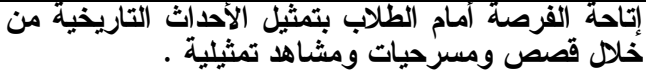 & $r$ & r \\
\hline$\therefore \vee \wedge$ & 1.70 & تلدريب الطلاب على رسم الخرائط التاريخية . & 1 & $\varepsilon$ \\
\hline.. $\mathrm{A}$ & 1.0 & تلدريب الطلاب على استخذام الأطلس التاريخى . & 0 & e \\
\hline.. $\mathrm{Al}$ & $1 . v \cdot$ & بلرجة متوسطة & & \\
\hline
\end{tabular}

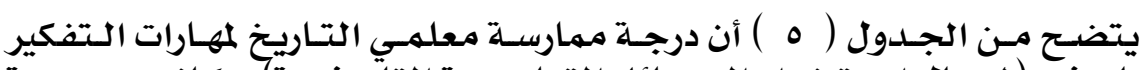

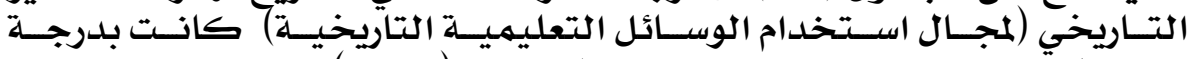

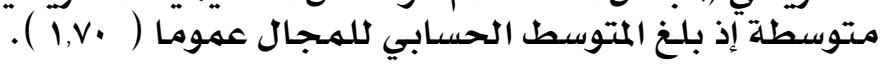

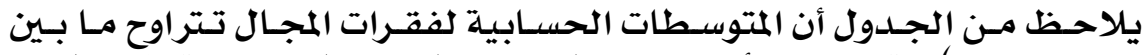

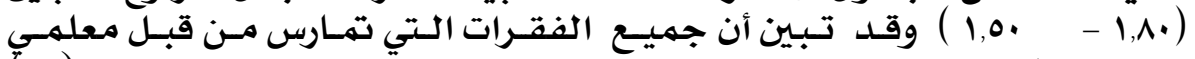

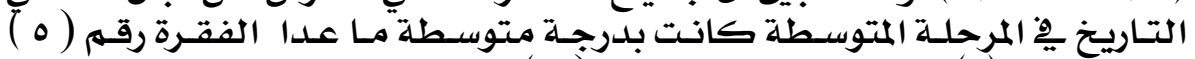

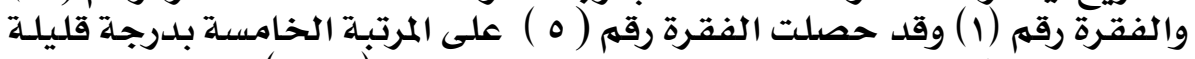

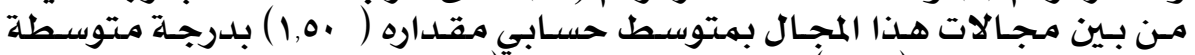

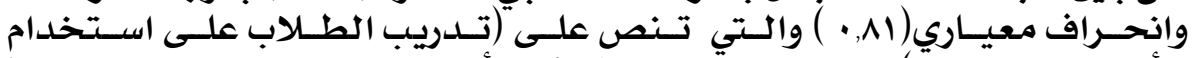

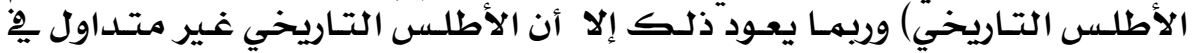

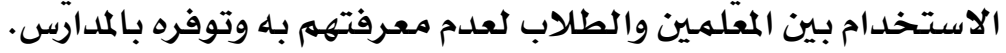

\section{$\varepsilon \varepsilon$}




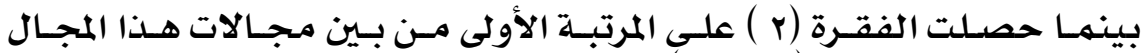

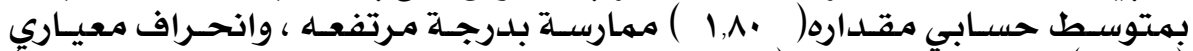

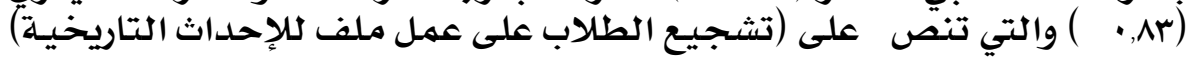

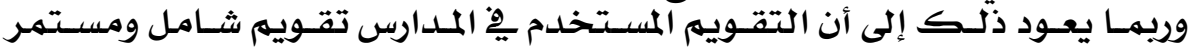

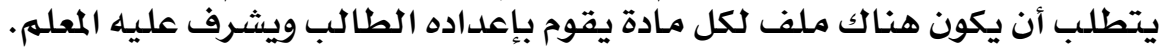

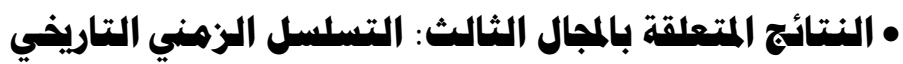

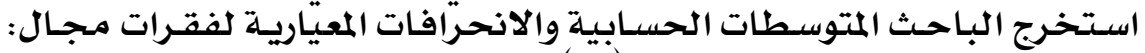

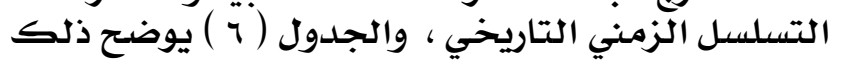

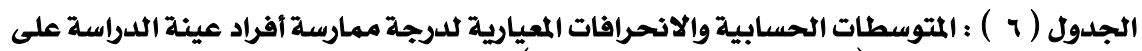

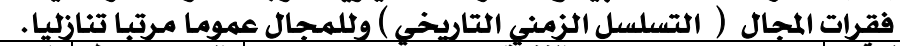

\begin{tabular}{|c|c|c|c|c|}
\hline المعياري آلاحيــــــ & الحستوسيـــ & آلفقرة & 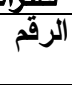 & 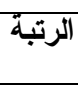 \\
\hline.$v_{0}$ & Y.TV & 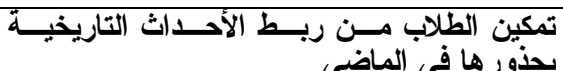 & r & .1 \\
\hline.. $\mathrm{TV}$ & T.T. & تُقيّميب الطلاب على قياس الزمن باكثر من نظام & 0 &. $\bar{T}$ \\
\hline. $.7 \mathrm{~V}$ & Y.O. & 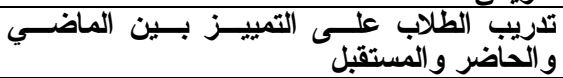 & 1 &.$\Gamma$ \\
\hline. .79 & Y.T. & تدريب الطلاب على التتبؤ بالآحداث المستقبلية. & $\varepsilon$ & . \\
\hline.. $\mathrm{V}^{\mathrm{T}}$ & r.rq & 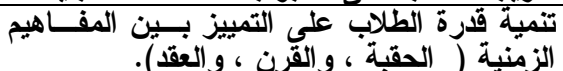 & 7 & .0 \\
\hline$\therefore v^{\circ}$ & Y.Y. & تتمية قلدرة الطلاب على ترتيب الآحداث زمنيا. & $r$ & .9 \\
\hline . & Y.TO & & & \\
\hline
\end{tabular}

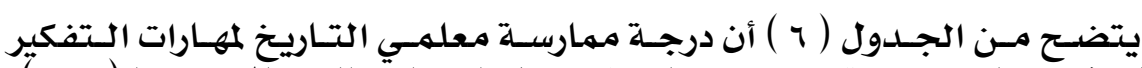

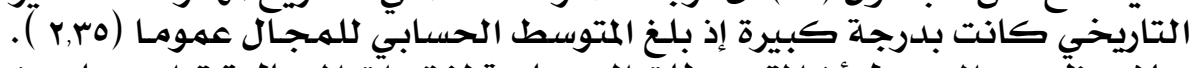

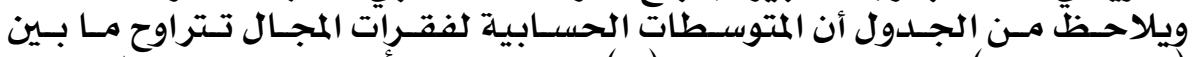

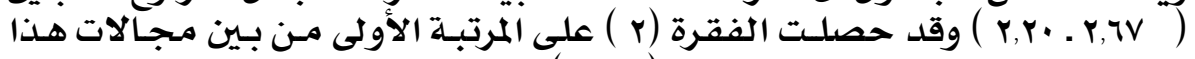

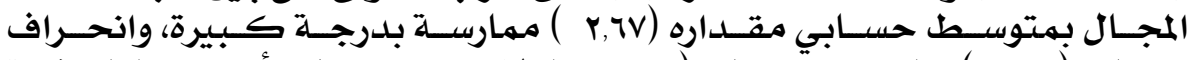

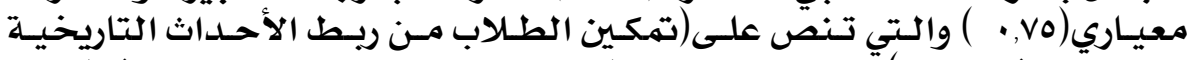

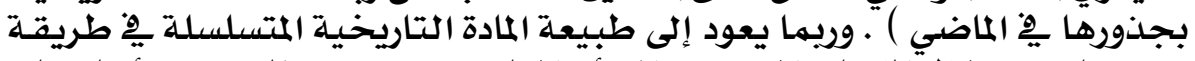

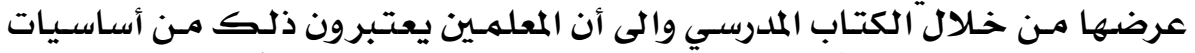

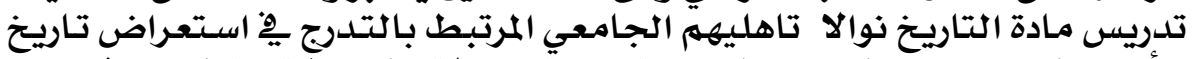

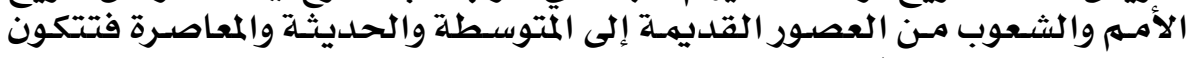

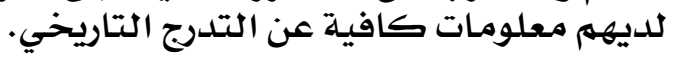

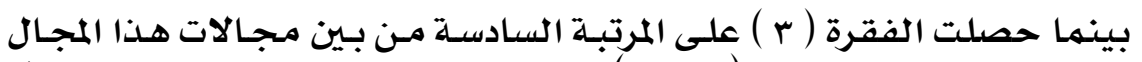

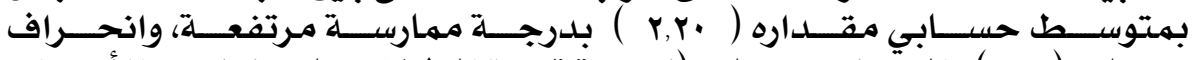

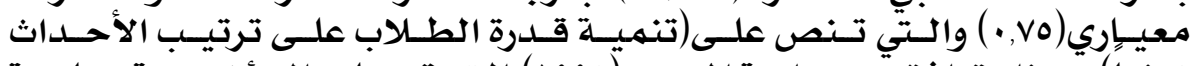

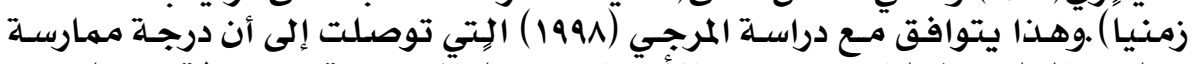

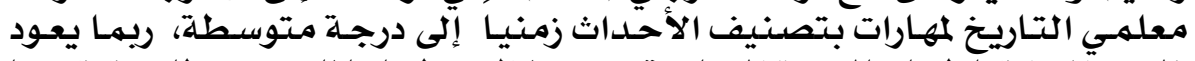

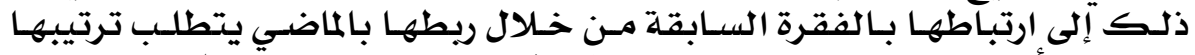

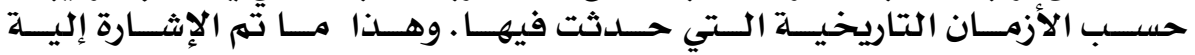

\section{$\varepsilon \theta$}




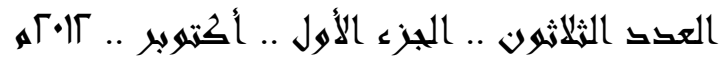

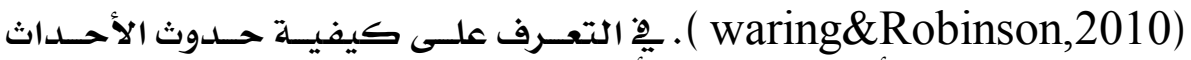
التاريخية على مـر الأزمان، وتحليل الأحداث التعـان التاريخية.

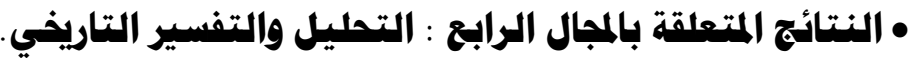

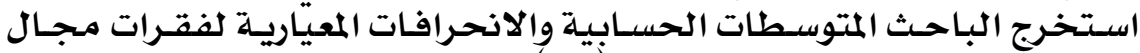

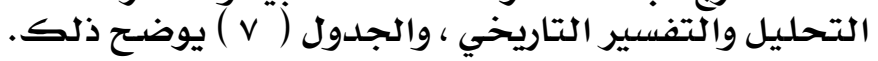

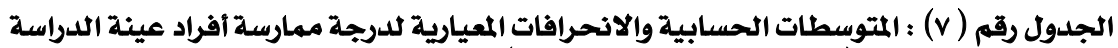

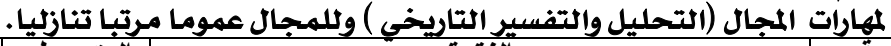

\begin{tabular}{|c|c|c|c|c|}
\hline المياري افي & 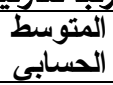 & الفقرةة & 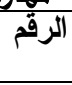 & الرتبة \\
\hline$. V \leqslant$ & 1.90 & 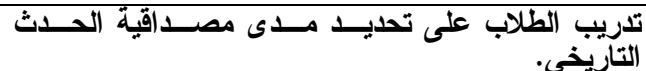 & $T$ & .1 \\
\hline. .199 & $1 . \vee \wedge$ & 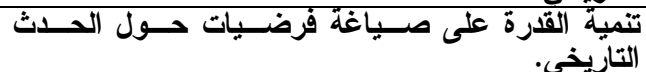 & 0 &. $\mathrm{r}$ \\
\hline.$\vee \wedge$ & I.V V & 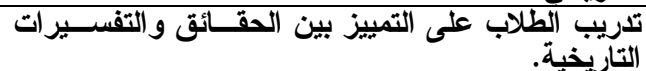 & $r$ &.$r$ \\
\hline. .17 & 1.17 & التاريخي الطناب عدة مصادر تاريخية. المضامين الواردة بالمحتوى & r &.$\varepsilon$ \\
\hline..$V^{\mu}$ & $1 . v_{0}$ & 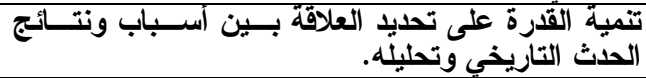 & $\varepsilon$ & .0 \\
\hline..$V^{4}$ & 1.1. & بلبرجة متوسطة & & \\
\hline
\end{tabular}

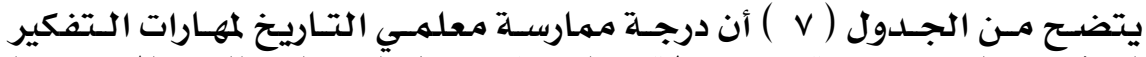

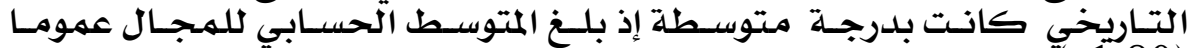

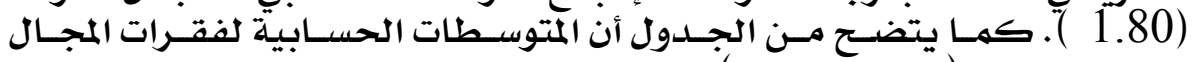

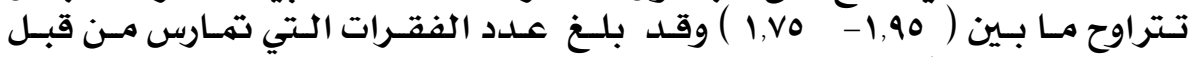

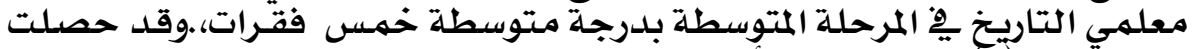

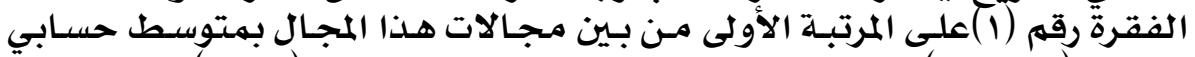

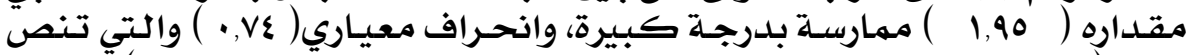

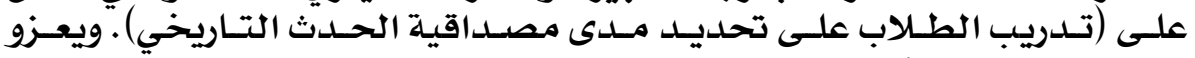

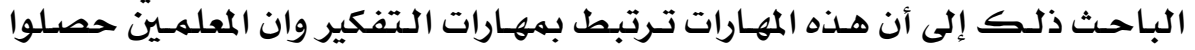

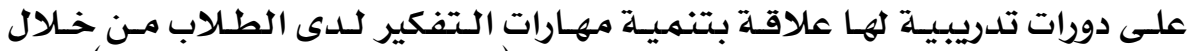

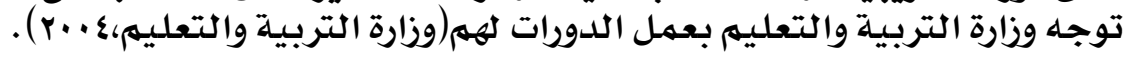

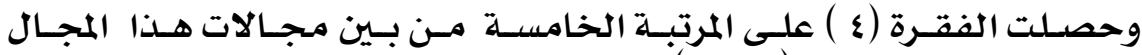

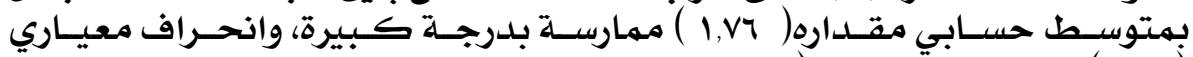

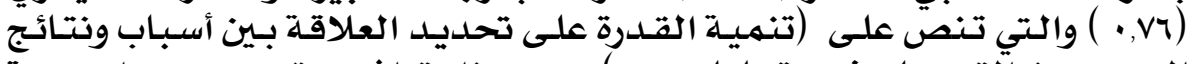

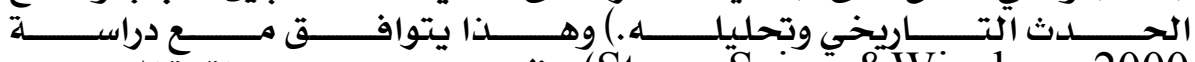

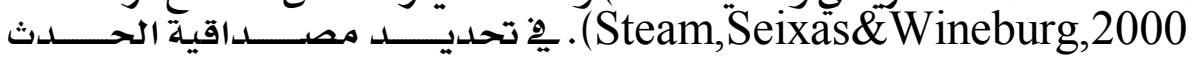

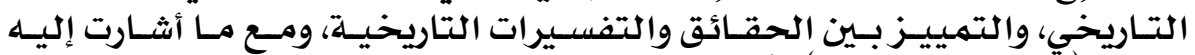

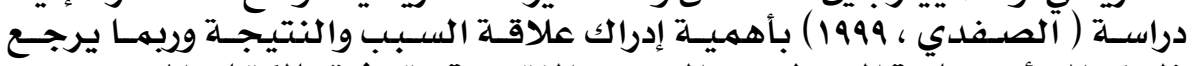

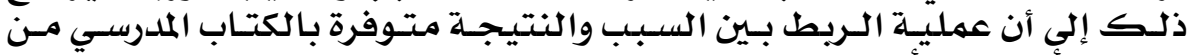

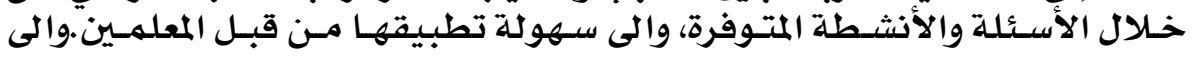

\section{$\varepsilon 7$}




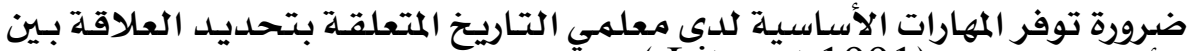
الأسباب والنتائج ( Litogot,1991 ).

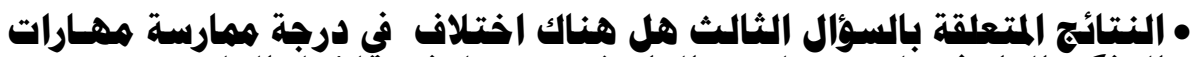

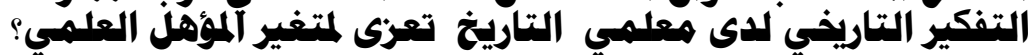

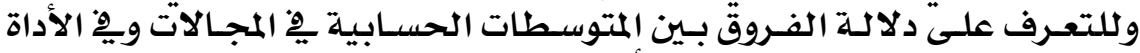

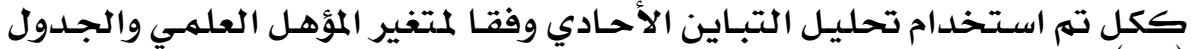

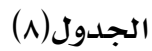

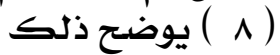

\begin{tabular}{|c|c|c|c|c|c|c|}
\hline \multicolumn{2}{|c|}{ ماجستير فأكتُّ (^) } & \multicolumn{2}{|c|}{ بكالوريوس+ دبلوم (· (1) } & \multicolumn{2}{|c|}{ بكالوريوس (Y I) } & \multirow[t]{2}{*}{ المجال } \\
\hline أحرأف & متوسط & أحر (ف) & تمتوسط & آحرر افت & متوسط & \\
\hline 1.1 & 9 & $.9 \mathrm{~V}$ & $9 . \% 0$ & $\cdot . \mathrm{VI}$ & V.V & استخذام المصادر والمراجع \\
\hline$\cdot . \wedge \wedge$ & $\Lambda . \leqslant \leqslant$ & $\because \mathrm{V}^{\circ}$ & 9.10 & $\cdot .^{\wedge \mu}$ & IY.VA & استخذام الوسائل التعليمية. \\
\hline$\cdot . \wedge \Lambda$ & $1 \leqslant . \leqslant \xi$ & $\because .91$ & $\Lambda .7 \mathrm{~V}$ & $\cdot . \wedge \wedge$ & $1 . .04$ & التسلسل الزمني التاريخي \\
\hline .94 & $1 Y .11$ & 1.1 & $9.7 \mathrm{~V}$ & $\cdot . \leqslant \leqslant$ & V.r & التحليل والتفسيِّ التاريخي \\
\hline$r .7$ & $V 0 . \leqslant \Lambda$ & Y.V4 & $\leqslant 1.0$ & $1 . \leqslant 4$ & $r \Lambda . r q q$ & الاداة ككل \\
\hline
\end{tabular}

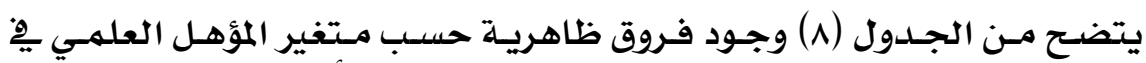

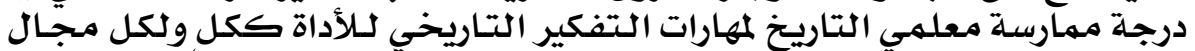

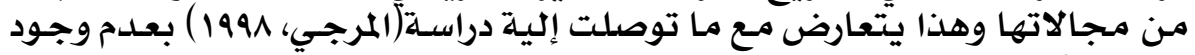

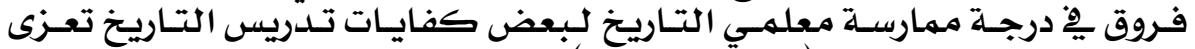

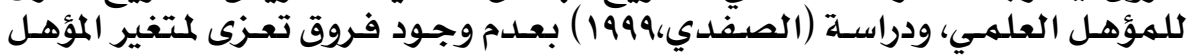

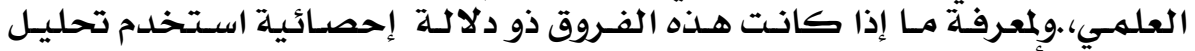

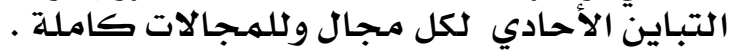

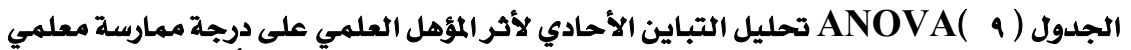

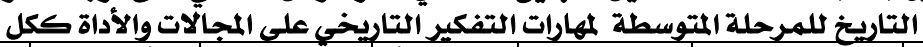

\begin{tabular}{|c|c|c|c|c|c|c|}
\hline مسلالة الدــتوى & قيمة ف & 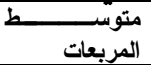 & الرجرية & 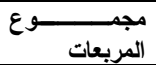 & مصدر التباين & المجال \\
\hline \multirow[t]{3}{*}{$\because \cdots$} & $\$ 1.10 Y$ & O०.VAr & r & 111.078 & بين المجموعات & \multirow{3}{*}{$\frac{\overline{3}}{3} \frac{\overline{1}}{3} \frac{\overline{3}}{2}$} \\
\hline & & 1.704 & $r v$ & r.. & داخل المجموعات & \\
\hline & & & rq & $1 \leq \Lambda .17 V$ & المجموع & \\
\hline \multirow[t]{3}{*}{$\because \cdots$} & $0 \leq . Y \cdot Y$ & $7 \cdot . r 1 Y$ & $r$ & $14 . .740$ & بين المجموعات & \multirow{3}{*}{ 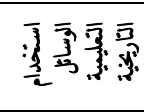 } \\
\hline & & $1.11 \%$ & rV & $r \cdot . \cdot \leq r$ & داخل المجموعات & \\
\hline & & & rq & $10 \cdot .77 \mathrm{~V}$ & المجموع & \\
\hline \multirow[t]{3}{*}{$\because \cdots$} & $0 . . \mathrm{VVV}$ & $79.91 \%$ & $r$ & Irr.97V & بين المجموعات & \multirow{3}{*}{$\overline{7} \overline{3} \cdot \overline{3}$} \\
\hline & & I.rr. & $r V$ & ro.9.. & داخل المجموعات & \\
\hline & & & rq & $179 . \wedge 78$ & المجموع & \\
\hline \multirow[t]{3}{*}{$\because \cdots$} & $P 1 . v \leq q$ & rr.qva & $r$ & $T V . r \Delta \Lambda$ & بين المجموعات & \multirow{3}{*}{ 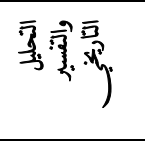 } \\
\hline & & 1.91 & $r V$ & $r \wedge .7 \leq r$ & داخل المجموعات & \\
\hline & & & rq & $97 . \ldots$ & المجموع & \\
\hline \multirow[t]{3}{*}{$\because \cdots$} & $\varepsilon \cdot . r \vee 1$ & $r \cdot r . \wedge 0$. & $r$ & $\varepsilon .0 . V \ldots$ & بين المجموعات & \multirow{3}{*}{$\frac{7}{10}$} \\
\hline & & 0. YO & $r V$ & 140.778 & داخل المجموعات & \\
\hline & & & rq & $0 \leq 1 . \mathrm{MVV}$ & المجموع & \\
\hline
\end{tabular}

$$
\text { يتضح من الجدول ( } 9 \text { ) ) }
$$

\section{$\varepsilon V$}




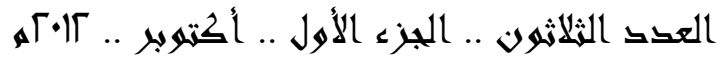

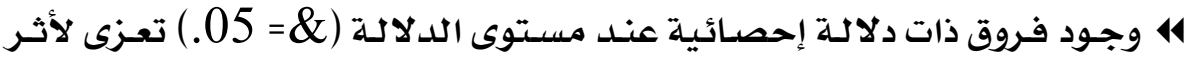

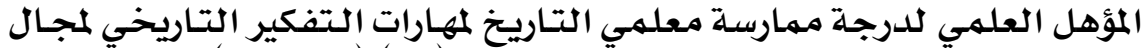

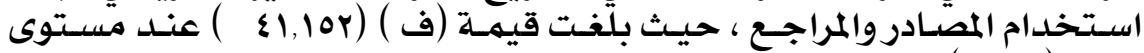

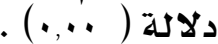

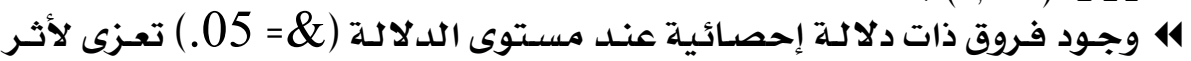

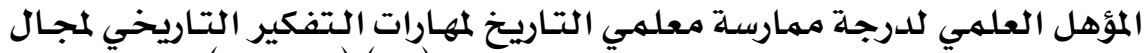

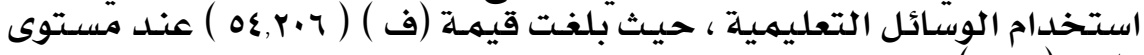

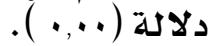

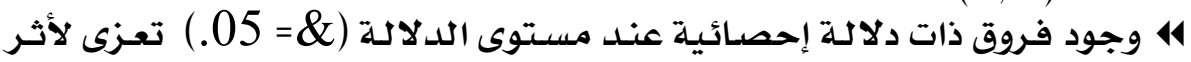

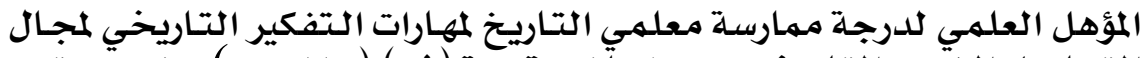

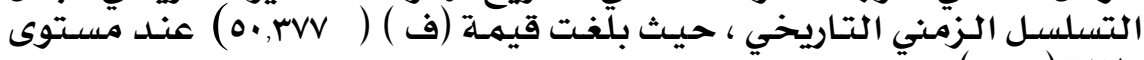

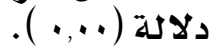

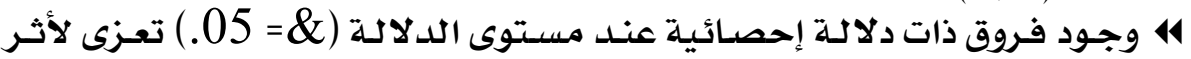

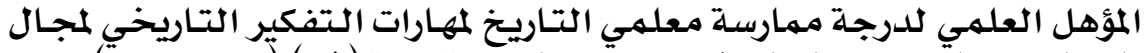

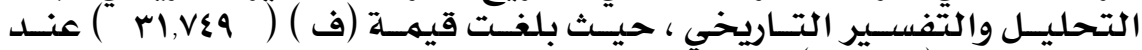

مستوى دلالة ( ل.,.

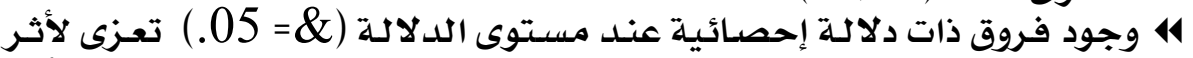

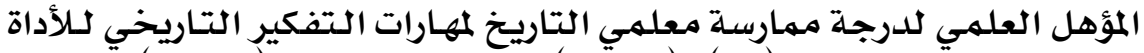

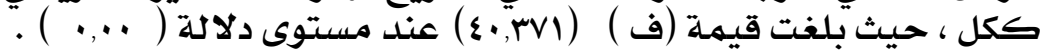
ولتحديد اتجاهات الفروق استخدم الباحث اختبار توكي للهقارنـات البعديـة

\begin{tabular}{|c|c|c|c|c|}
\hline & & الجدول & & \\
\hline الخطأ المعياري & فروق الأوساط & المؤهل ب & المؤهل 1 & المجال \\
\hline .0 & $1 . r$ & 1 & $r$ & \multirow{3}{*}{1} \\
\hline .04 & \&.V० & 1 & \multirow{2}{*}{$r$} & \\
\hline. .00 & r.00 & r & & \\
\hline الخطأ المعياري & فروق الأوساط & المؤهل ب & المؤهل 1 & المجال \\
\hline .0 & $1.7 \% 0$ & $r$ & r & $\dot{r}$ \\
\hline الخطا المعياري & فروق الأوساط & المؤهل r & المؤهل 1 & المجال \\
\hline. .49 & r. & 1 & $r$ & \multirow{3}{*}{$r$} \\
\hline .04 & 0.10 & $T$ & \multirow[t]{2}{*}{$r$} & \\
\hline. .00 & Y.10 & Y & & \\
\hline الخظأ المعياري & فروق الأوساط & المؤهل ب & المؤهل 1 & المجال \\
\hline$\cdot . \leqslant$ & $1.0 r$ & 1 & $Y$ & \multirow[t]{3}{*}{$\xi$} \\
\hline$\cdot . \leqslant \mathrm{V}$ & r.VI & 1 & \multirow[t]{2}{*}{$r$} & \\
\hline$\cdot . \leqslant 9$ & Y.TV & $r$ & & \\
\hline الخطأ المعياري & فروق الأوساط & المؤهل r & المؤهل 1 & المجال \\
\hline$\because 90$ & $1.7 \mathrm{~V}$ & 1 & r & \multirow{3}{*}{ كلي } \\
\hline $1.0 Y$ I & 1.91 & $T$ & \multirow[t]{2}{*}{$\Gamma$} & \\
\hline $1.9 T Y \Lambda$ & V.YO & $r$ & & \\
\hline
\end{tabular}

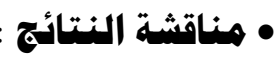

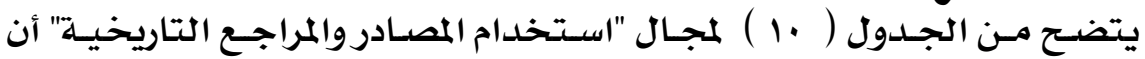

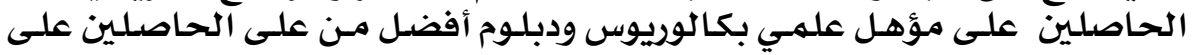




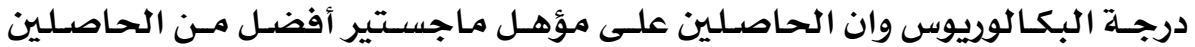

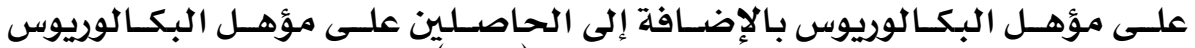

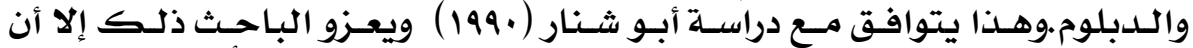

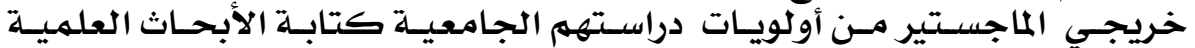

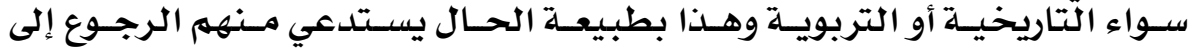

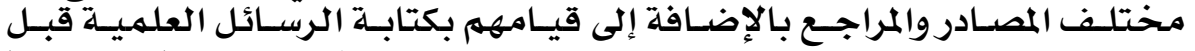

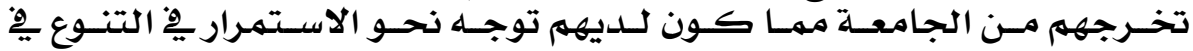

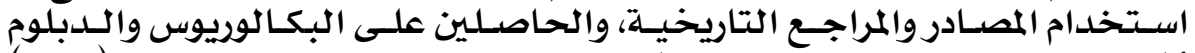

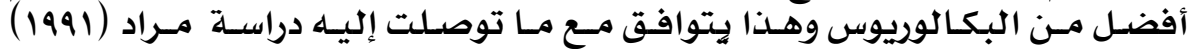

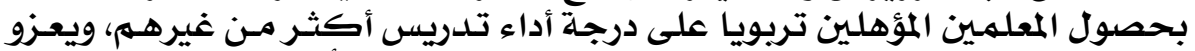

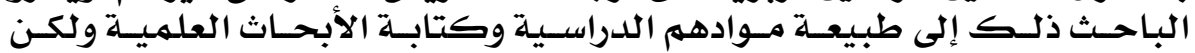

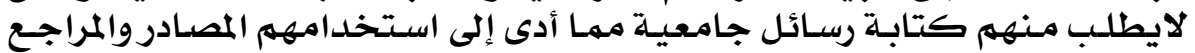

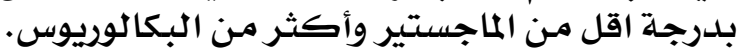

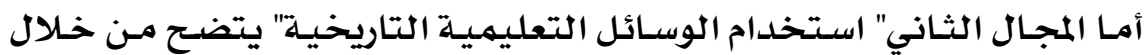

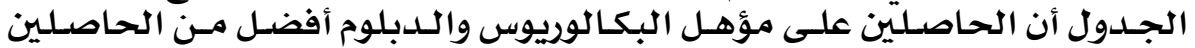

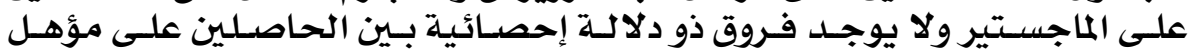

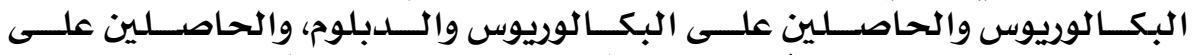

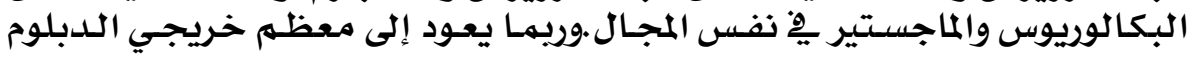

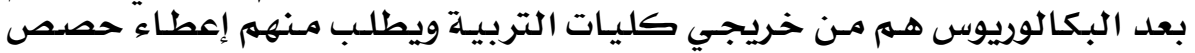

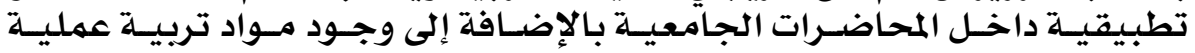

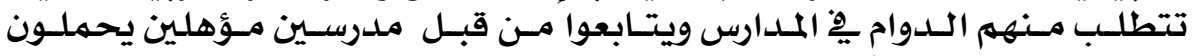

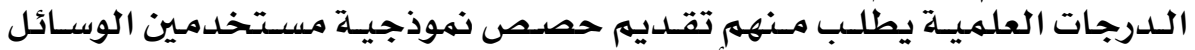

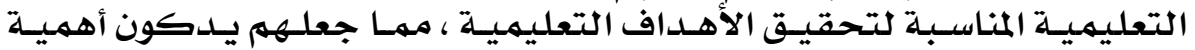

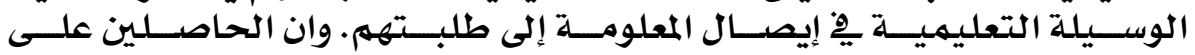

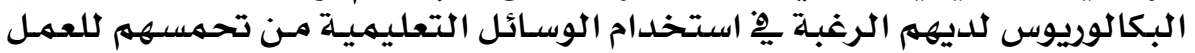

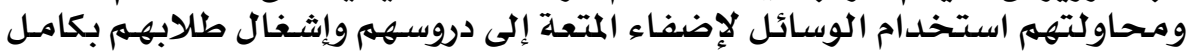

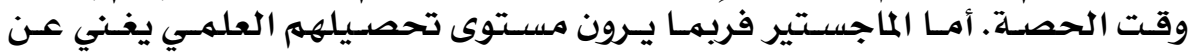

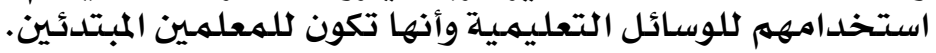

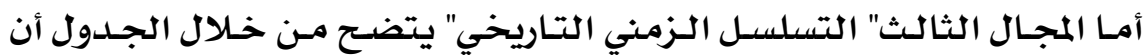

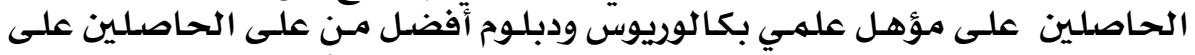

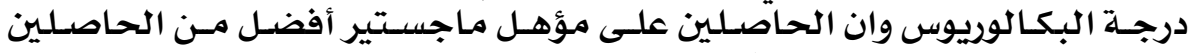

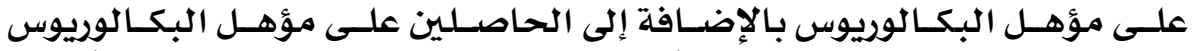

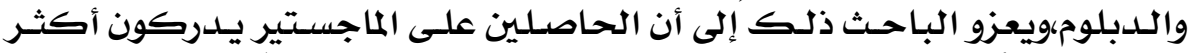

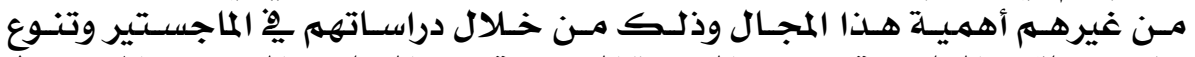

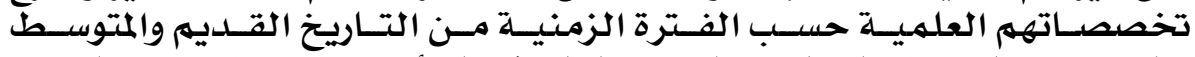

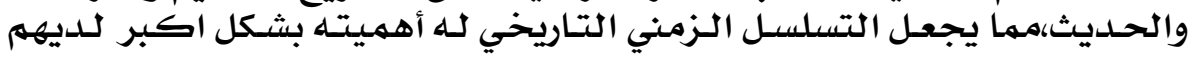
من المؤهلات السـابقة السجة.

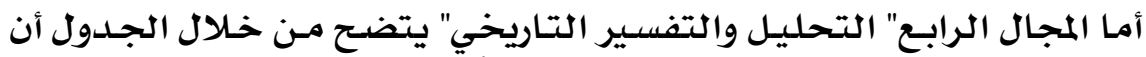

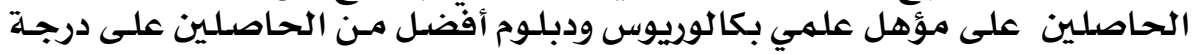

\section{$\varepsilon q$}




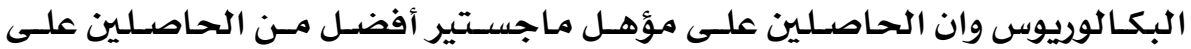

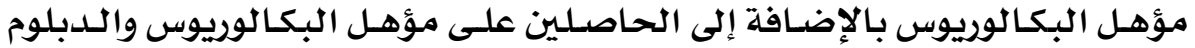

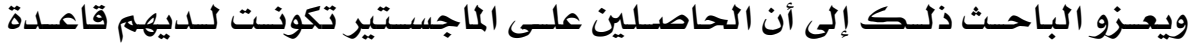

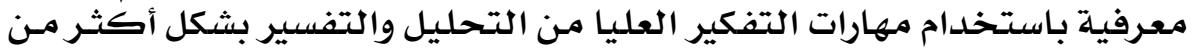

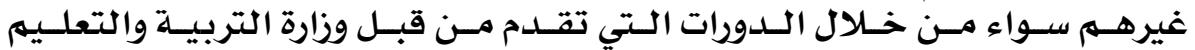

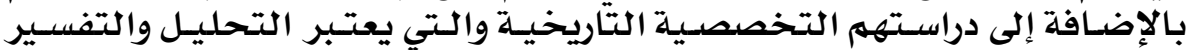

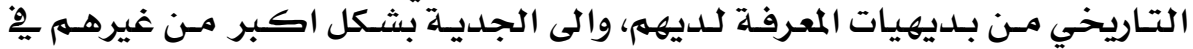

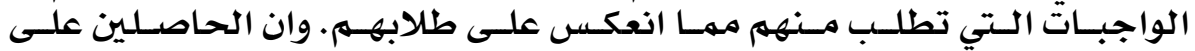

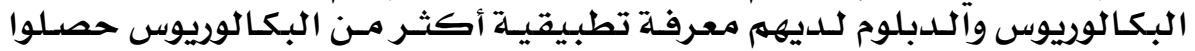

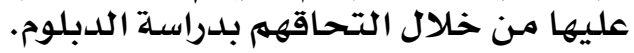

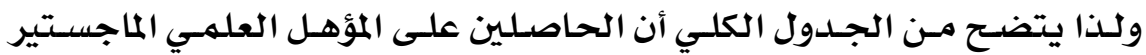

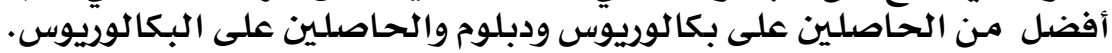

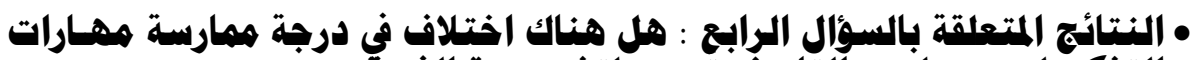

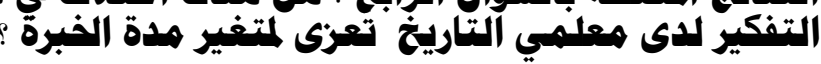

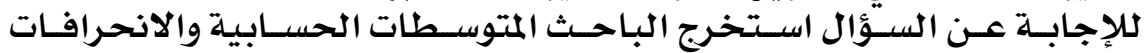

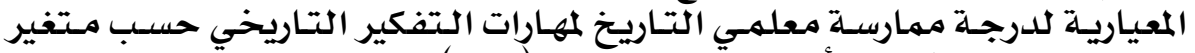

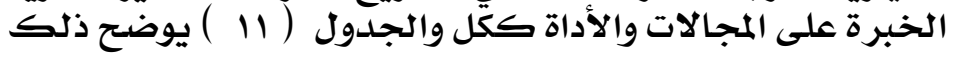

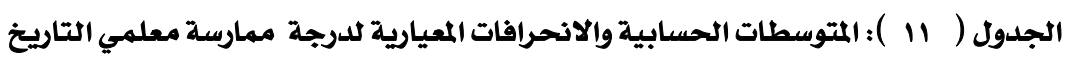
لمهارات التفكير التاريخي حسب الخبرات المبرايرة

\begin{tabular}{|c|c|c|c|c|c|c|}
\hline \multicolumn{2}{|c|}{ أكثُر من (10سنوات) } & \multicolumn{2}{|c|}{ من(5- 10سنوات) } & \multicolumn{2}{|c|}{ أقل من (5 سنوات) } & \multirow[t]{2}{*}{ المجال } \\
\hline الاتحر اف & الحسابي المتوســ & الانحر اف & الحستابي & الاحصر اف & الصستوسب & \\
\hline 1.11 & 9 & $.9 \mathrm{~V}$ & 9.10 &..$\vee 1$ & V.7V & استخدامالمصادر \\
\hline$\cdot . \wedge \wedge$ & $\Lambda . \leqslant \leqslant$ & $\cdot . \mathrm{V}_{0}$ & Q.V० & $\cdot . \wedge r$ & IY.VA & العلخيمدامالوسائل \\
\hline$\cdot . \wedge \wedge$ & $1 \leqslant . \leqslant\{$ & .91 & 1.TV & $\cdot . \wedge \wedge$ & $1 . .04$ & 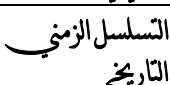 \\
\hline .94 & 19.11 & 1.1 & $9.7 \mathrm{~V}$ & . . $\leqslant \leqslant$ & V.rY & التاريخ \\
\hline$\{.9$ & Q४.५YV & Y.TVV & Vo.TV & T.1T & $V ५ . \leqslant \leqslant$ & الأداة ككل \\
\hline
\end{tabular}

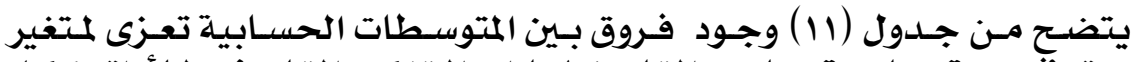

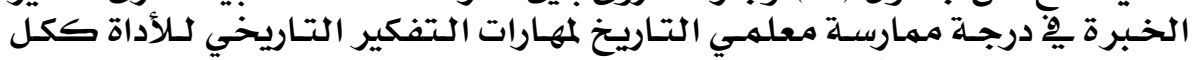

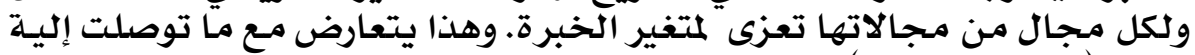

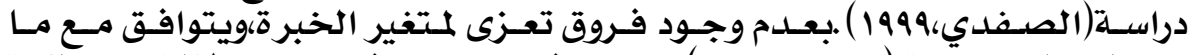

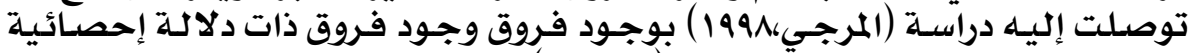

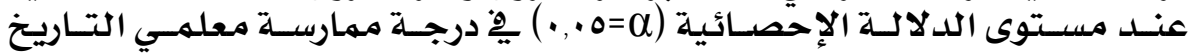

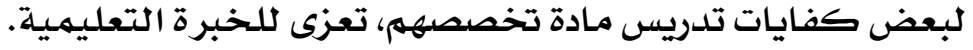

\section{$\bullet$}


العكد الثلاثهون .. الجزء الأول .. أكتهبر .. Гا. مه

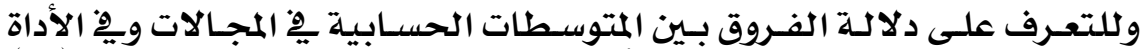

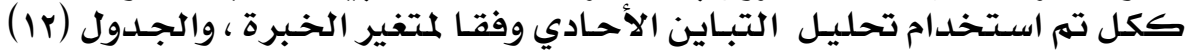
يوضح ذلك ته

الجلدول (r ا ) : تحليل التباين لأثر الخبرة على درجة ممارسة معلمي التاريخ للمرحلة المتوسطة

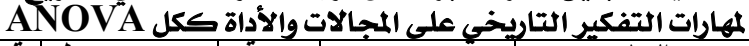

\begin{tabular}{|c|c|c|c|c|c|c|}
\hline مستوى الالاية & قيمة ف & 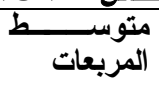 & لدرجة & المزبعـات لــوع & مصدر التباين & المجال \\
\hline$\because \cdots$ & $\varepsilon V . \cdot Y$ & $71.17 \varepsilon$ & $\ddot{r}$ & TM.MY & بين المجموعات & \multirow{3}{*}{ والمراجحامامعصادر } \\
\hline & & 1.20 & YV & $r q .119$ & داخل المجموعات & \\
\hline & & & rq & $180.57 V$ & المجموع & \\
\hline$\because \cdots$ & TV.Y & $\varepsilon \varepsilon .919$ & Y & $\wedge q . \wedge r q$ & بين المجموعات & \multirow{3}{*}{ التعليمية الوسائل } \\
\hline & & $\cdot .7 \mathrm{~V}$ & YV & $1 \Lambda_{.} \cdot r \Lambda$ & داخل المحمو عات & \\
\hline & & & rq & $1.8 . \wedge 7 V$ & المجموع & \\
\hline \multirow[t]{3}{*}{$\because \cdots$} & 1.1 .07 & $\Lambda 7.9 Y \Lambda$ & $r$ & IVY.A07 & بين المجموعات & \multirow{3}{*}{ التاريخحل الزمنيـــ } \\
\hline & & $\cdot .17$ & YV & YY.II & داخل المجموعات & \\
\hline & & & rq & $197.97 \mathrm{~V}$ & المجموع & \\
\hline \multirow[t]{3}{*}{$\because \cdots$} & TY.AT & or.VVA & $r$ & 1.8 .007 & بين ألمجموعات & \multirow{3}{*}{ التاريخليلوالتسير } \\
\hline & & $\cdot . \wedge 7$ & YV & Yr.II & داخل المجموعات & \\
\hline & & & rq & $1 \% \cdot .77 \mathrm{~V}$ & المجموع & \\
\hline \multirow[t]{3}{*}{$\because \cdots$} & IY..VY & $1 \% \wedge 9 . V 11$ & $r$ & YOVQ.รYY & بين المجموعات & \multirow[t]{3}{*}{ الآداة ككل } \\
\hline & & $1 \cdot .7 \wedge r$ & YV & $r \wedge \wedge . \leqslant \leq \leqslant$ & داخل المجموعات & \\
\hline & & & rq & 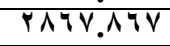 & المجموع & \\
\hline
\end{tabular}

$$
\text { يتضح من الجدول ( ا I ) ) : }
$$

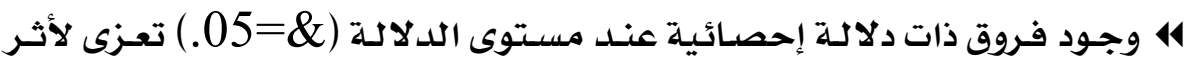

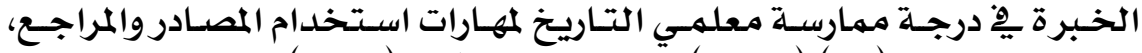

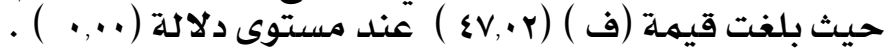

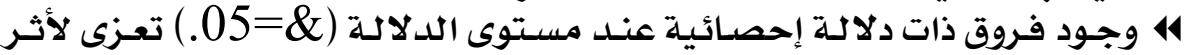

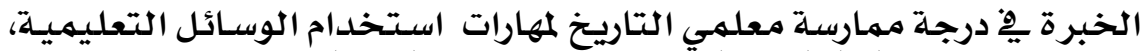

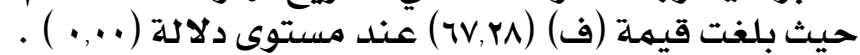

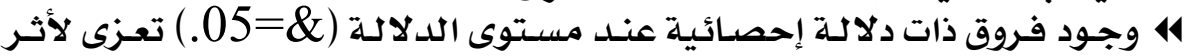

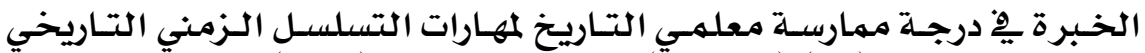

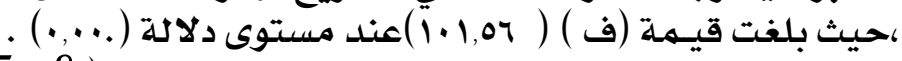

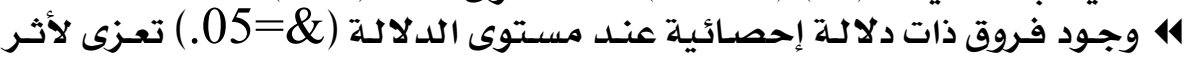

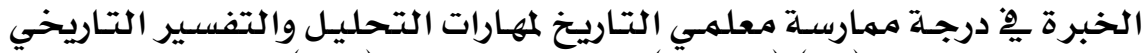

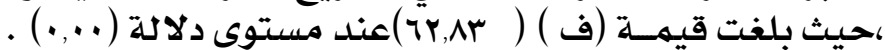

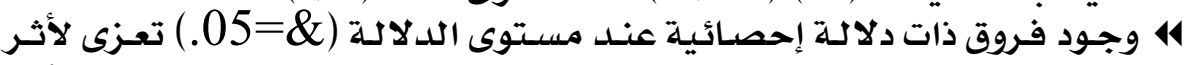

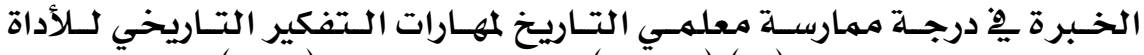

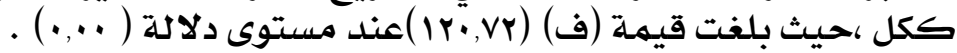
ولتحديد اتجاهات الفروق استخدم الباحث اختبار توكي للمقارنات البعدية، والجدول رقم (r) يوضنح ذلكات اتفوق

\section{1}




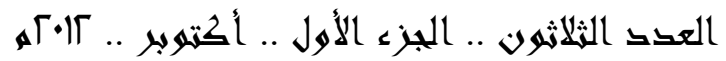

\begin{tabular}{|c|c|c|c|c|}
\hline \multicolumn{5}{|c|}{ الحدول(r) } \\
\hline الخطا المعياري & فروق الأوسـاط & الخبرة r & الخبرة & المجال \\
\hline .04 & $r_{.} \cdot \Lambda$ & 1 & r & $i$ \\
\hline $.0 \mathrm{~V}$. & $0 . \leqslant \leqslant$ & 1 & \multirow[t]{2}{*}{$r$} & \\
\hline .04 & r.r. & $T$ & & \\
\hline الخطا المعياري & فزوق الأوساط & الخبرة r & الخبرة & المجال \\
\hline$\cdot{ }^{\mu \tau}$ & $r . r$ & r & \multirow{2}{*}{ - } & \multirow[t]{2}{*}{$\dot{r}$} \\
\hline$\cdot \Gamma \wedge$ & $\varepsilon . \mu$ & $r$ & & \\
\hline الخطا المعياري & فروق الأوسـاط & الخبرة r & الخبرة 1 & المجال \\
\hline$\because \leqslant 1$ & 1.19 & r & 1 & \multirow[t]{3}{*}{$r$} \\
\hline..$\leqslant \varepsilon$ & $r .19$ & 1 & \multirow[t]{2}{*}{$r$} & \\
\hline$\because \leqslant 1$ & $0 . V A$ & $r$ & & \\
\hline الخطأ المعياري & فروق الأوسـاط & الخبرة r & الخبرة 1 & المجال \\
\hline$\because \leqslant 1$ & Y. $\leq \varepsilon$ & 1 & $r$ & \multirow[t]{3}{*}{$\varepsilon$} \\
\hline.$\leqslant \leqslant$ & $\varepsilon .19$ & 1 & \multirow[t]{2}{*}{$r$} & \\
\hline$\because \leqslant 1$ & T. $\leqslant \varepsilon$ & $r$ & & \\
\hline الخطا المعياري & فروق الأوسـاط & الخبرة r & الخبرة 1 & المجال \\
\hline $1 . \leqslant \leqslant$ & $\cdot \vee \wedge$ & r & 1 & \multirow[t]{2}{*}{ الكلي } \\
\hline $1.0 \leqslant$ & $19.8 \wedge$ & 1 & $r$ & \\
\hline
\end{tabular}

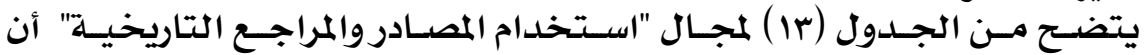

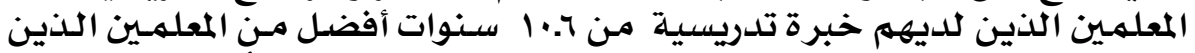

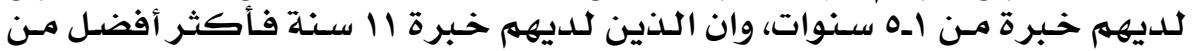

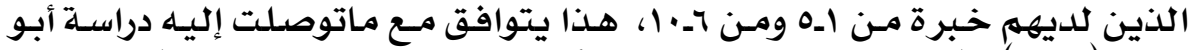

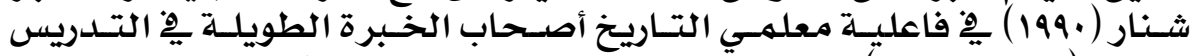

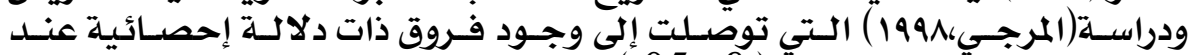

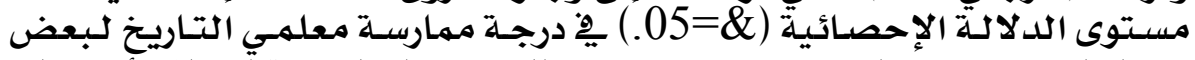

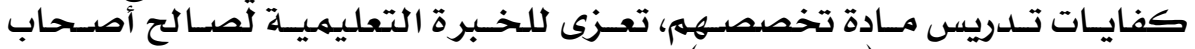

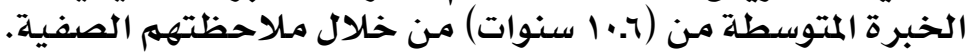

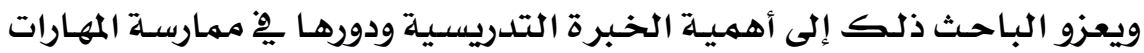

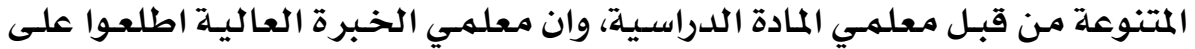

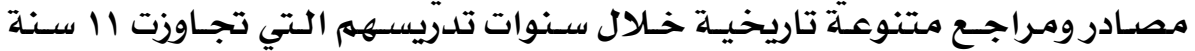

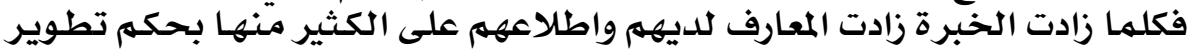

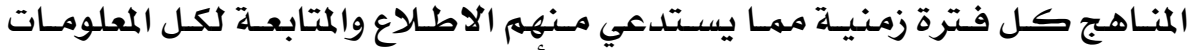

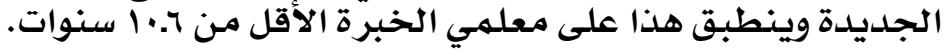

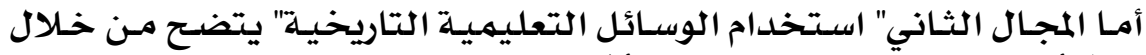

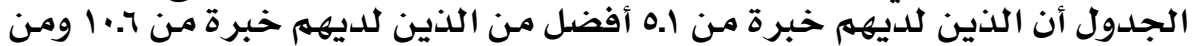

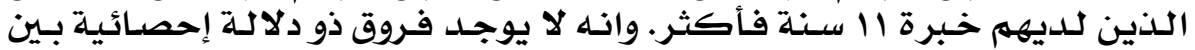

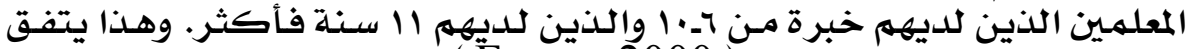

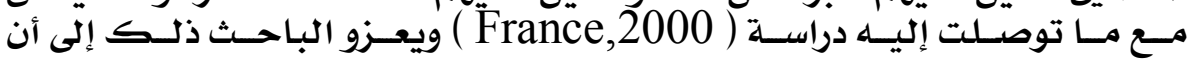

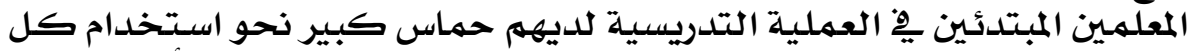

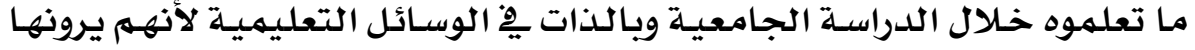

\section{๑}


العقد المثلاثهن .. الجزء الأول .. أكتهوبر .. Гا•مه

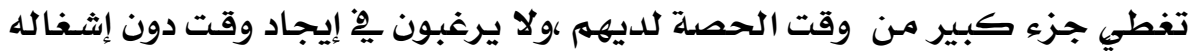

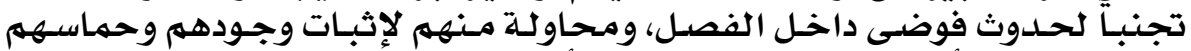

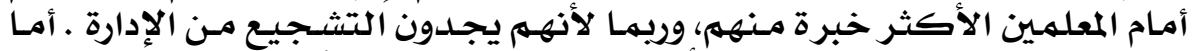

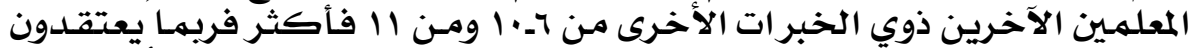

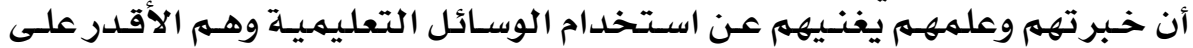

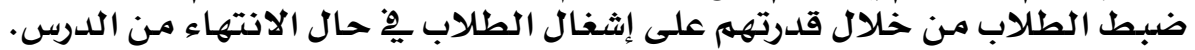

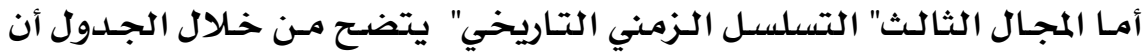

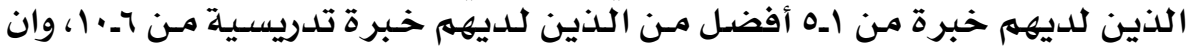

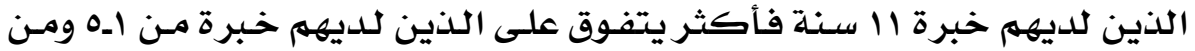

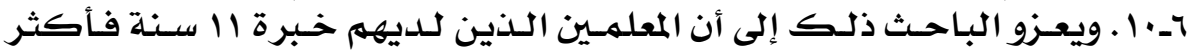

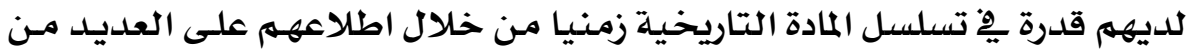

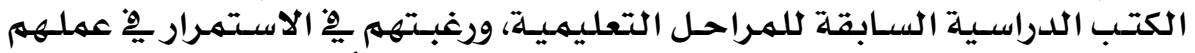

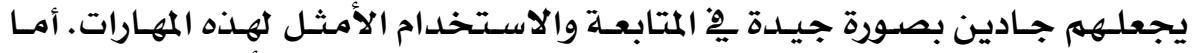

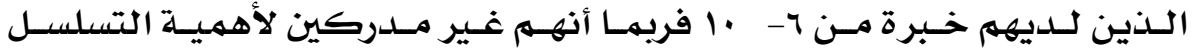

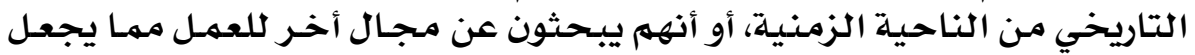

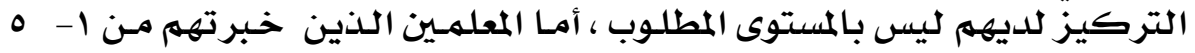

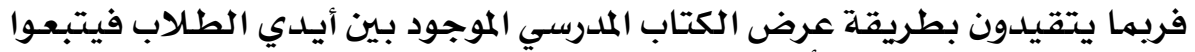
نمط التأليف المتسلسل بطريفل لأحدراث التاريخية.

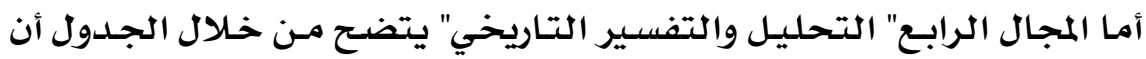

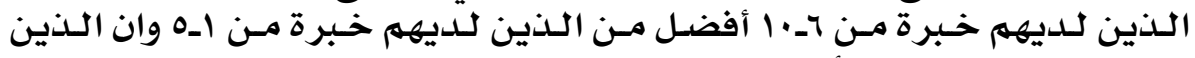

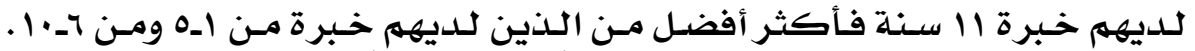

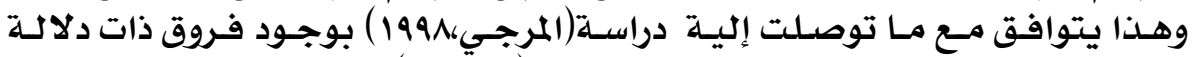

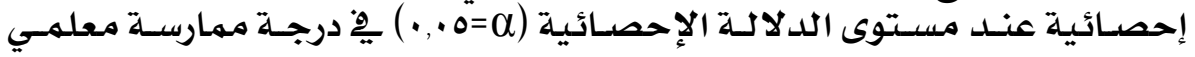

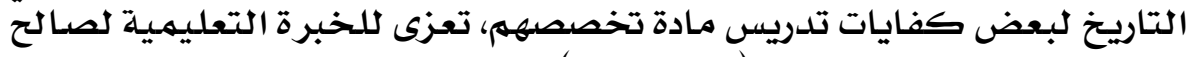

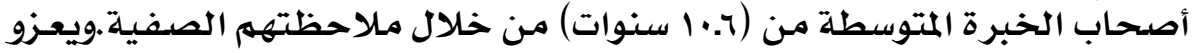

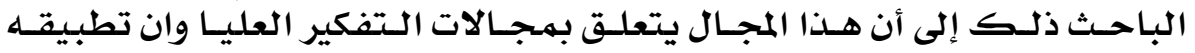

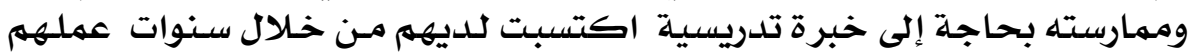

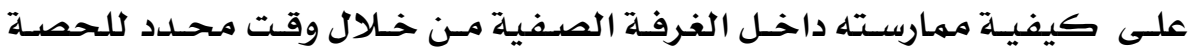

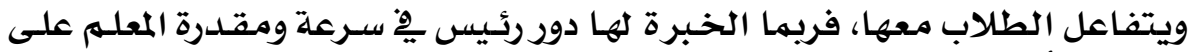

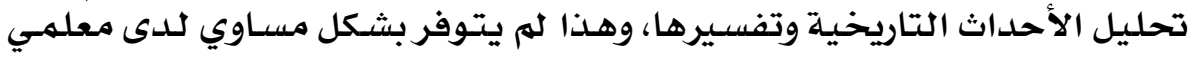

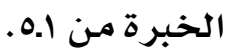

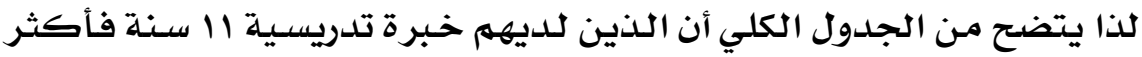

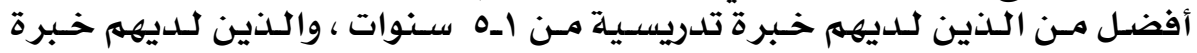

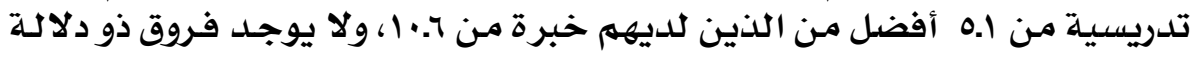

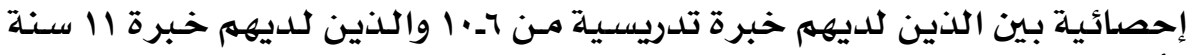
فأكثر.

\section{$\theta \boldsymbol{Y}$}




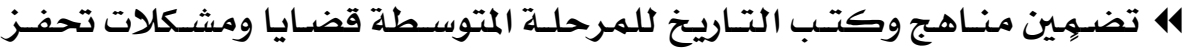

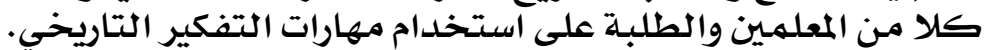

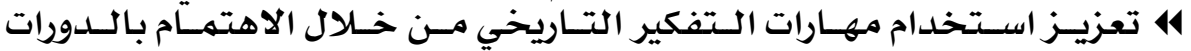

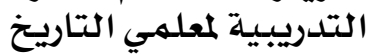

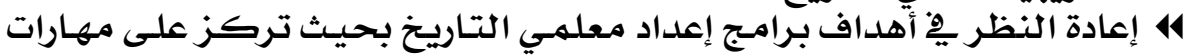
التفكير التاريخي.

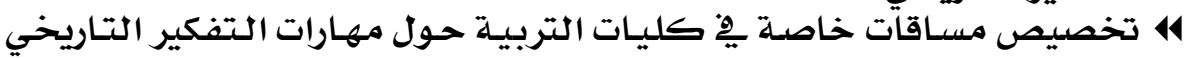

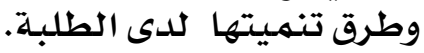

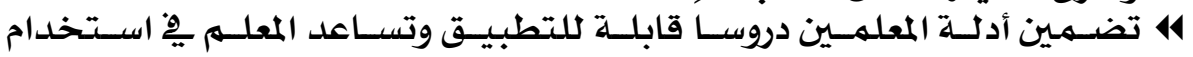
وممارسة مهارات التفكير التاريخي.

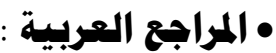

إبراهيم، فاضل خليل (1999). آفاق جديدة ِِّْ تدريس التاريخ . مجلة أبحاث اليرموك

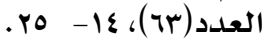

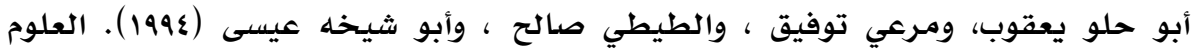

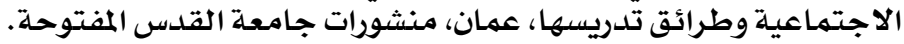

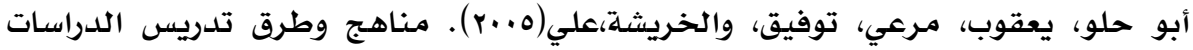
الاجتماعية. الكويت، ألجامعة العربية المفتوحة.

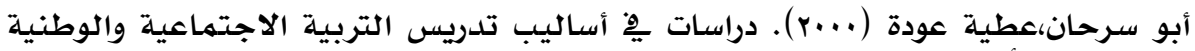

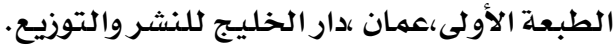

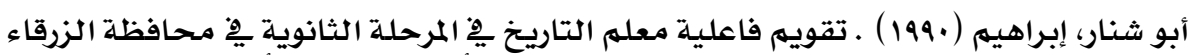

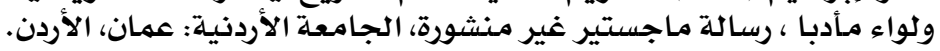

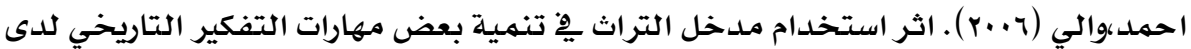

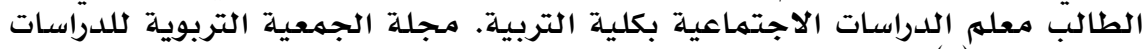

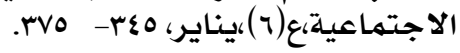

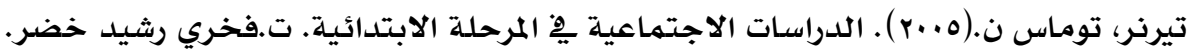

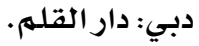

جامل،عبد الرحمن عبد السلام (ץ...r). طرق تدريس المواد الاجتماعية ، الطبعة الأولى ،عمان

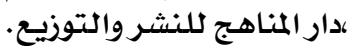

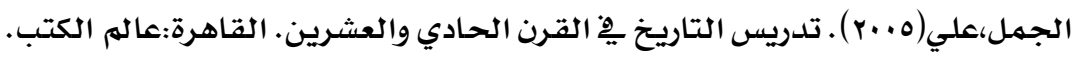

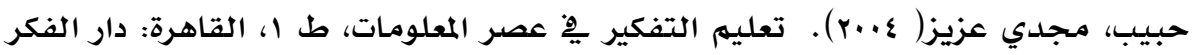

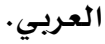

الحميدان، إبراهيم(0. .ب) .التدريس والتفكير. ط(1)، القاهرة: مركز الكتاب للنشر.

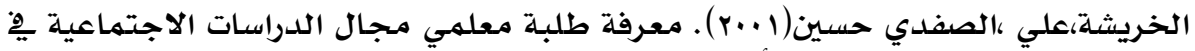
كليات التربية بالجامعات الأردنية لمهارات التفكير التاريخي، مجلة جامئل التعة دمشق للعلوم

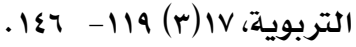

\section{o\&}




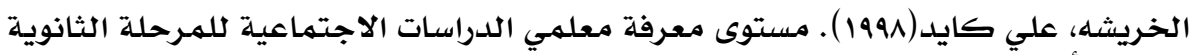

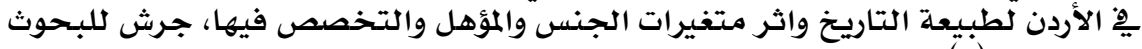

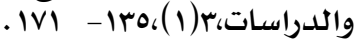

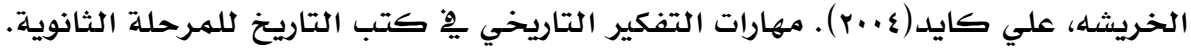

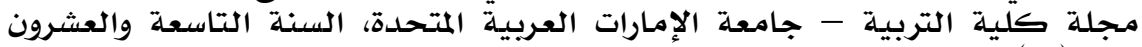

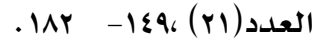

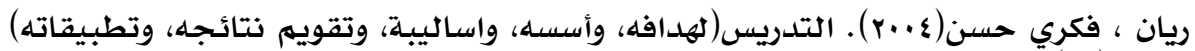

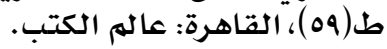

زيتون ، حسن حسين .(1 +.ץ). مهارات التدريس " رؤية يِ تنفيذ التدريس " ، القاهرة : عالم الكتب آنون

سعادة، جودت(r.r.r). تدريس مهارات التفكير (مع مئات من الأمثلة التطبيقية) ، الأردن: دار

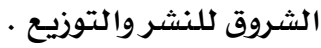

السكران ، محمد (1919 ). أسـاليب تدريس الدراسـات الاجتماعية ، عمان، دار الشروق.

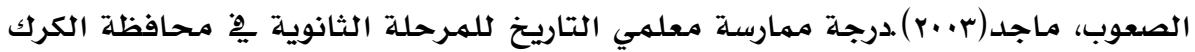

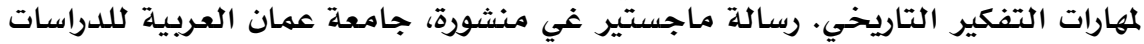

العليا.

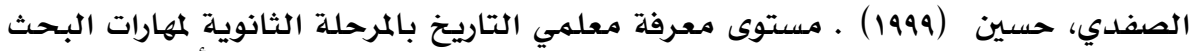

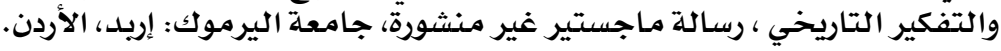

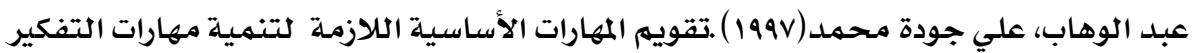

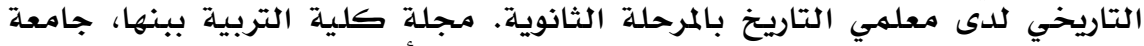

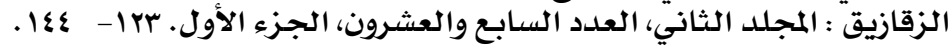

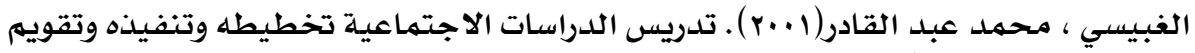

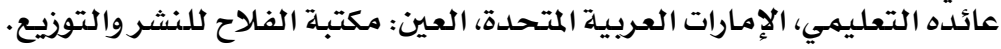

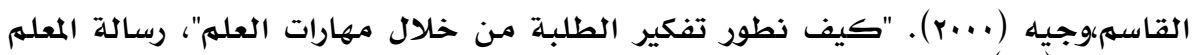

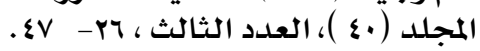

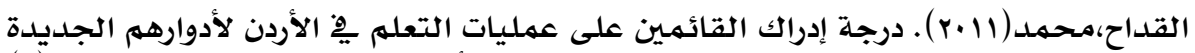

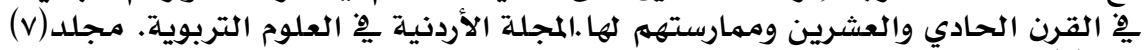

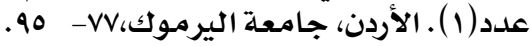

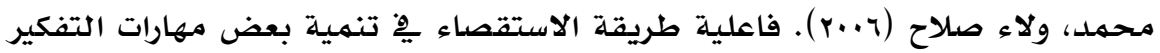

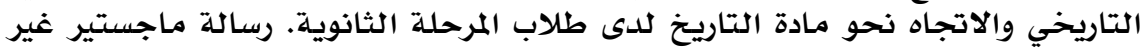

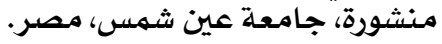

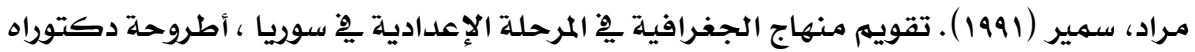

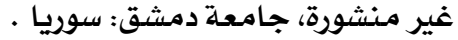

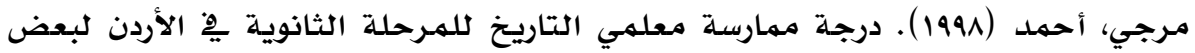

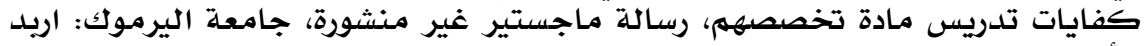
الأردن مفات

\section{๑}




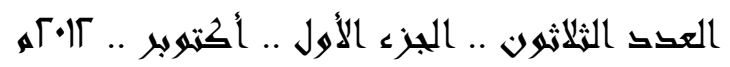

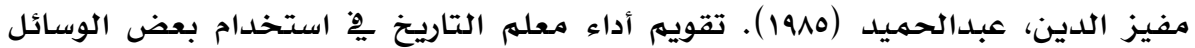

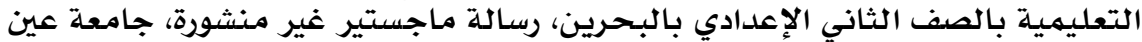
شمس: القاهرة.

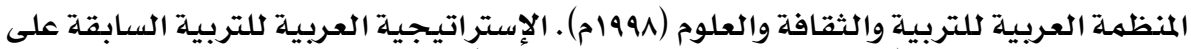

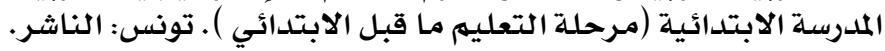

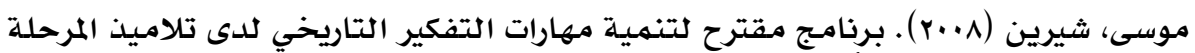

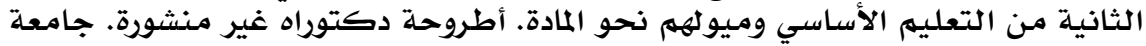
عين شمس. مصر.

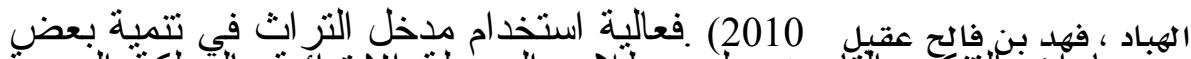

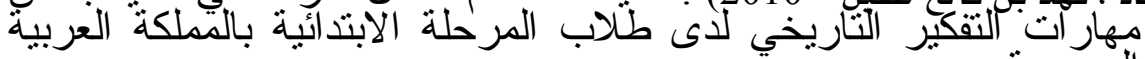

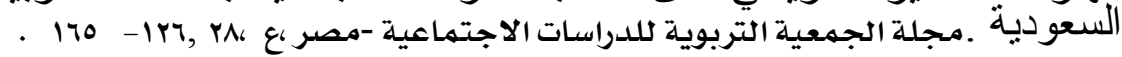

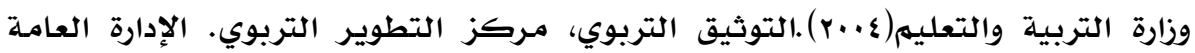

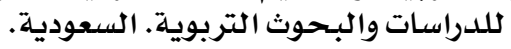

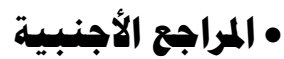

Barbiero,joseph,(1996).A study of desired national standards for united states history in Connecticut public schools(history education). Dissertation Abstract International, DAI vol 57,(09)A.212-216.

Barton, D,(2002)."Oh,that's tricky piece':Children,mediated action, and the tools of historical time. The Elementary School Journal, 103(2), 161-183.

Colorado Model Content Standards for History(1995).Available at: Retrieved,November,17,2010,from:http;//www.Colorado standards.com.

Doppen,france,(2000).teaching and Learning multiple perspectives: he atomic bomb, The Social Studies, Retrieved, November, 17,2010,from. http://www.highbean.com.

Eggen.p and Kauchak,D,(1996).Strategies for teachers: thinking content and thinking skills. Boston: Allen and Bacon.

Forsgren,jens(1997). An examination of factors affecting secondary teachers Levels of use of the " national standards of united states history (history instruction, Dissertation Abstract International, DAI vol 58,(06).118-122.

Francis, mann(1992). Authentic evaluation in history " O,A,H magazine of histore, vol, 6.no.4.345-374.

Frans,H,(2002). Beginning Social Studies Teachers Use of Technology in Teaching of History.Dissertation Abstract International, DAI vol 56,(04).A,453-460 


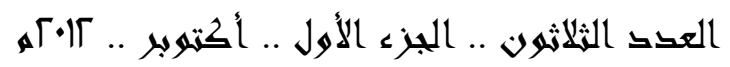

Greene,stuart,(1994)“" The Problems of Learning to Think Like Historian :Writing History in The Culture of Classroom" Educational Psychologist, vol. 29,no.2. 89-96.

Heyking,Amy,(2004).Historical Thinking in The Elementary Years. Canadian social studies,. special issue: social studies research and teaching in elementary schools. vol 39,n1,1-13.

Kathryn, T and Luther, W, (1994) "Learning to Think Historically " Educational Psychologist, Vol 29,No.2, . 71-77.

Kay, Treiber, (1998). Teaching Historical Thinking to Elementary and Middle School Students, Price Laboratory School Professional Development .

Levstik,Linda and barton,Keith,(1996).they still use some of their past: historical salience in elementary children's chronological thinking" curriculum studies. Vol.60-09A.14-19.

Litogot, Sondra, A (1991) "Using Higher Order Skills in American History" The Social Studies, Vol.82.No.1,.22-25.

Lumpkin, Cynthia, (1991) "Effect of Teaching Critical Thinking Skills on The Critical Thinking Ability, Achievement, and Retention of Social Studies Content by Fifth and Sixth Graders" Dissertation Abstracts International, Vol.51, No.11,p.3694.

Marius , Richard (1989) A Short Guide to Writing about History, Library of Congress Cataloging-in-Publication Data, Printed in the United Kingdom.

National Center for History in The School(2005).National Standers for History, Historical Thinking standards, Retrieved, November, 17,2010, from : www.sscnt,edu//nchs/ Standards/Thinking-5-12 htm.

National Council for The Social Studies (1994) A vision of Powerful Teaching and Learning in The Social Studies :Building Social Understanding and Civic Efficacy, The Curriculum Standards For Social Studies . 157- 177 . Washington. D.C .

National Standards for History(2002). Retrieved from The Worldof Internet:http://WWW.sscnet.ucla.edu/nchs/standards/ thinking(511-2011) htm,August.

Newmann, Freed, M. (1991). Promoting Higher- Order Thinking Skills in Social Studies: overview of A study of 16 High school Departments. Theory and Research in Social Education, VOI. XIX, NO.4,.324-340.

Salinas,Cinthia,Bellows,E. and Liaw,L(2011). Preservice Social Studies Teachers Historical Thinking and Digitized Primary 


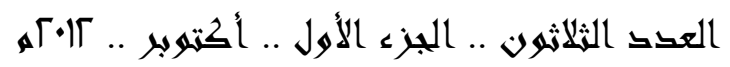

Sources: What They Use and Why. Contemporary Issues in Technology and Teacher Education.v11,n2. Jun.184-204.

Schachter,Ronald.(2003).Bringing history to life: middle and high school students can visit the virtual past technology and Learning .

Seixas,peter(1996).Conceptualizing the growth of historical understanding. The Handbook of Education and Human Development. Olson,DR and Torrance,Cambridge,MA:Blackwell publishers, 765-783.

Steam,p,Seixas,p,\&Wineburg,S(2000).(Eds).Knowing, Teaching and Learning History: National and International Perspectives. New York:NYU Press.

Strading, r.(2001).teaching 20th, century curopean history, education history teaching,ISBN,http://book.coe:int/GB/Cat/Lts/Lis 82/htm.

VanSledright,B(2002).Confronting history's interpretative paradox while teaching fifth graders to investigate the past. American Educational Research Journal,39(4),1089-1115.

Waring,S\&Robinson,K(2010). Developing Critical and Historical Thinking Skills in Middle Social Studies. Middle School journal.v42,n1,22-28.

Whitaker,douglas.(2003).the impact of Digital Images and visual Narratives on the Ability of fourth grades to engage in historical Thinking. " Dissertation Abstracts International, vol 64 (03)A155-160.

Yeager, Elizabeth \& Davis. JR ( 1994 ) “ Understanding The Knowing How of History: Elementary Student Teachers, Thinking About Historical Texts" Journal of Social Studies Research. Vol. 18. No.2..29- 44.

Yeager, Elizabeth Anne \& Foster,S. j, and Greer,j (2002).How eight graders in england the United States view history significance. The Elementary School Journal, 103(2), 199-219.

Yeager, Elizabeth Anne and Wilson, Elizabeth, K (1997) " Teaching Historical Thinking in The Social Studies Methods Course: A Case Study" The Social Studies. May/Jun.

\section{溇潾溇溇潾}

